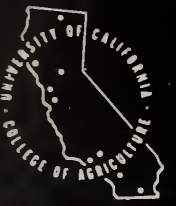

Division of Agricultural Sciences

U N I VERSIT Y O F C A L I FOR N I A

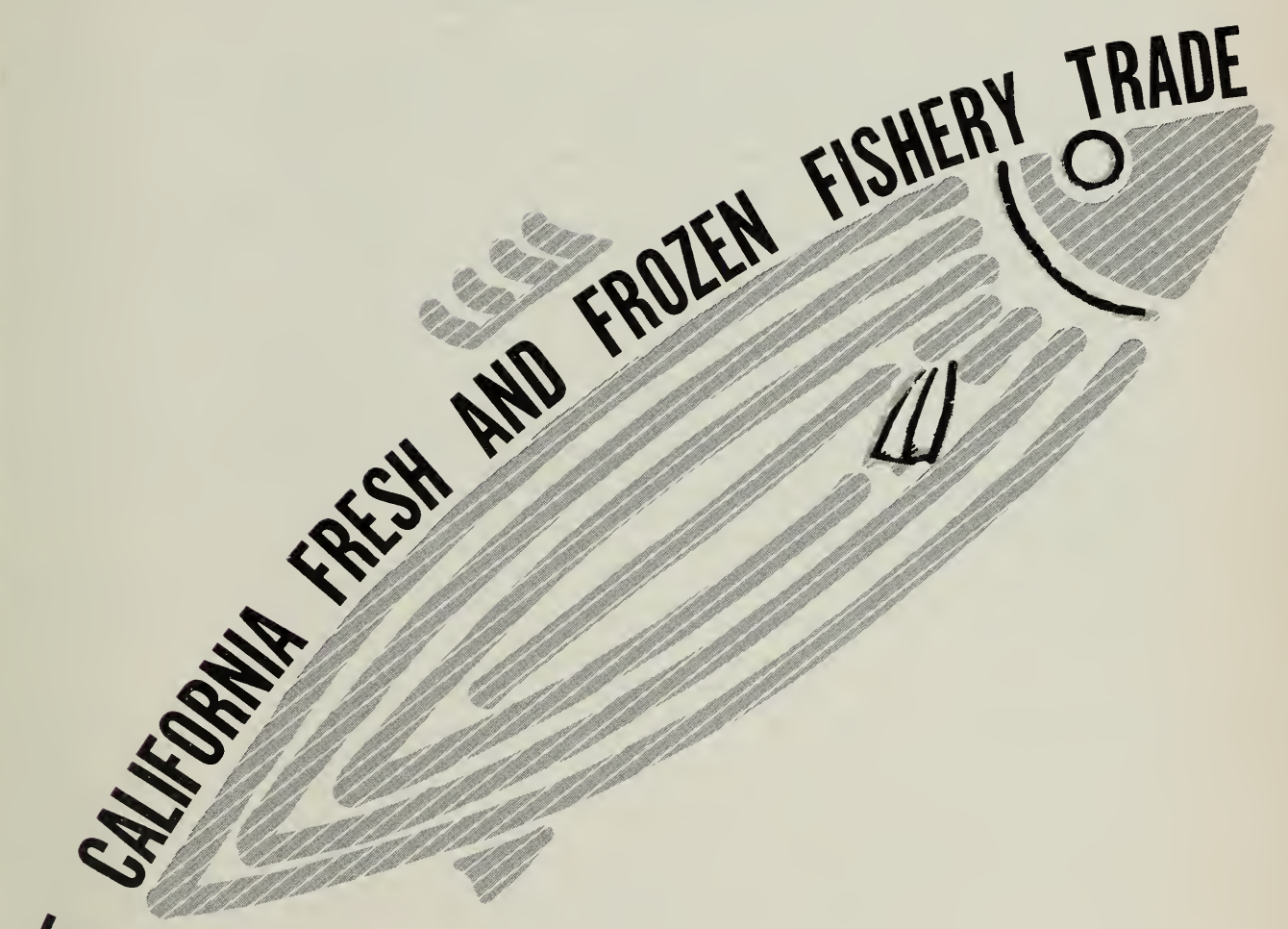

A. D. O'ROURKE - D. B. DeLOACH

CALIFORNIA AGRICULTURAL EXPERIMENT STATION

BULLETIN 850 
This study describes and examines the structure of the California fresh and frozen fish and shellfish industry from the fishing through the retailing operations. It analyzes the interrelationships between structure and the industry's past and present performance as a basis for estimating future developments. The shift of the California industry from its dependence on an abundant supply of a wide variety of fish and shellfish from adjacent coastal waters to an importer of these products from other states and foreign countries is reviewed. Consideration is given to the ecological, economic, and sociological factors that have contributed to a decline in the supplies of the more desirable species in California waters at a time when the total demand is increasing. Competition from various industry and recreational groups for the waters where fish spawn and grow has disclosed the disorganized and weak tactical position of the California industry in formulating a public policy relating to the use of the fishery resource. The analysis of the industry's structure and performance indicates a real need for a revitalization of the industry. This will require an infusion of new capital and managerial talent, as well as an elimination of many of the inefficient firms that now exist because of unduly favorable prices and margins.

\section{JUNE, 1971}

\section{THE AUTHORS :}

A. D. O'Rourke is Assistant Professor of Agricultural Economics, Washington State University, Pullman. He was formerly an Associate-in Agricultural Economics in the Department of Agricultural Economics, University of California, Davis.

D. B. DeLoach is Professor of Agricultural Economics and Agricultural Economist in the Experiment Station and on the Giannini Foundation, University of California, Davis.

The table of contents is on page 79 . 


\section{THE CALIFORNIA FRESH AND FROZEN FISHERY TRADE ${ }^{1}$}

\section{INTRODUCTION}

The problem. During 1969 California's fresh and frozen fish and shellfish industry enjoyed the highest product prices and margins ever experienced, primarily because total fish consumption increased while production of the desirable species remained stable or declined, and the prices on substitute or competing protein food items, particularly meat, reached record highs (figure 1). Despite the 1969 price conditions, leaders of the industry were concerned about its ability to survive as a viable sector of California's economy, considering the bionomic and institutional changes affecting the fisheries' businesses.
Most of the problems faced by the fresh and frozen sector of the California fishing industry are common to other parts of the United States. However, the problems have been intensified by both a population increase from 7 to 20 million between 1940 and 1970 and a rapid industrialization, neither of which is conducive to the maintenance of a fishery industry.

Our research dealt, to some extent with the conditions under which a supply of desirable species of fish can be maintained and made arailable for the California fresh and frozen fisheries users; but concentrated on the characteristics

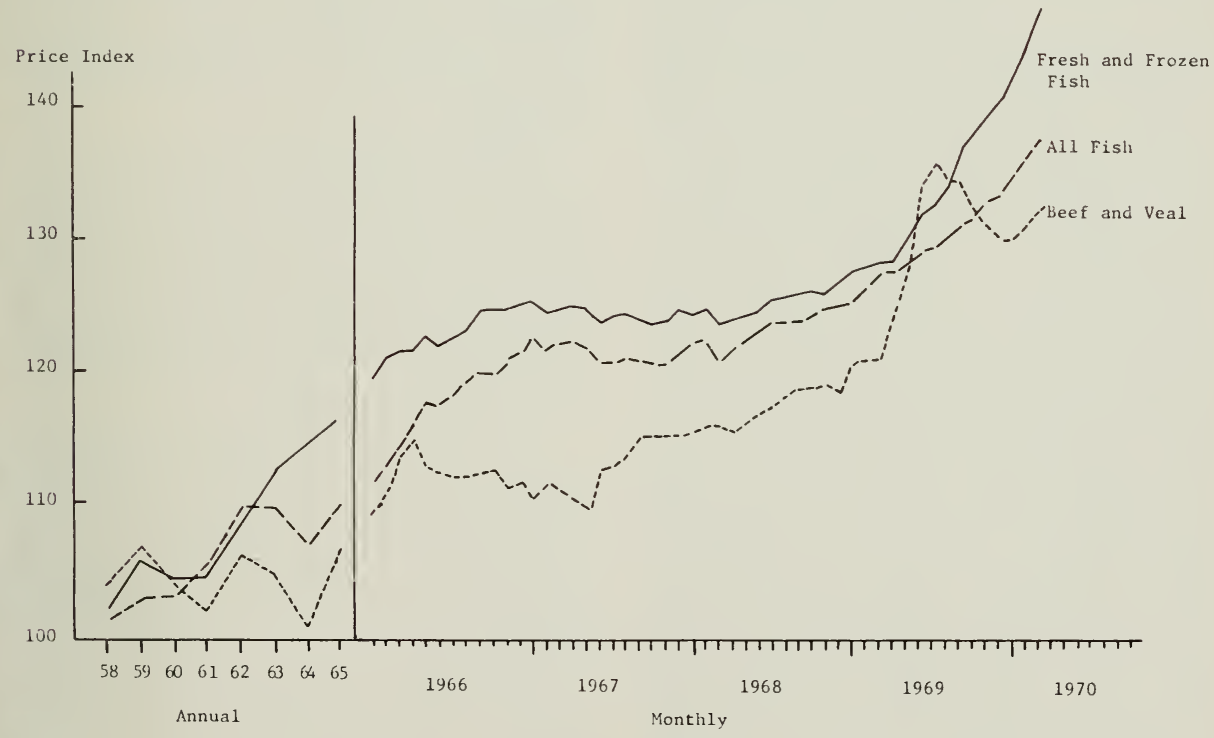

Fig. 1. U. S. Retail price index for beef and veal, all fish, ${ }^{*}$ and fresh and frozen fish. Base 1957-1959 = 100.

* Does not include canned, dried, etc. Source: Consumer Price Index, BLS (Monthly).

${ }^{1}$ Received for publication October 6, 1970. 
of the competition from both domestic and foreign sources, and on the efficiency with which industry performs its production and marketing functions.

The capacity of the California fresh and frozen fish and shellfish trade to agree on and solve its basic problems has been weakened by prolonged and sometimes bitter clashes of interest between fishermen and boat owners, fishermen and primary producer-wholesalers, and among primary producer-wholesalers (DeLoach, 1938, p. 28; Crutchfield, 1954. p. 83). Only recently has a new generation of managers been able to patch over the deep cleavages among prominent in. dustry leaders who were immigrants or descendants of immigrants. In 1966 an attempt was made to secure a marketing order for fresh and frozen fish and shellfish under the auspices of the California State Department of Agriculture. The order was not accepted by the industry, but its stated objectives indicate what the industry considered to be its main problems. First, it sought authorization for an advertising and sales promotion program "for the purpose of maintaining existing markets and creating new and larger markets for such fish and seafood ... and products thereof without reference to a particular private brand name or trade name ...," second, "to carry on or cause to be carried on reseach and survey studies in the marketing or distribution of fish and seafood and products thereof." Clearly the sponsors of the proposed marketing order believed that demand stimulation was the major industry need. However, shortage of supplies of desirable species and an improving demand weakened support for the order and it was rejected. Since 1966, the shortage of the most desired species became even more pronounced, in the face of the rising consumption of fish and shellfish.

Lacking a common objective and a willingness to join together for selfpreservation. individual firms and the California industry as a whole become increasingly endangered as our nation restructures its priorities for the development and use of all resources. For example, to some people, the buoyant sportfishing-recreation-tourism complex would seem to yield greater long-term benefits to society than the struggling and often patently inefficient commercial fish trade. In the international trade, the United States would seem to benefit from retaining low tariffs on fish in order to win access to other markets for goods in which it has a competitive advantage and to keep down food prices at home. Some also argue that California's commercial fish business ought to be sacrified for the sake of compensating gains in other sectors of the economy.

Objective and procedures. This study of California's fresh and frozen fish trade aims to answer two questions: Is the existence of such a business economically and socially justified, considering other demands for the use of the fisheries and the waters in which the fish breed and grow? And: Could the industry's present structure and performance be improved to fulfill better its economic and social functions?

To meet these objectives we:

- Examined the structure of the California fresh and frozen fisheries industry in order to learn the relationship between structure and the production and marketing practices for the principal products sold through various marketing channels; and, insofar as possible,

- Analyzed the economic performance of the industry, including an assessment of the effects on performance of certain institutional arrangements, demographic characteristics, comptition, and efforts to expand sale of fishery products.

Research was constrained by data limitations. For an important part of our study we assembled, from miscellaneous sources, descriptive and statistical information which enabled us to present a coherent picture of the current status of the industry and of the forces encouraging 
change. This part has been thoroughly documented. For a second major partthe establishment of the relationship between industry characteristics of structure and conduct and observed perform. ance-we found that only under the assumptions of perfect competition could we relate given structural characteristics and market conduct to a socially desirable norm of economic performance (see, for example, Bator, 1957, pp. 22-59). Such assumptions were used to analyze the primary producer-wholesaler sector, the only sector for which any meaningful data were available. The extent of deviations from the perfectly competitive equilibrium position could be taken as an approximate measure of the inefficiencies present in the producer-wholesaler sector of the industry.

In other sectors, the assumptions of perfect competition either did not apply or could not be used because of lack of data. As an alternative we drew extensively from the concept of workable competition, whose advocates have striven to develop a listing of desirable economic results which society can reasonably expect. For example, society can reasonably expect firms to use efficient production and marketing methods, to be progressive in adopting new technology, and to equitably reward their labor, capital, and enterprise (Sosnick, 1969, pp. 1-20). The major problem in applying the concept of workable competition is in finding objective measures of what is efficient, progressive, or equitable.

The criteria for workable competition suggested by Sosnick (1969) have been used as a checklist in our systematic assessment of the industry's economic efficiency. While some of these criteria were unimportant or inapplicable to this industry, most are discussed in descriptive terms and, where possible, a quantitative measure of efficiency was derived. For example, the quantity and quality of sales promotion were regarded as relatively unimportant among those inter- viewed. In the case of product suitability, for which no quantitative measurement was possible, we did pinpoint those aspects which posed obstacles or opportunities for the trade. For criteria such as efficiency of production and price flexibility, tentative objective measures were developed. On other criteria critical to both the trade and society, e.g., conservation of natural resources and external effects, the scope of the problem was so vast that we chose to describe the characteristics of the problem, its relationship to structure and performance, and to suggest a framework for specific research.

Finally, keeping in mind the problems of decision-makers, we used the approach of the casual empiricist where the theoretical underpinnings of perfect or workable competition were not directly applicable. This applies particularly to a later section where published data on survival, growth, and distribution of firms over time were used to infer tentative conclusions about the relative performance of the fish trade in California compared to that in other states.

Sources of data. We relied on the many publications of $\mathrm{FAO}$, in the U. S. Bureau of Commercial Fisheries, and the California Department of Fish and Game for much of the current and historical data on the production and consumption of fish in the world, the United States. and California. The U. S. Bureau of the Census reports provided summary data on the structure and characteristics of various sectors of the California fish trade. To supplement inadequate published sources, we conducted personal interview surveys of all the major firms in the California fresh and frozen fish trade at the primary producer-wholesaler, broker, and fabricator levels, and interviewed three retail grocery chains-one national, one local, and one cooperativeprominent in the distribution of fish. However. in many cases the kind of data needed to evaluate the industry's structure and assess its economic performance 
was either nonexistent or unavailable. Accordingly, considerable improvisation and adaptation of standard measures of industry efficiency were needed to derive meaningful economic lessons from the data available.

\section{SUPPLY AND DEMAND}

World fish and shellfish production from 1948 through 1967 increased threefold (19.6 to 60.5 metric tons), mostly because of commercialization of fisheries in less developed areas of the world. The United States relied more on imports of fresh and frozen fish as its domestic production declined and its total consumption rose. By 1967, more than one-half of all fresh and frozen fish used for human consumption in the United States was imported. In California, one-half of fresh and frozen fish sold to consumers was obtained from other states or foreign countries. These out-of-state supplies, in general, consisted of the more desirable and costly species.

California fishermen also encounter increasing competition from sports fishermen for the right to capture the available fish, and from other groups in our society who claim a higher right for the use of the waters from which the fish are taken.

To maintain the industry as a viable force in the California economy, we have to (a) lessen the business risks of producing and marketing of fish, (b) infuse new capital, and (c) recruit new, qualified management personnel.

California gets its supplies of fresh and frozen fish and shellfish from various parts of the world. Buyers from California must compete with those from other parts of the United States and those from foreign countries. This section examines some of the basic facts about potential supply and likely competitive demand. which are relevant to the California trade.

\section{World}

Total estimated world production of fish has slightly more than trebled from 19.6 million metric tons (live weight) in 1948 to 60.5 million tons in 1967 (table 21 . In North America and Europe, the rate of growth has been slowest. Since 1948 both Russia and Japan have built up large long-distance fishing fleets (Borgstrom. 1961, p. 7) while many developing countries have promoted fishing as a cheap source of supply of protein and an important export-earner of foreign exchange (FAO, 1968). Production of crus. taceans and mollusks has not kept pace with that of finfish. Although the fresh market still accounts for the greatest volume of fish for human consumption, the proportion of fish marketed fresh or cured has fallen while freezing volume has increased more than sevenfold (table 1). The most remarkable growth has been in fish reduced for oil and meal, which is now the single most important outlet for fish.

World consumption data are even less reliable than those for production. Many countries keep poor or inadequate statis. tics. Different species sustain different weight losses in processing and marketing; thus, live-weight volume may be a poor indication of weight actually consumed. This study needed some indication where the world supplies of fish are consumed and where demand is growing fastest. The comprehensive FA() (1967) study gives an insight into the current and prospective levels of demand for fish and shellfish. The derivations from that study (table 2) show that in 1962. five areas-the United States, E. E. C.. I.S. S. R.. mainland China. and Japanaccounted for slightly more than 50 per cent of world consumption. Based on 
TABLE 1

WORLD FISH PRODCCTION, BY REGION, GROLP OF SPECIES,
AND UTILIZATION

\begin{tabular}{|c|c|c|c|c|c|c|c|c|c|}
\hline & 1948 & 1958 & 1960 & 1962 & 1963 & 1964 & 1965 & 1966 & 1967 \\
\hline & & & & lion $n$ & ic ton & ve wei & & & \\
\hline \multicolumn{10}{|l|}{ Region } \\
\hline Africa. & 1.0 & 2.1 & 2.3 & 2.6 & 2.7 & 3.0 & 3.1 & 3.2 & 3.7 \\
\hline North America. & 3.6 & 4.0 & 4.1 & 4.5 & 4.4 & 4.3 & 4.4 & 4.4 & 4.4 \\
\hline South America. & .5 & 1.6 & 4.4 & 8.3 & 8.4 & 11.0 & 9.0 & 11.1 & 12.2 \\
\hline Asia ................. & 6.8 & 14.6 & 17.4 & 18.6 & 19.0 & 19.3 & 19.9 & 21.4 & 22.5 \\
\hline Europe .. . . . . . . . . . & 6.1 & 7.8 & 8.1 & 8.7 & 9.0 & 9.7 & 10.8 & 11.6 & 11.8 \\
\hline Oceania........ & 0.1 & 0.1 & 0.1 & 0.1 & 0.1 & 0.2 & 0.2 & 0.2 & 0.2 \\
\hline U. S. S. R..... & 1.5 & 2.6 & 3.1 & 3.6 & 4.0 & 4.5 & 5.0 & 5.4 & 5.7 \\
\hline \multicolumn{10}{|l|}{ Group of species } \\
\hline Freshwater fish. & 2.5 & 5.4 & 6.4 & 6.5 & 6.7 & 6.8 & 7.2 & 8.1 & 8.2 \\
\hline Marine fisheries. & 14.7 & 23.9 & 29.0 & 35.3 & 36.1 & 40.7 & 40.4 & 44.1 & 46.9 \\
\hline Crustaceans, mollusks & 2.0 & 2.9 & 3.5 & 3.8 & 4.1 & 3.8 & 4.1 & 4.3 & 4.5 \\
\hline Other aquatic animals and plants.. & 0.4 & 0.6 & 0.6 & 0.8 & 0.7 & 0.7 & 0.7 & 0.8 & 0.9 \\
\hline \multicolumn{10}{|l|}{ Utilisation } \\
\hline Human consumption. & 17.1 & 27.5 & 30.9 & 33.4 & 34.6 & $3 j . j$ & 36.1 & 38.6 & 39.2 \\
\hline Fresh........... & 9.7 & 14.5 & 16.3 & 16.9 & 17.3 & 17.6 & 17.5 & 18.4 & 18.7 \\
\hline Freezing....... & 1.0 & 2.7 & 3.4 & 4.3 & 4.7 & 5.1 & 5.7 & 7.0 & 7.3 \\
\hline Curing. & 5.0 & 7.3 & 7.5 & 8.1 & 8.5 & 8.4 & 8.1 & 8.2 & 8.0 \\
\hline Canning. & 1.4 & 3.0 & 3.7 & 4.1 & 4.1 & 4.4 & 4.8 & 5.0 & 5.2 \\
\hline Other purposes........ & 2.5 & 5.3 & 8.6 & 13.0 & 13.0 & 16.5 & 16.3 & 18.7 & 21.3 \\
\hline Reduction..... . . & 1.5 & 4.3 & 7.6 & 12.0 & 12.0 & 15.5 & 15.3 & 17.7 & 20.3 \\
\hline Miscellaneous ........ & 1.0 & 1.0 & 1.0 & 1.0 & 1.0 & 1.0 & 1.0 & 1.0 & 1.0 \\
\hline TOT AL World Production..... & 19.6 & 32.8 & 39.5 & 76.4 & 47.6 & 52.0 & 52.4 & $5 \% .3$ & 60.5 \\
\hline
\end{tabular}

SOURCE: FAO (1968a).

T.1BLE 2

ESTIMATED SHARE OF TOTAL, WORLD DEMAND FOR FISH AND SHELLFISH IN SELECTED ZREAS

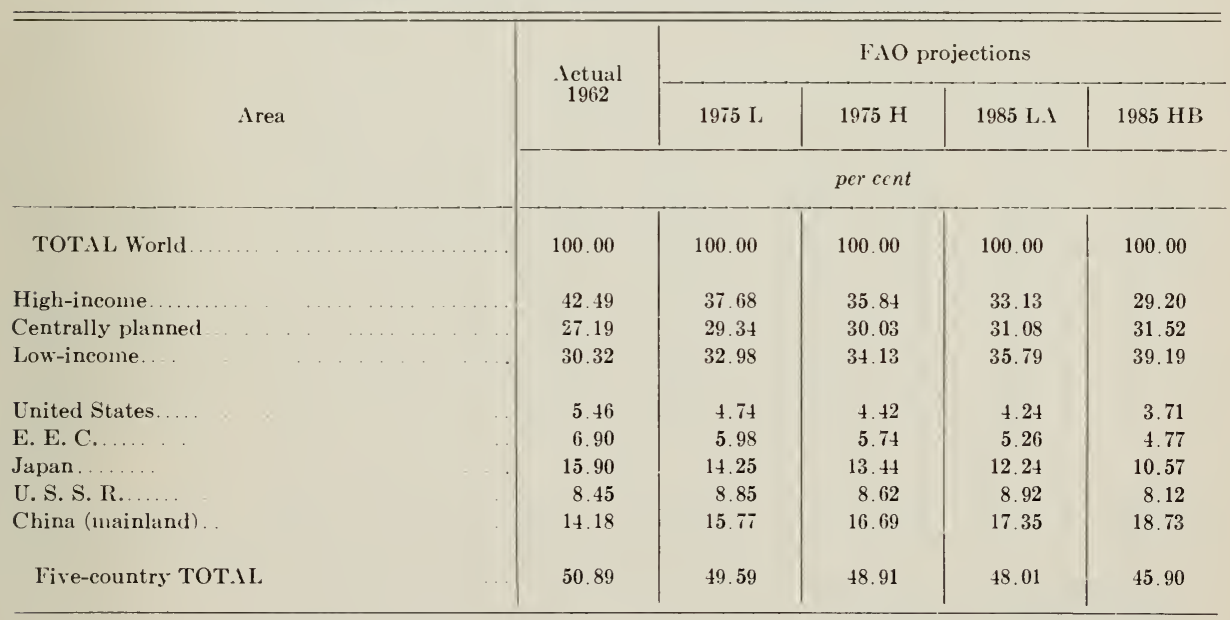

Notes: $\quad \mathrm{L}=\mathrm{I}$,ow GDP assumption

$\mathrm{H}=$ High GDP assumption

$\mathrm{LA}=$ Combination of low GDP assumption with low population assumption

$\mathrm{HB}=$ Combination of high GDP assumption with high population assumption

Source: FAO (1967). 
these $\mathrm{FAO}$ projections of income and population growth for 1975 and 1985, the high-income countries will account for a steadily reducing share of world demand. By 1985, the U. S. share is likely to drop to around 4 per cent of world demand. Under most of the FAO assumptions for all periods up to 1985, the United States will lag behind most of the world in rate of growth of per-capita gross domestic product, population growth, and the elasticity of demand for fish with respect to income ${ }^{2}$.

These projections suggest that the United States, in bidding for world supplies to supplement its declining domestic catch, will face more powerful foreign competition in the next two decades. Since our population is now increasing only at about 1 per cent per year compared to the FAO projection of 1.4 per cent per year for the 1965-1975 period, we would expect to see some evidence of this stronger competition already apparent in our fish import and world trade figures. Indeed, between 1962 and 1967, while our imports of fish rose 47.9 per cent in volume and 38.5 per cent in value, world imports of fish rose 34 per cent in volume and 48.6 per cent in value indicating the rising purchasing power of other countries (FAO, 1968a). Our share of total dollars spent on imported fish fell from 27.0 per cent in 1962 to 25.2 per cent in 1967 while, for example, Japan's share climbed from 1.2 to 6.2 per cent. The problem may be intensified in the future if the catch of many of the species in greatest demand in the United States fails to increase. Salmon, flounders, halibut, Atlantic cod, haddock, and many shellfish supplies are decreasing.

TABle 3

UNITED STATES: SLPPLY AND UTILIZATION OF COMMERCIAL FRESH AND FROZEN FISH, * 1950-1968

\begin{tabular}{|c|c|c|c|c|c|c|c|c|c|}
\hline \multirow{4}{*}{ Year } & \multicolumn{4}{|c|}{ Supply } & \multicolumn{5}{|c|}{ Utilization } \\
\hline & \multirow{3}{*}{$\begin{array}{l}\text { Domes- } \\
\text { tic } \\
\text { produc- } \\
\text { tion }\end{array}$} & \multirow{3}{*}{$\begin{array}{l}\text { Im- } \\
\text { ports }\end{array}$} & \multirow{3}{*}{$\begin{array}{l}\text { Begin- } \\
\text { ning } \\
\text { stocks }\end{array}$} & \multirow{3}{*}{$\begin{array}{l}\text { Total sup- } \\
\text { ply }\end{array}$} & \multirow{3}{*}{ Total use } & \multirow{3}{*}{ Exports } & \multicolumn{3}{|c|}{$\begin{array}{l}\text { Domestic disappearance for } \\
\text { food }\end{array}$} \\
\hline & & & & & & & \multirow[b]{2}{*}{ Military } & \multicolumn{2}{|c|}{ Civilian } \\
\hline & & & & & & & & Total & $\begin{array}{l}\text { Per } \\
\text { capita }\end{array}$ \\
\hline & \multicolumn{8}{|c|}{ million $l b$} & pounds \\
\hline $1968 \dagger$. & 597 & 723 & 200 & 1,520 & 1,302 & 54 & 29 & 1,219 & 6.2 \\
\hline 1967. & 633 & 620 & 215 & 1,468 & 1,268 & 54 & 32 & 1,182 & 6.0 \\
\hline 1966. & 643 & 637 & 183 & 1,463 & 1,248 & 49 & 31 & 1,168 & 6.0 \\
\hline $1965 \ldots$ & 647 & 568 & 174 & 1,389 & 1,200 & 37 & 27 & 1,136 & 6.0 \\
\hline 1964. & 613 & 534 & 201 & 1,348 & 1,174 & 34 & 20 & 1,120 & 5.9 \\
\hline $1963 \ldots$ & 631 & 518 & 179 & 1,328 & 1,127 & 24 & 20 & 1,083 & 5.8 \\
\hline $1962 \ldots$ & 626 & 511 & 153 & 1,290 & 1,111 & 18 & 20 & 1,073 & 5.8 \\
\hline 1961. & 616 & 453 & 186 & 1,255 & 1,102 & 13 & 23 & 1,066 & 5.9 \\
\hline $1960 \ldots \ldots$ & 678 & 388 & 164 & 1,230 & 1,044 & 11 & 23 & 1,010 & 5.7 \\
\hline \multicolumn{10}{|l|}{ Averages } \\
\hline $1960-1968$ & 632 & 550 & 184 & 1,366 & 1,175 & 33 & 25 & 1,117 & 5.8 \\
\hline $1950-1959$ & 688 & 317 & 130 & 1,135 & 999 & 7 & 26 & 966 & 6.0 \\
\hline
\end{tabular}

* Includes finfish and shellfish.

t Preliminary.

Source: U. S. Department of Agriculture, 1966

${ }^{2}$ For a theoretical discussion of the methods and results of these FAO estimates, see Goreux (1960, pp. 1-13). 


\section{United States}

Total utilization of commercial fresh and frozen fish and shellfish in the United States has moved upwards in step with population growth so that per-capita consumption has remained remarkably stable in the last two decades (table 3). However, domestic producers have not been able to maintain their share of total supplies, which have had to come increasingly from imports. The share of total consumption provided by imports has risen from an annual average of 32.8 per cent in the 1950's to 49.2 per cent in the 1960 's. Imports have come to dominate U. S. supplies of important sections of the fresh and frozen fish trade. For example, in 1968, they accounted for 87.6 er cent of L. S. supplies of groundfish and Atlantic ocean perch fillets and steaks, and for 57.8 per cent of all other fillets and steaks. Much of this increase in imports is attributable to lower costs of catching and processing fish in many of the countries which supply the United States (U. S. Department of the Interior, 1969a, p. 53; Dykstra and Holman, 1968, pp. 105-07; and White, 1954, p. 6) .

The volatility in the composition of supplies is reflected in significant changes in per-capita consumption of major fresh and frozen species. Comparing annual average per-capita consumption in the 1960 's with that of the 1950's, shrimp, cral and flounders (including sole) have experienced increases of more than 30 per cent, and lobster about 20 per cent. In contrast, per-capita consumption of oysters, cod, haddock. ocean perch, and halibut has fallen from 10 to 30 per cent (table 4). While availability of supply has been an important factor contributing to these changes, it has interacted with innovations in the technology of production and marketing, and shifts in consumer tastes. Frozen-fish sales grew

TABLE 4

U. S. PER CAPITA CONSUMPTION OF IEADING SPECIES OF FRESH AND FROZEN FISH AND SHELLFISH, 1955-1968

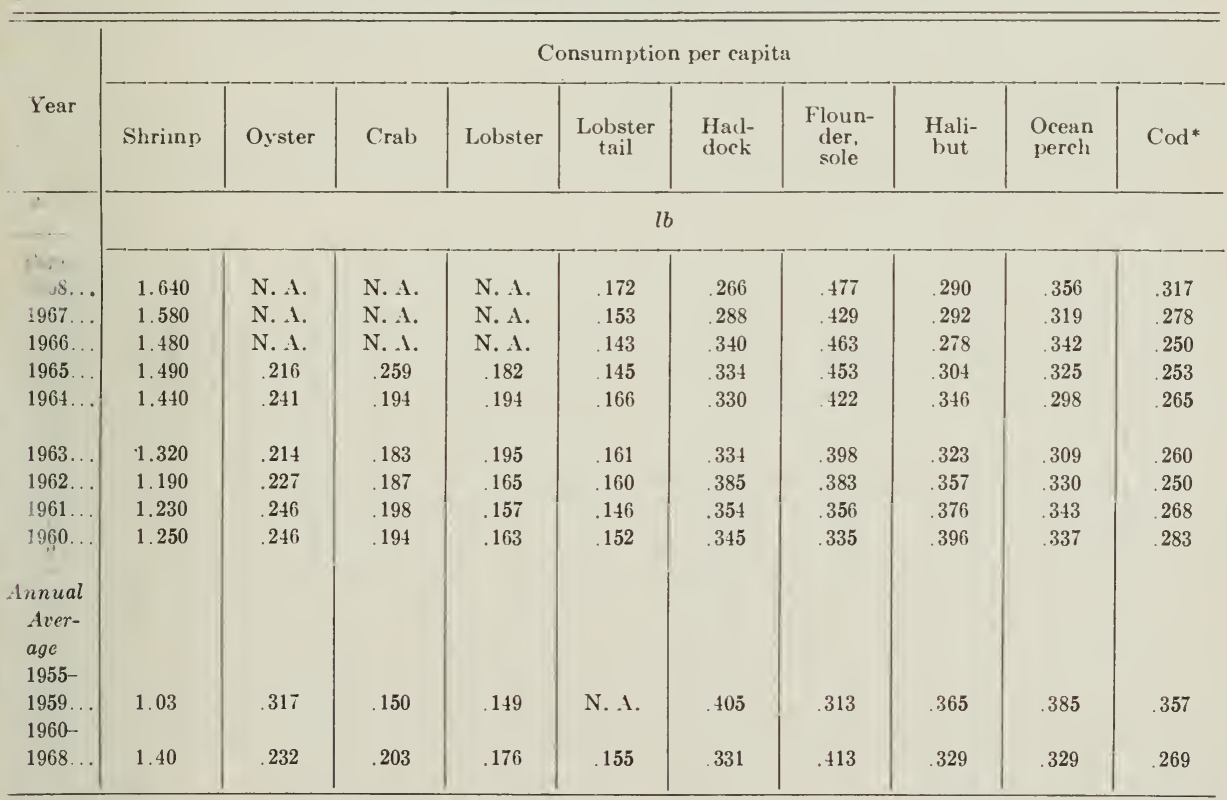

* Excluding frozen blocks.

N. A. = Data not available.

Source: U. S. Department of Interior 1969' and 1970, and Suttor and Aryan-Nejad, 1969. 


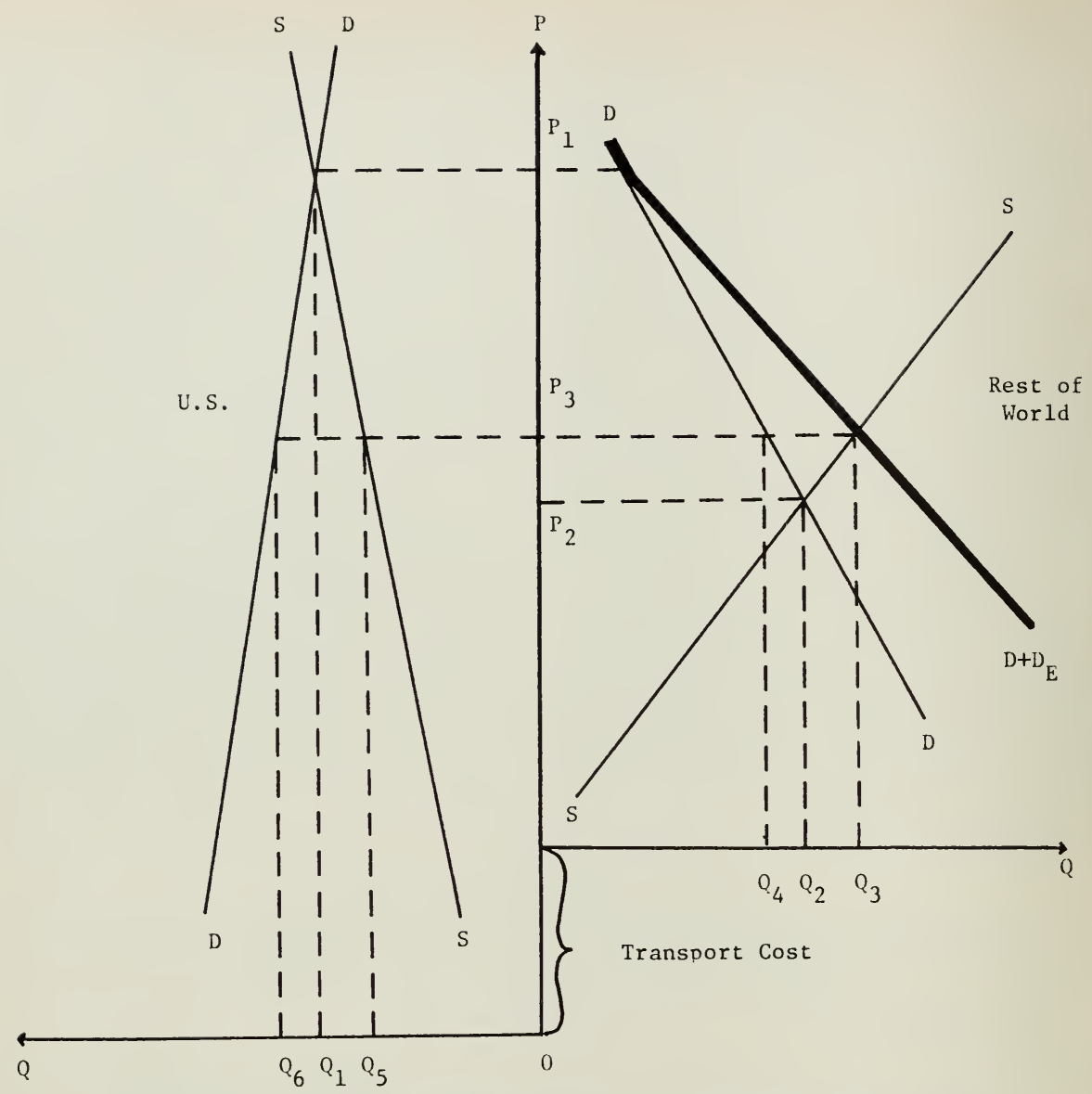

Fig. 2. Impact of world supply and demand on U. S. supply and price of fish.

rapidly in the 1940's, the convenience factor became prominent in the 1950'snotably in breaded shrimp, fish sticks, and breaded fish portions, while in the 1960's there was continued growth of prepared, prepacked, precooked, branded consumer packs (Gruber, 1968, pp. 22728). Much of the processing industry has come to rely for raw materials on a steady supply of low-cost imported fish. principally in the form of frozen blocks or slabs. At the same time, an increasing proportion of domestic production of packaged fish is sold fresh (more than 60 per cent in 1968).

This heavy dependence of the fresh and frozen industry on the availability and price of foreign supplies of fishery products has important economic implications for U. S. fishermen, processors, and consumers. A simple back-to-back diagram can be used to illustrate the essential features of the current situation, and the likely impact of world trends in supply and demand discussed in the previous section (figure 2).

Figure 2 shows hypothetical fish supply and demand schedules for the United States and for the rest of the world. If there were no trade, U. S. equilibrium price would be $P_{1}$ and quantity demanded and supplied, $Q_{1}$. The rest of the 
world equilibrium price would be $\mathrm{P}_{2}$ and quantity, $Q_{2}$. However, with trade, effective demand in the rest of the world becomes $\mathrm{D}+\mathrm{D}_{\mathrm{E}}$. that is, the rest of the world demand plus excess U. S. demand where $D_{E}$ equals excess of $\mathrm{L}$. S. demand over supply at any price, and a new world price is established at $P_{3}$. This has the following effects in the U.S.: Domestic supply falls from $Q_{1}$ to $Q_{5}$. Total supply for the United States is increased to $Q_{6}$ by imports of $Q_{6}-Q_{5}$ and price falls to $P_{3}$. In the rest of the world, domestic supply retained at home falls from $Q$.2 to $Q_{4}$. Exports are equal to $Q_{3}-Q_{4}$ (equals $\left.Q_{6}-Q_{5}\right)$ and price rises to $P_{3}$ minus transport costs.

What happens if, as projected by the FAO, demand in the rest of the world markets increases? The line DD, and accordingly the total world demand $\mathrm{D}+\mathrm{D}_{\mathrm{E}}$, will move upward and to the right cutting the supply curve at a price above $P_{3}$ and reducing both exports and
U. S. imports. This move would tend to hurt U. S. consumers and benefit U. S. producers. It is a moot question whether technological progress can permit the rest of the world supply schedule to shift downward and to the right with sufficient magnitude and speed to offset the effects of upward demand shifts on prices and trade. A weakening of the competitive pressure of imports could have significant implications for the future plans and prospects of the U.S. fishing fleet.

\section{California}

Like the Lnited States, California's trade balance is in deficit with respect to fresh and frozen fishery products. While California's share of the U.S. population has been rising steadily through the last three decades, the share of U. S. supplies of fresh and frozen fish and shellfish coming from California fishermen may have declined slightly (table 5). Under the assumption ${ }^{3}$ that California's per-capita

TABLE 5

CALIFORNIA FRESH AND FROZEN FISH SLPPLIES IN POLNDS AND AS A PERCENTAGE OF TOTAI, U. S. SUPPLIES AND CAIIFORNIA'S POPILATION AS A PERCENTAGE OF TOTAI, I'. S.

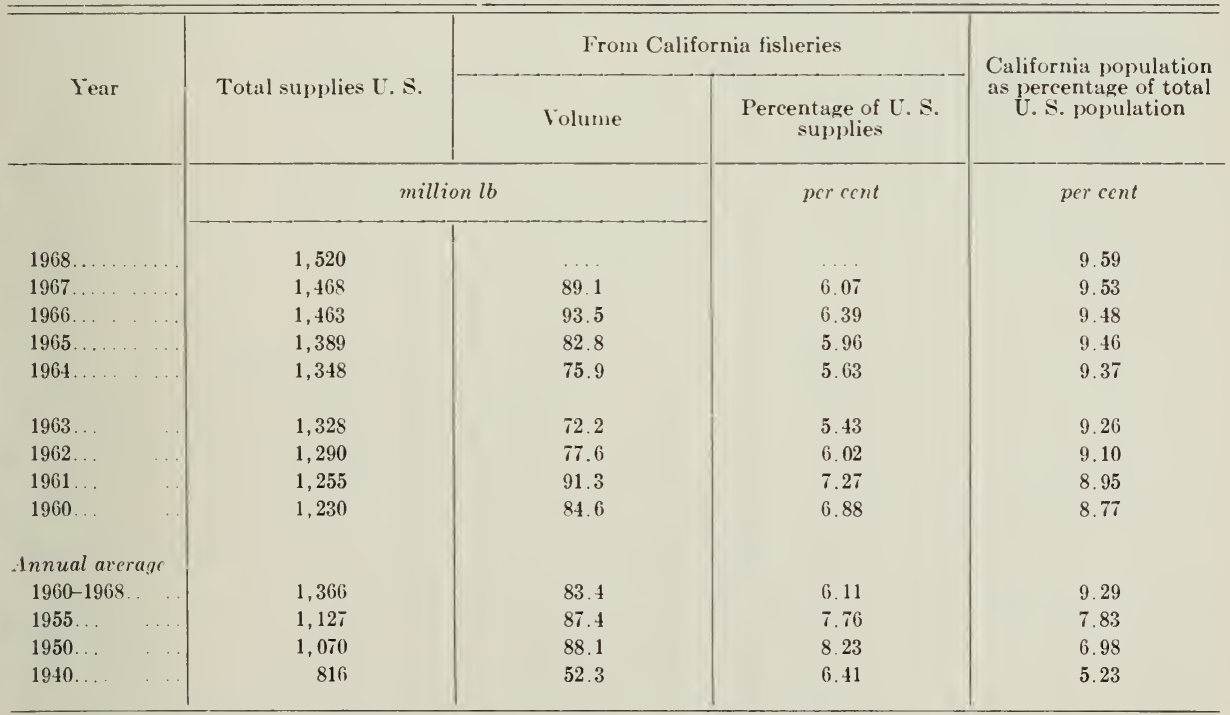

Source: U. S. Department of Agriculture, 1970 and California Department of Fish and Game, miscellaneous bulletins.

${ }^{3}$ Supported by recent findings for the Pacific region (Nash, 1970, pp. 2-3). 
consumption is at about the national average, and making allowance for some export of California species, it is probable that California fishermen now supply less than one-half the state's consumption needs. Of the major species consumed, only in sole, rockfish, fresh salmon, and Dungeness crab are California suppliers a dominant factor.
There is a small California shrimp fishery, but all haddock, cod, halibut, lobster tails, and scallops must come from outside the State.

Statistics on California landings of fish and shellfish are reported by ports and by statistical areas. The statistical areas are as defined by the California Department of Fish and Game (e.g.,

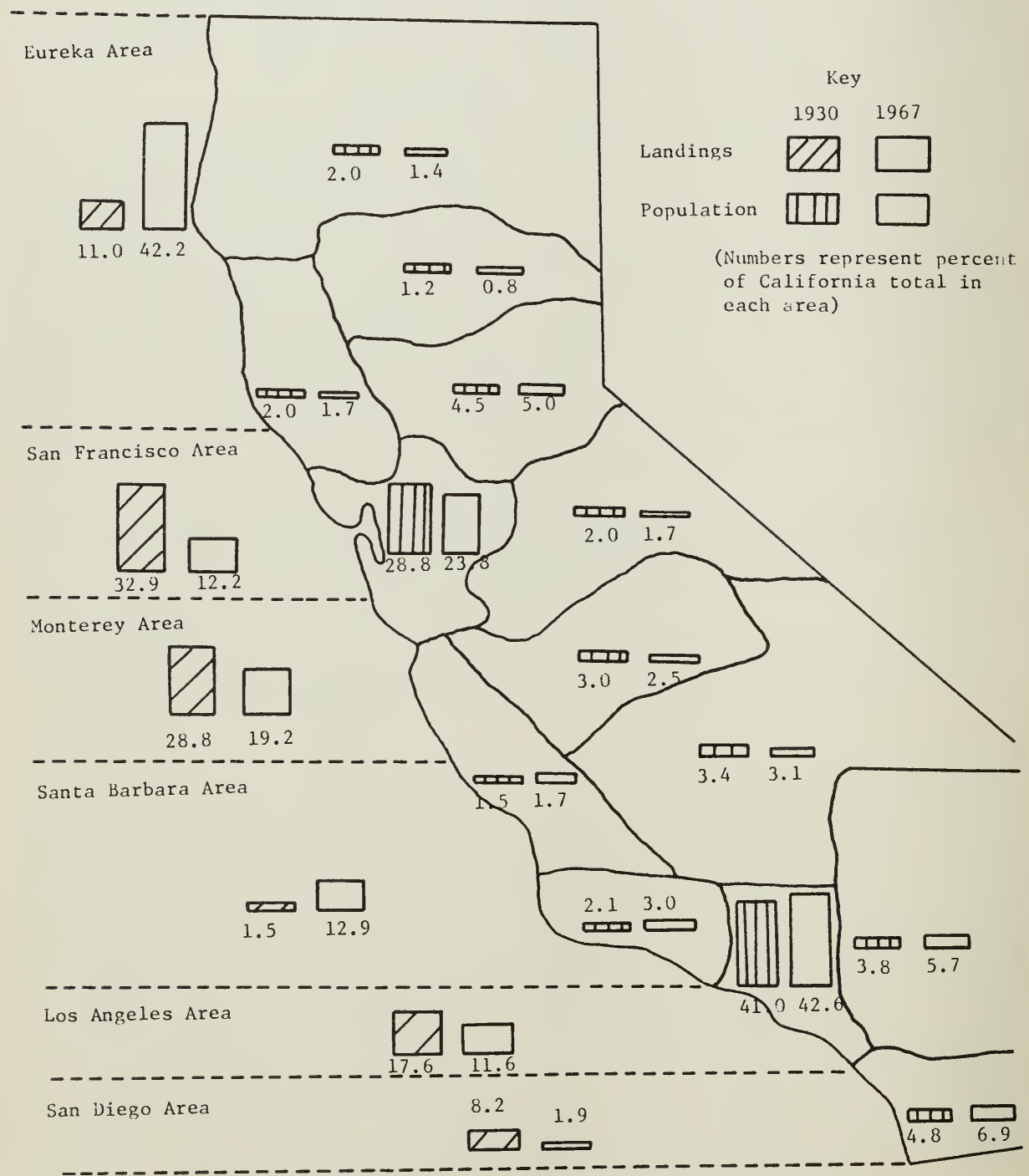

Fig. 3. California market fish and shellfish catch by area of landing, and distribution of California population by region, 1930 and 1967. 
Heimann, 1968) and shown in figure 3. The diagrams superimposed on figure 3 and the data in table 6 illustrate the changes which have taken place in the California fresh and frozen fishery resource since $1930^{ \pm}$. The most notable features are (a) the relative stability of the total catch since 1950, (b) the northward shift of the main supplying areas since 1930, and (c) the relative decline of the fishing areas nearest the Los Angeles and Bay areas, the major markets for fresh and frozen fish. Given the growth in California's population, the relative stability of catch implies a sharp decrease in per-capita availability of fresh and frozen fish. Value of landings is heavily dependent on the composition of catch. It was $\$ 8.5$ million in 1950 , $\$ 10.5$ million in 1960 , and $\$ 13.6$ million in 1967.
Until the beginning of World War II, the San Francisco area was a leading supplier for many species, in particular sole and other flatfish, salmon, rockfish, sablefish, crab, shrimp, and oysters (DeLoach, 1938, p. 12). While the area is still a supplier of small quantities of a wide variety of species, its importance has declined. Depletion of the nearby resources encouraged greater exploitation of the Eureka area. War needs for seafood and improved technology led to the development of extensive processing facilities in Eureka. The story of one species found in abundance off Eureka is recorded by Hagerman (1952, pp. 10-11).

"Less than 10 years have elapsed since the Dover sole ceased to be considered as a trash fish, and became a sought-after article of com-

TABLE 6

VOLUME OF CALIFORNIA COMMERCIAI, CATCH OF MARKET FISH AND SHELLFISH AND PERCENTAGE OF CATCH LANDED IN EACH STATISTICAL AREA, 1930-1967

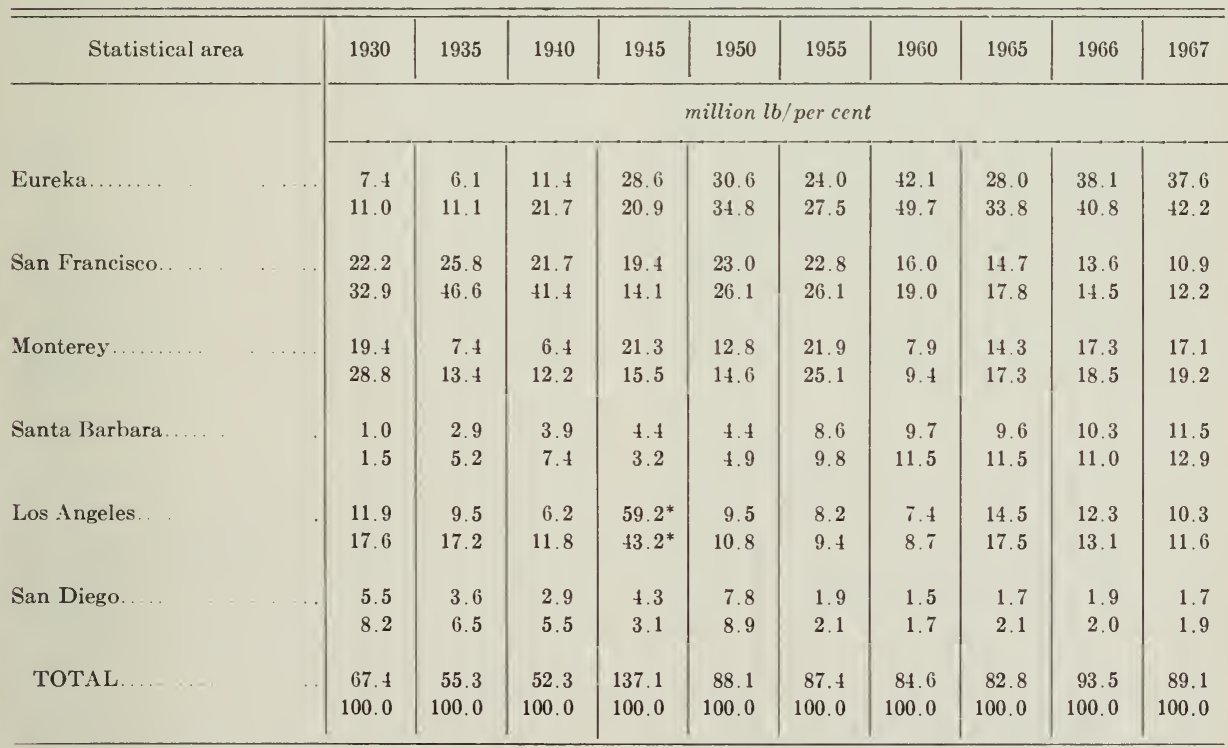

* Abnormal volume attributable to landings of 53.4 million lb of Pismo clams.

Source: California Department of Fish and Game, miscellaneous bulletins.

- Market fish (table 6 and figure 3) include barracuda, flounders and sole, lingcod, rockfishes, salmon, sablefish, seabass, swordfish, and other species not canned. Shellfish include species of crab, prawn, shrimp, oyster, spiny lobster, abalone, and squid. 
merce. New techniques of fish handling, packaging, and freezing, introduced during the early war years, were very important in the development of a market for the Dover sole. It was learned that by the quickfreeze method the soft tissues of the fish would harden and produce a marketable fillet. Furthermore, since other species of flatfishes were becoming less abundant, necessitating longer trips and greater effort on the part of the fishing fleet, the trawlers were glad to turn their attention to the large population of Dover sole which ranged along the northern coast of California in depths greater than those usually frequented by other commercial flatfishes."

Eureka benefited from a similar development with respect to rockfish (California Department of Fish and Game, 1949, pp. 118-19). The prominence of Dover sole and rockfish in the Eureka catch has continued for the last two decades. Dover sole in 1967 accounted for almost 14 per cent of the volume and more than 5 per cent of the value of total Eureka catch, while rockfish accounted for 6 per cent of the volume and 2 per cent of the value. The Eureka area in 1967 supplied over 80 per cent of California landings of Dover sole and 25 per cent of rockfish landings by volume and value. However, Eureka's present dominance in the California fresh and frozen fish trade stems from the wide variety of species in addition to Dover sole and rockfish, e.g., salmon, crab, other bottomfish, shrimp, and albacore, found in neighboring waters. In contrast, the regions south of San Francisco rely heavily on the catch of one or two species.

The shift of the supply side of the industry farther from the greatest concentrations of customers has had obvious implications for the cost and location of processing and distribution facilities. Assuming constant freight costs per ton mile in real terms in both 1930 and 1967, the distribution cost per ton is likely to have risen because of longer average distances travelled. This is supported by a simple transportation model assuming that total supplies are absorbed in each area in proportion to its population. Average cost of distribution per pound, assuming constant freight charges, would have doubled between 1930 and 1957, thus greatly reducing the locational advantage of California products over those shipped from out of State.

Data on California supplies from out of State are inadequate in three ways: (1) little information is available on supplies from other parts of the United States; (2) data on imports of fish from foreign countries are combined for the California and Arizona customs districts (Keilman and Allen, 1969, pp. 10-17); and (3) there is no way of determining what proportion of these imports is intended for consumption in other states. However, we can assume that the bulk of these imports is consumed in Califor. nia. Imports of fresh fish into California and Arizona mainly from Mexico, have fluctuated between two and three million pounds in the years 1960-1967. Frozen fish imports (other than tuna for canning) from all countries have fluctuated around 70 million pounds in the same period. Seabass is the dominant fresh import. Shrimp is the major frozen import, usually accounting for 75 per cent of all frozen imports. Lobster tail imports have grown from 1.3 million pounds in 1960 to 9.0 million in 1967. Cod and swordfish are the only other frozen imports whose volume regularly exceeds two million pounds.

Large quantities of northern halibut, salmon, ${ }^{5}$ crab, and flounder fillets from

\footnotetext{
${ }^{5}$ In a letter of May 13, 1970, Lloyd Turnacliffe of the Meredith Fish Company, Sacramento, estimated annual shipments of northern halibut at 7-8 million pounds and salmon at 4-5 million pounds.
} 
the Northwest states, haddock, perch, Maine lobsters, and scallops from the Northeast, and shrimp from the Southeastern states are sold in California. Most of the above items are received in frozen form.

The daily, weekly, and seasonal stability of supply of many California species is susceptible to dramatic fluctuations because of the size changes and migratory habits of the fish populations, weather, ocean temperature, number of vessels fishing, etc. To help firms plan for and adapt to cyclical or predictahle variations in catch, the extent of variation in landings of a species due solely to random or unpredictable elements (table 7 ) is used as an indicator. By use of the variate difference method, coefficients of

\section{T.IBLE 7}

COEFFICIENTS OF VARIATION FOR QUANTITY OF LANDINGS, BY SELECTED SPECIES, SELECTED OPERATING EQUIPMENT, AND SELECTED AREA, 1939-1967

\begin{tabular}{|c|c|}
\hline Selected fishery & $\begin{array}{c}\text { Coefficient } \\
\text { of } \\
\text { variation * }\end{array}$ \\
\hline & per cent \\
\hline \multicolumn{2}{|l|}{ Main species, total landings } \\
\hline Sole..... & 14 \\
\hline Salmon. & 16 \\
\hline Rockfish. . & 12 \\
\hline Sablefish.... & 47 \\
\hline Sea bass, white... & 22 \\
\hline Market crab...... & 19 \\
\hline Shrimp......... & 18 \\
\hline Abalone.... & 12 \\
\hline Squid...... & 68 \\
\hline \multicolumn{2}{|l|}{ Main operating units, landings per unit } \\
\hline Otter trawls: total catch per vessel... & 23 \\
\hline Monterey area catch per vessel.... & 59 \\
\hline San Francisco area catch per vessel. & 23 \\
\hline Eureka area catch per vessel. . ..... & 24 \\
\hline Santa Barbara area catch per vessel & 27 \\
\hline Shrimp trawl catch per vessel... ... & 58 \\
\hline Salmon troll catch per line...... & 30 \\
\hline Crab trap catch per trap........ & 47 \\
\hline
\end{tabular}

* Measures the variation in a time series due to random elements. The coefficient of variation is given in terms of the standard deviation as a percentage of the mean value. For a fuller discussion see Tintner, 1940, Carter and Dean, 1960.

Source: Computed from California Department of Fish and Game, miscellaneous bulletins. variation were derived for annual landings of main species and for average annual landings per unit for main types of operating unit (Tintner, 1940). For example, the variation in annual landings of sole due to random factors was equal to 14 per cent of the mean quantity of landings over the years 1939-1967. Firms owning ressels or buying from fishermen suppliers are subject to great variation in supplies of individual species and considerable variation in total supplies. both seasonally and annually. In general, firms which specialize in one or a small number of species lead a precarious existence with little incentive to plough back the profits of good years into improving facilities. Two ways in which California firms have tried to combat this uncertainty of supply are (1) by broadening the scope of their operations, e.g. adding restaurant or retailing facilities, and (2) by handling as wide a range of products as possible. Fish farming offers a third alternative method of reducing uncertainty of supply. However. in California it has gained only little attention, and primarily as an alternative "crop" for rice growers and other farmers whose acreage can be adapted for the commercial rearing of fish. It has not been adopted by any of the firms currently procuring or processing fish from the sea. Moreover, little or no research has been conducted on the long-term economic outlook for this activity.

\section{Sportfishing}

Sportfishing-fishing for recreational purposes-probably adds to the uncertainty of supply of California species. Of the nine leading species of sportfish, only three (salmon, rockfish, and California halibut) are also important in the commercial fresh and frozen fish trade (table 8). The sportfishing catch in Southern California dropped sharply after 1963. This does not belie the fact that sportfishermen continue to be serious competitors for the available supply of spe- 
T.IBLE 8

AVERAGE ANNUAL SPORTFISH

CATCH, 1958-1961 AND 1963-1966

\begin{tabular}{|c|c|c|c|}
\hline \multirow{2}{*}{ Species } & \multirow{2}{*}{$\frac{\begin{array}{c}\text { Total } \\
\text { California* }\end{array}}{1958-1961}$} & \multicolumn{2}{|c|}{$\begin{array}{l}\text { Southern } \\
\text { California }\end{array}$} \\
\hline & & 1963 & $1963-1966$ \\
\hline & \multicolumn{2}{|c|}{ thousand $l b$} & \\
\hline Bonito. & 3,170 & 3,168 & 1,579 \\
\hline Barracuda. & 2,458 & 2,455 & 565 \\
\hline Rockfish... & 2,439 & 733 & 881 \\
\hline \multicolumn{4}{|l|}{ Kelp and sand } \\
\hline bass.......... & 1,517 & 1,517 & 1,208 \\
\hline Albacore tuna. & 2,766 & 2,763 & 110 \\
\hline Perch.......... & 1,065 & 141 & 616 \\
\hline California halibut & 725 & 722 & 280 \\
\hline Croakers.......... & 644 & 500 & 1,090 \\
\hline \multirow{4}{*}{$\begin{array}{l}\text { SalmoT } A \mathrm{~L} \text { for } \\
\text { leading } 9 \\
\text { species....... } \\
\text { GRAND TO- } \\
\text { TAL for all } \\
\text { species........ }\end{array}$} & \multirow{3}{*}{14,784} & N. A. & N. A. \\
\hline & & \multirow[t]{2}{*}{11,999} & \multirow{2}{*}{6,329} \\
\hline & & & \\
\hline & 19,153 & 13,264 & 7,302 \\
\hline
\end{tabular}

* Comparable data for total California for 1963-1966 not available.

N. A. = Data not available. $\left(1966^{\mathrm{b}}\right)$

Source: California Fish and Wildlife Plan, 1965

cies which have great commercial importance to specialist groups of fishermen, e.g., lingcod, salmon, and barracuda. Competition between sport and commercial fishermen for rights to use the fisheries is keen. Moreover, the trend has been to curb certain commercial fishing practices to protect the resource for recreational use. Continued growth in the California population, if not accompanied by an increase in availability of sportfish, could intensify the conflict between these two groups of fishermen.

\section{Ethnic influence}

The California fresh and frozen fish trade has in the past drawn heavily for its manpower on unskilled immigrants, many with experience of fishing under even harsher climatic and economic conditions. The first commercial fishermen in California were immigrant Italians fishing out of San Francisco. They were joined by Chinese, Portuguese, Norwegians, Yugoslavs, and Japanese (Sco- field, 1954, p. 7). Immigrant fishermen and their descendants have become leaders in seafood wholesaling, processing, and restaurant operations. Stricter immigration laws and more attractive alternative occupations in other industries have virtually eliminated recruitment from abroad. Descendants of immigrants show a clear tendency to reject the fish industry as not meeting their personal standards for employment. Accordingly, there has been little headway in maintaining and improving the level of managerial competence needed to assure a dynamic industry.

Despite all these problems, the processing sector of the California trade has grown rapidly, absorbing an increased volume of California landings and of fish from out-of-state sources. Total output has risen from a low of about 5 million pounds worth $\$ 2.1$ million to the fishermen in 1951 to a high of 44.6 million pounds worth $\$ 27.9$ million in 1967. A breakdown by leading products which primarily utilize species of California origin and byproducts primarily based on out-of-state raw materials gives a clue to the composition of total fresh and frozen fish consumption in the State (table 9). In the 1960's an increasing volume of flounders, rockfishes, lingcod, and abalone from the California catch has been commercially processed. Despite recent setbacks because of poor catch years, the long-term trend in salmon, crab, and oysters has been upward. Because total California catch has been stable, the rise in utilization in processed form indicates a sharp decline in sales of whole round fish. The last main California product, squid, is mainly exported. Of the products processed from out-of-state raw materials, shrimp and scallops have dramatically increased in volume. Halibut undoubtedly has suffered from reduced availability. The category, all other classifications, which includes mainly fish sticks and portions based on imported raw material, has 
almost doubled in volume since 1960 . These trends in output of processed products suggest that California is tending to follow the patterns of fish consumption found for the United States as a whole, with rising incomes and increased dining-out leading to greater consumption of convenience items and of the more expensive shellfish. Strong demand accompanied by supply problems in recent years have ensured California processors a ready market for their products with little expenditure on promotion.

\section{INDUSTRY STRUCTURE}

The existing structure of the fresh and frozen fish industry in California is shaped by what is required to harvest, process, and market. Fresh fish sold to consumers quickly moves from the fishing boats into the dockside processing plants of producer-wholesalers, then to retail outlets and restaurants. If the Eureka area is excluded, about 80 per cent of California-caught fresh fish was marketed within a 50-mile radius of the landings. For frozen fishery products, time and distance are less important to preserving quality. They may be sold from the fishermen to producer-wholesaler to wholesalejobbers to retailers and restaurants to consumers Brokers are important intermediaries at all levels of marketing.

The 26 producer-wholesalers interviewed for this study, probably one-third of the total, made 90 per cent, or $\$ 45$ million, of all 1968 sales; the four biggest firms sold slightly more than 59 per cent and had 55 per cent of the assets of producer-wholesalers. In spite of this, the sampled firms were relatively small. On the average, their annual sales were below $\$ 2$ million, their full-time workers numbered 45 , and their investment, at replacement value, was about $\$ 668,000$. Bank borrowing for working capital was commonplace among the larger firms, but internal financing and family sources dominated with smaller firms, reflecting their characteristic family ties.

With possibly one exception, the 14 brokers surveyed were buying and selling on their own account. Their true brokerage activities accounted for a minor part of their business. This dual function was necessary for economic survival. Financing of fishermen and producer-wholesalers, particularly in foreign countries was an expanding activity for the larger brokerage firms.

Fabrication was becoming more important in California as the demand increased for precooked, ready-to-cook, and frozen fish dinners. The fish for fabrication came mostly from out-of-state, and the fabricators' sales were almost entirely to California restaurants and retailers.

Interviewed retailers were optimistic about the future of fresh and frozen fish sales. Expansion of business seemed hampered by a lack of well qualified personnel and the maintenance of fish quality.

Future development of the frozen fish business is likely to rest with multiproduct frozen food marketing firms.

The main aspects of structure and conduct of firms in the California fresh and frozen fish trade are outlined in this section as a basis for a later discussion of economic performance. Because published data were insufficient for a meaningful economic analysis, it was necessary to interview a cross-section of firms at each level of the fish processing and distribution system. The location of the three main classes of interviewees indicates the structure of the industry (figure 4). Almost all the primary producers were located at fishing ports, often with their main plant on the landing dock. All but one of the brokers were located 


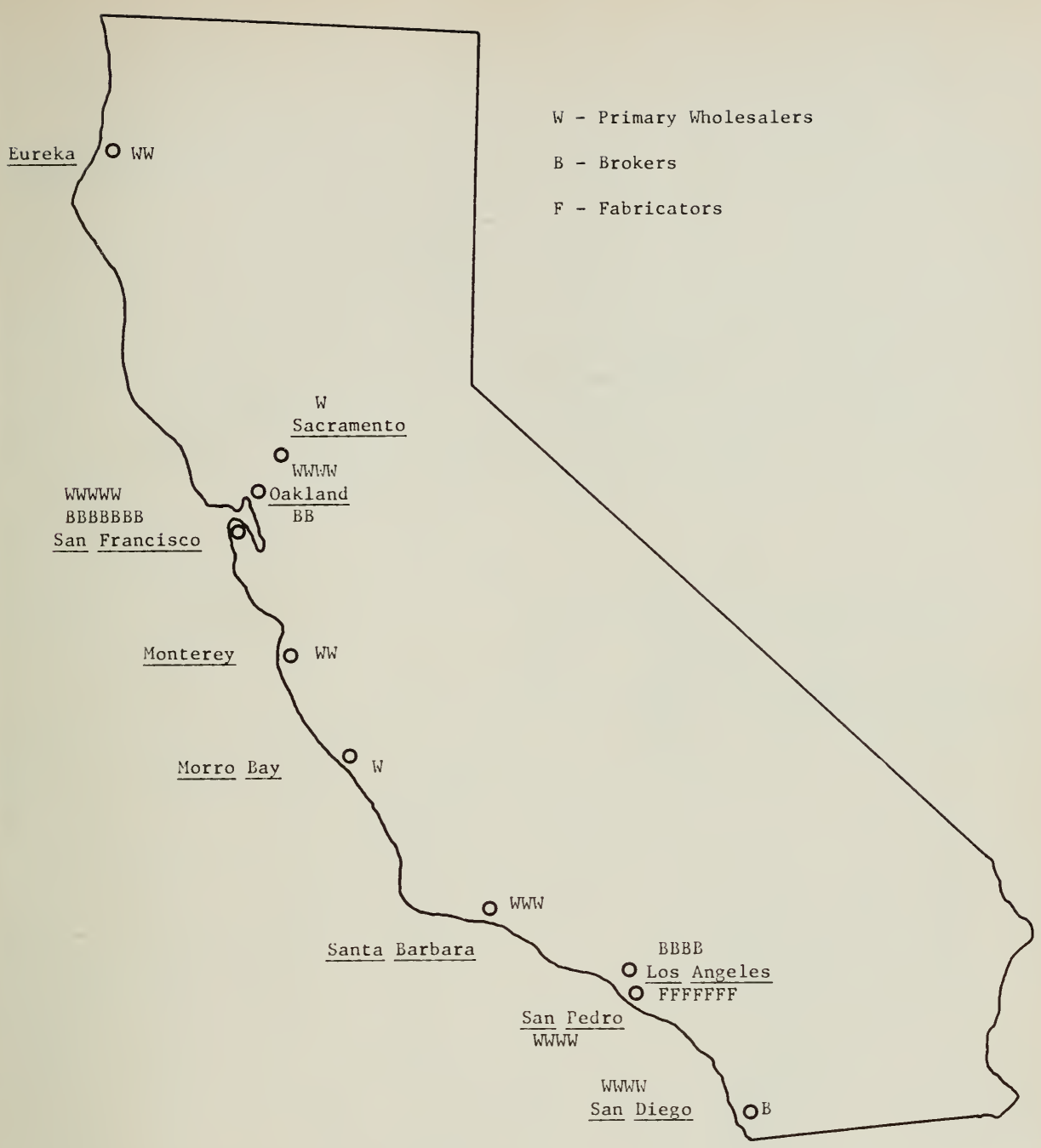

Fig. 4. California fresh and frozen fish study: Location of firms interviewed.

in the Los Angeles or Bay areas. All fabricators were in Los Angeles. the largest consumer market in California. The industry flow-chart (figure 5) shows the position and interrelationships of the various operators in the channels of trade. Statistics on the volume of fish products handled at each level are not available, but one can glean considerable information about the characteristics of alternate channels. California's primary producer-wholesalers got their supplies mainly from California fishermen and sell mainly to other California wholesalers, retailers, and restaurants. However, much of the supplies needed by California consumers came from other states and other countries. Brokers were often the key in procuring these supplies. Then, depending on the amount of processing needed, seafood products were sold to fabricators or frozen-food wholesalers for distribution to restaurants, retailers, and institutions. Food chains 


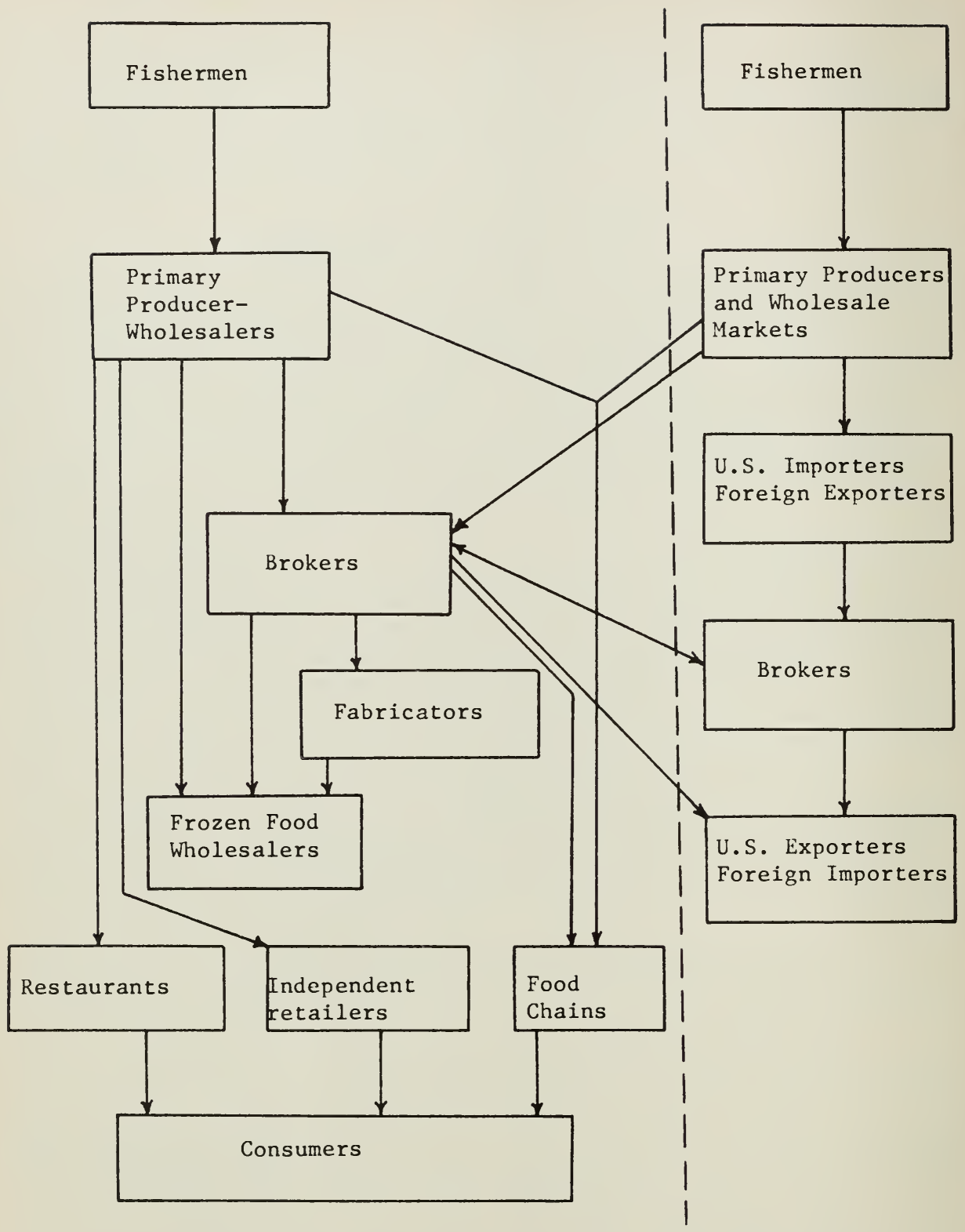

Fig. 5. Major alternate trade channels for fresh and frozen fish and shellfish products (California, 1969).

tended to deal as directly as possible with the primary producer. There were no auction markets for fish destined for the fresh trade fish.

\section{Primary producer-wholesalers}

The 26 producer-wholesalers that were interviewed during the summer of 1969 reported 1968 sales exceeding \$45 mil- 
lion, or more than 90 per cent of the estimated industry total. The 26 firms probably accounted for about one-third of the producer-wholesalers. The common background of these firms was that at one time they obtained most of their supplies of fish from fishermen delivering to the California ports where the producer-wholesalers had their main plants or branch receiving depots. They also provided initial preparation services such as sorting, eviscerating, trimming, and packing in crates (DeLoach, 1938). As our survey showed, a considerable shift from this earlier pattern took place grad- ually to compensate for changes in local supplies, new technology, market pressures within and outside California, and changes in consumer tastes.

Structure. All the primary producerwholesalers studied were relatively small firms. Thirteen of the 26 firms were corporations, 12 were partnerships, usually with two to four partners, and one had a single owner. Both the corporations and partnerships were largely family-ownedand-operated businesses in which the manager was usually a member of the family-owner group. Twenty had been founded by the present owners or in-

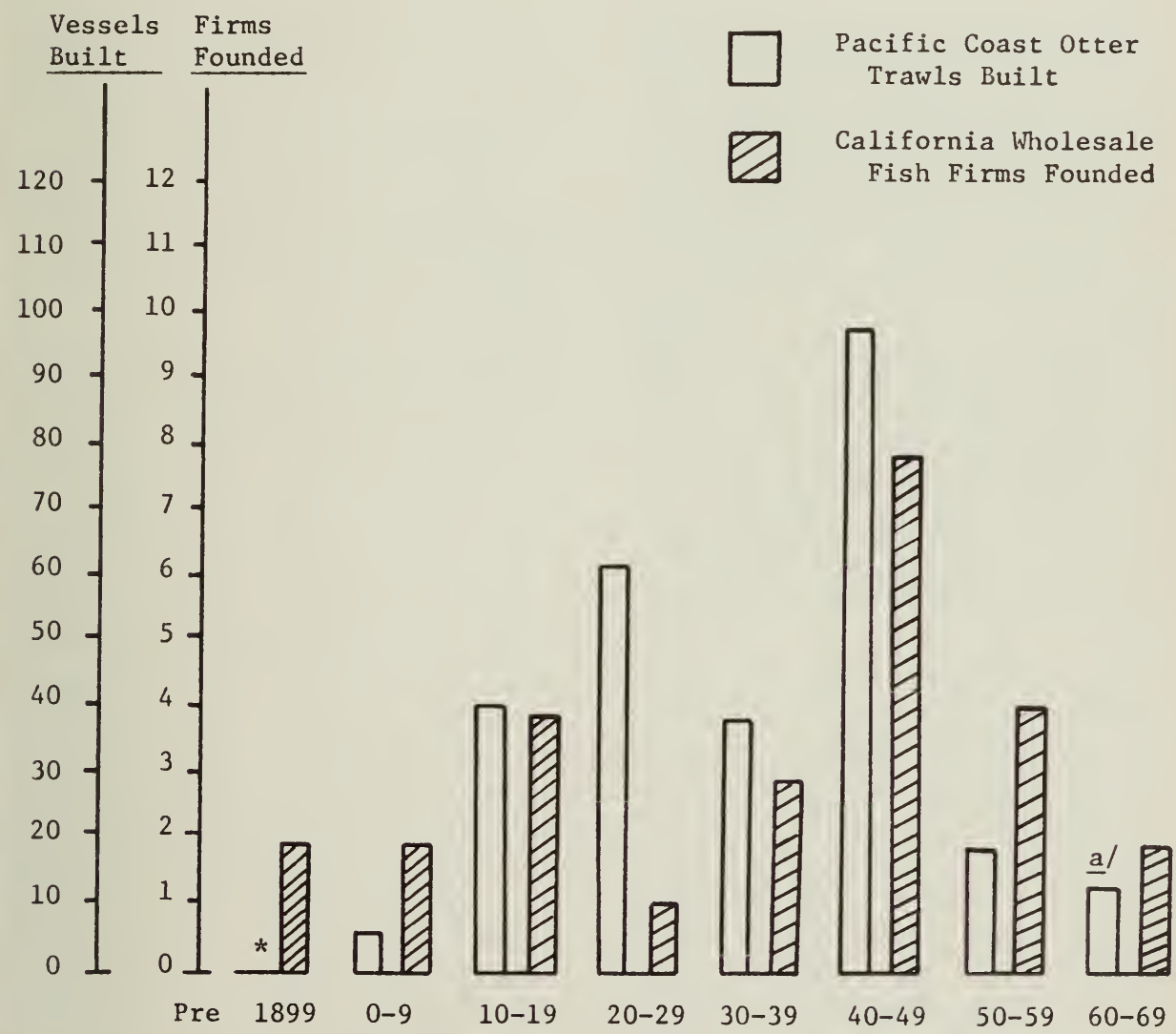

Fig. 6. Pacific coast otter trawls built and California wholesale fish firms founded in each decade, 1900-1969.

"Data covers years 1960-1966.

Source: Lyles, C. H., Fishery Statistics of the United States, 1966, U. S. Bureau of Commercial Fisheries, Wash., D.C., 1968, 678 pp. Data on wholesale firms derived from survey results. 
herited. Of the six firms which had been purchased from previous owners, the most recent purchase was in 1956, the earliest in 1942. The average age of firms was 37 years. Only two firms had been founded in the last ten years and only six within the last 20 years. The close relationship between the date wholesale firms were founded and new vessel entrants into the Pacific Coast Otter Trawl Fleet is evident from figure 6. In 21 firms the senior managers were of Italian descent, a factor pertinent to survival in a business where close personal ties are important. This racial dominance has changed very little since 1938 (DeLoach, 1938).

By the standard of most other industries, the firms used limited resources. Seventeen firms had only one plant (usually no more than 40 feet by 80 feet of floor area for processing fish), only three had more than three branches and those were equally small receiving depots. The average number of full-time employees in 1969 was 31, of part-time, 56. Assuming four part-time employees as the equivalent of one full-time employee, average adjusted full-time employment was only 45 per firm. Average sales in 1968 were less than $\$ 2$ million. Estimated total assets per firm averaged $\$ 415,000$ at book value and $\$ 668.000$ at replacement value.

Concentration at this level of the industry was high. Of the two largest firms, one had two subsidiaries, the other had one. These two corporate groups accounted for 26 per cent of the book value of all firms, more than 60 per cent of full-time employees, almost 70 per cent of part-time employees, and nearly 40 per cent of 1968 sales. The four largest companies and subsidiaries accounted for 55 per cent of the book value of assets and 59 per cent of 1968 sales. Not only was a considerable part of the fish producer-wholesale business concentrated in the hands of four separate firms, some of these firms were also associated by family ties.

Three main operations were carried on by most firms: preparation of fresh fish, freezing, and cold storage. However, in only a few cases was freezing a major operation, and in general cold storage capacity was sufficient only to handle the normal inventory needs. Over half the firms interviewed rented cold storage space for any additional buildup of inventory.

In general, the largest firms had the most integrated operations. They owned boats, processing facilities, wholesale operations, and retail and restaurant outlets. This suggests that expansion in terms of dollar sales in the industry came from adding more activities as much as from growth in any one activity. Nine firms combined owned a total of 35 boats (of which one specialist in shellfish owned 11); six firms engaged in seafood retailing. The smaller firms concentrated either on procurement or distribution.

Operating practices. The larger firms frequently obtained much of their working capital from commercial banks. Although smaller firms used bank credit, they strongly relied on "family" resources for both working and fixed capital, the latter being of no great significance because of the prevailing attitude among many firms that the fresh fish industry in California "has no future." The tendency, therefore, was to postpone indefinitely replacement of outmoded equipment and other facilities. No firm had obtained a government subsidy for its operations, although some thought this a necessity if the industry's supply problems are to be overcome.

Firms were asked to list their main products and the main sources of supply for each. Sole was the main product for 16 firms, shrimp for 15 , salmon for 13 , crab for 12, halibut for ten, and rockfish and lobster for eight. A high proportion of products were sold fresh and un- 
branded, with little effort by firms to differentiate the products they sold. However, firms had limited monopoly power over items which were supplied mainly from their local area, such as squid in Monterey, abalone in Santa Barbara. bass in San Pedro, and totuava in San Diego. The fairly predictable day-to-day needs of standard items such as sole. rockfish, and shrimp usually were supplied from the producer-wholesaler's boats. Other supplies were bought locally from independent fishermen when possible. However, in some items where California supply fell short of local needsnotably salmon and all shellfish, and in other popular items, such as haddock which is not produced in Californiasupplies were bought from out-of-state dealers through brokers.

Estimates also were obtained as to the disposition of the products handled. In dollar terms, 46 per cent of total sales in 1968 were made to other wholesalers and almost 10 per cent to brokers. Twentythree per cent of sales were made to retailers and 16 per cent to restaurants, leaving 5 per cent to miscellaneous outlets such as institutions, ships, and petfood manufacturers. The proportion of sales going to retailers and restaurants was significantly higher among firms in San Francisco and Oakland. Destination of sales seemed to be a function of firm size and nearness to main consumer markets. The 14 per cent of total sales shipped out of California, mostly to the East Coast, came mainly from the four largest producer-wholesalers. However. within California the firms in the Eureka. Monterey, and Santa Barbara areas made only 1 per cent of their sales within a 50-mile radins of head office. Firms in Oakland. San Francisco, Los Angeles. and San Diego (the major consumer areas for both fish and shellfish) made over 70 per cent of their sales within a 50 -mile radius.

Selling procedures were fairly uniform, the majority of firms usually quot- ing prices f.o.b. with a small minority quoting c.i.f. Not surprisingly, since 26 firms claimed a total of only 70 full-time sales personnel, practically all sales were made to customers who telephoned their orders to the seller or were called by the seller. Sixteen firms claimed that 90 per cent or more of their customer contacts and orders were by telephone. Personal sales calls were the main selling method of one San Francisco Bay area shellfish firm. Eleven firms used brokers, but in only two of these cases were brokers the main avenue for sales. Brokers were usually the firm's agent and were normally paid a brokerage fee of 5 per cent, except on higher priced fish and shellfish products for which the fees were lower. Only 15 firms were able or willing to give a breakdown of sales by the days of the week, these being mainly smaller firms. About one-third of their sales were made on Mondays and Tuesdays, slightly more than one-half on Wednesdays and Thursdays, and most of the remainder on Fridays.

Conduct. An effort was made to ascertain the conduct of primary producerwholesaler firms with respect to price, product, and promotional policies and other competitive behavior. Some evidence is arailable from written contractual agreements between firm principals and parties within and outside the firm. Three firms, or approximately 10 per cent of all producer-wholesalers engaged in fishing. had written agreements with fishermen. stipulating minimum prices for a wide variety of fish and procedures for weighing. rejections, allowance for ice and slime, etc. However, because two of the largest firms participated in these agreements it is reasonable to hypothesize that the contract prices act as a floor for prices throughout the State.

Twelve firms had collective bargaining agreements covering plant employees or distribution workers. In general, union negotiators took cognizance of the indus. try's ability to pay so that agreed-on 
minimum wages were 15 per cent below those in meat-processing plants. ${ }^{6}$ These collective bargaining agreements are negotiated separately for each local union area.

An effort was made to ascertain how firms determined prices and gross margins." In answer to the question "what determines the prices at which you can sell fresh and frozen fish to retailers and restaurants?" more than 50 per cent of firms said, "supply of the species ordered." This reply is confirmed by studies showing weak substitution effect between most species of fish (Suttor and Aryan-Nejad, 1969, p. 12). Less than 20 per cent of firms considered supply of all fish as the major determinant of price. Only three firms thought income an important determinant of price which suggests that firms tend to look at pricing as a short-run decision. From other general comments, it appears that firms expect prices of California species to dip seasonally in midsummer as increased supply meets reduced demand.

The majority of firms, 19 out of 26 , claimed to have a target gross margin at which they aimed. Three said they sought an undefined "maximum possible level." Five others gave no specific figure. For the remainder of the 19 firms, the range of gross margins cited was 10 per cent of sales for manufacturing operations, 15-25 per cent for wholesaling operations, and 40-60 per cent for retailing operations. No firm claimed to have consistently achieved its targeted gross margin. The main reason for this emerged from answers to a further question as to their usual method of pricing their products. Seven tried to use the percentage markup method, five attempted to base their prices to customers on a dollar or cent markup per pound, 20 firms or almost 80 per cent of all firms, said they closely followed competitors' prices, but only one firm which used the markup method claimed to be a price leader. In more detailed comments on this answer, firms revealed that their markup policy was quite flexible since they adopted whatever pricing method was necessary to sell their products in a competitive market. For example, competition among sellers on the higher-priced species often kept margins below 10 per cent while the margin on lower-priced fish often was very wide in percentage terms.

To maintain their profitability, firms tend to charge higher prices-their estimate of what the market will bear-to customers with less bargaining power, so that at any time they are quoting not one price, but a "cluster" of prices (Crutchfield, 1954, p. 127).

Advertising expenditure was low, and most firms saw little or no competitive advantage in increasing that expenditure. The 26 producer-wholesalers contacted claimed to have spent a combined total of about $\$ 40,000$ on advertising, or less than one-tenth of 1 per cent of their 1968 sales. Only seven firms considered it worthwhile for an individual firm to advertise, 13 thought an industry-wide cooperative campaign to advertise fish would be worthwhile. However, only five had made any effort to use the fish educational program materials issued by the National Seafood Institute or the U.S. Bureau of Commercial Fisheries.

In general, competitive tactics of firms could be characterized as "live and let live." Firms conducted much business with each other. Financial links, racial links, and ties of family and friendship were strong among several California firms. Few firms seemed sufficiently confident of their competitive abilities to openly engage in predatory tactics such as sharp price-cutting, which might bring

\footnotetext{
${ }^{6}$ Based on union agreements on file with the California Board of Industrial Relations, San Francisco.

${ }^{7}$ Gross margin is the difference between the price paid for the raw material and the price received for the finished product and by-products and is equivalent to the value added by the handler.
} 
costly retaliation. Competition, while earnest, was usually kept within bounds set by a firm's estimate of its rivals' ability to react.

Other industry comments. Certain questions of a historical nature were asked to help give perspective to the analysis of current structure and conduct. These questions related to major changes in the industry since 1959, a span of ten years. Three firms had noted increased sales volume in all their activities. Five, all south of Monterey, reported no change in business functions. One each had dropped out of boat owning, receiving facilities, fillet-making, retailing, and the small fish (mackerel, sardines) business. Activities seemed to be centering on wholesale distribution. Six firms claimed not to have been affected by new products and technologies. The smaller firms had been affected loy the advent of portioned and graded instant quick-freeze packs and by prepared precooked consumer and institutional packs for which most now acted as wholesale distributors. Larger firms with manufacturing operations had been affected by the widespread use of mechanical and labor-saving devices such as fork-lift trucks, loading pallets, packaging, shrimp peeling, deveining machines, improved plant refrigeration, fast-freezing methods. and closed refrigerated delivery trucks. While much of the handling equipment has been improved and can now be op. erated electrically, processing operations are still carried on mainly by hand. The advent of air freight services had markedly broadened the potential market for high-price fresh fish and shellfisl., but only four firms did sufficient sales volume in such products to take extensive advan. tage of these services.

With regard to changes in the number and kinds of products offered for sale, in addition to the comments already made, there was general agreement that firms handled a greater number of prod- ucts in 1969 than in 1959. One manager claimed that six to eight items were sufficient to keep business profitable in 1959 but rising costs and intense competition in 1969 required about fifty items for profitable operations. However, only six firms could claim to have invested extensively in new buildings, handling or trucking equipment since 1959, indicating that perhaps most of the product lines added were purchased in frozen packs.

Of 25 firms explaining what they considered to be "the principal obstacle to an expansion of the sale of fresh and frozen fish," 40 per cent said, "shortage of supply," 24 per cent said, "housewives' ignorance of cooking methods," and 20 per cent said, "poor quality of products." Some also saw the unwillingness of meat butchers to handle fish as a reason for an alleged reluctance of retailers to stock fish.

Economic overview. While concentration ratios in the primary producerwholesaler sector were relatively high, this seemed to represent more the weakness of many of the smaller firms than the result of deliberate effort by the four largest firms to attain monopoly power. It seems likely that the main source of monopoly power lay, if anywhere, in a firm's access to supplies of the more desirable California species. Product differentiation, either through branding, advertising. or aggressive selling, seemed of relatively minor proportions. Evidence of two possible types of barriers to entry, uncovered by firm interviews, will be examined more thoroughly in a subsequent section; however, it some areas it appeared that returns to existing firms were so low that new firms would be discouraged from entering the industry. Also, it appeared that a new firm wishing to enter the industry as a primary producer could be impeded from getting sufficient supplies of market fish by the existing network of financial, ethnic, and family links. 
While rising prices and stronger demand in 1968 brought an 8.5 per cent increase in total industry dollar sales, ten firms claimed no noticeable increase and three had experienced a decrease, primarily because of short supply of fresh fish. Four firms were expecting to go out of business within the next decade, rather than replace equipment and outmoded buildings. Undoubtedly, more strict health and sanitation requirements were speeding up the demise of some firms with obsolete buildings and equipment.

\section{Brokers}

Brokers in the fishery trade tend to perform whatever business function they can perform as both a means of using their resources and of economic survival of their businesses. A broker is defined by the National Food Brokers Association (NFBA. 1959, p. 15) as, "an independent sales agent who performs the services of negotiating the sale of food and/or grocery products for and on account of the seller as principal. and who is not employed or established by, nor an affiliate or subsidiary of, any trade buyer, and whose compensation is a commission or brokerage paid by the seller." A member of the NFBA cannot speculate, nor can he buy or sell for his own account. By this definition 13 of the 14 California firms calling themselves fresh and frozen fish brokers where wholesale merchants or jobbers, not brokers because they bought and sold fish on their own account. However, for the purposes of our discussion they will be referred to by their customary title of "broker." The oldest surviving brokerage house was founded in 1933 to fill a gap created by the increasing geographical distance between supply and consuming areas. The business of brokers has increased greatly since World War II as U. S. domestic production of fish has lagged and trade in imported fish products has continued to grow.

Structure. The secondary function of fish brokers was to represent sellers, primarily for a flat commission. Also, brokerage firms helped finance production by their overseas clients. In one case such financing amounted to 15-20 per cent of a broker's dollar volume, in another case for 30 per cent of the firm's total volume, and in a third for 45 per cent. Five brokers also represented buyers for a flat commission, but this was a minor part, probably 5 per cent or less, of their business. Nine of the firms did some split commission business with other brokers, often with firms located on the Atlantic coast and with foreign countries.

Brokers need not ever have physical possession of products traded. Because transactions are usually conducted by telephone, a purchase of Indian shrimp landed in New York may be held there in cold storage until sold, and routed directly to a large wholesaler or food chain.

We were unsuccessful in our efforts to obtain sales data, either in volume or dollar terms, from the brokers interviewed; hence the usual measures of concentration and size are impossible. However, considerable information was elicited about firm activities. More than half of the brokerage firms regularly provided marketing counsel to their suppliers on (1) the state of demand for different kinds of fish and shellfish sometimes to the point of dictating what should be produced. (2) sanitary conditions under which products must be produced and shipped to meet $\mathrm{U}$. S. import regulations and Pure Food and Drug Act requirements, (3) clearance through customs of imported products, (1) storage of products for principals, usually in public cold storage, and (5) packaging and shipping of products to buyers.

In addition seven of the 14 firms financed principals by advancing money on products during the marketing phase. As soon as the order was confirmed, the broker usually paid the supplier 75 per cent of the current value of the shipment based on New York market prices. On 


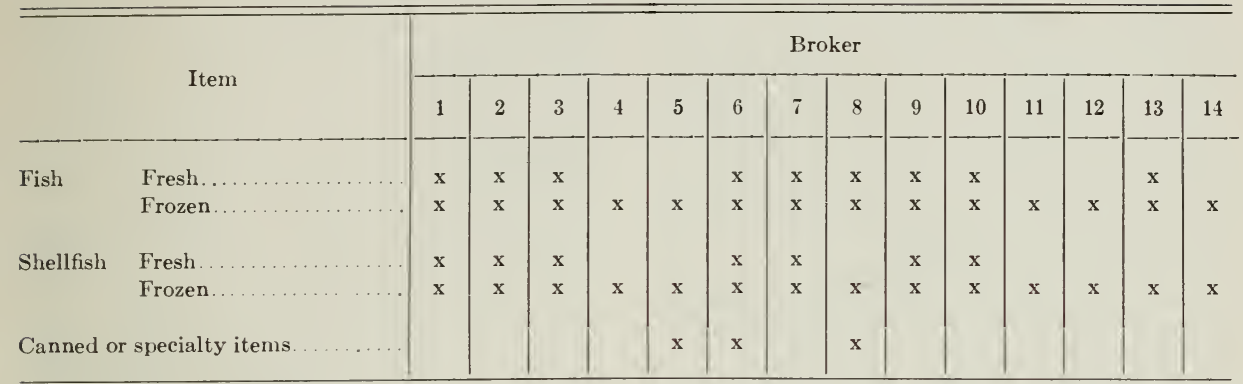

receipt of the goods, the broker then completed payment to the supplier based on the New York market price on the day of arrival for the total shipment, after deducting a prearranged commission and interest charge, usually 5 to 8 per cent of total value. One broker also stipulated that risks in transit be borne by the supplier, raising a legal question - as yet unresolved in the courts-as to who is the real owner of goods in transit.

All brokers interviewed handled both frozen fish and shellfish (table 10). However, five did not handle fresh fish. seven fresh shellfish. Indeed, only one firm claimed to specialize in fresh fish, a reflection of the problem of insuring continuous supply. At the other extreme, one firm specialized in handling the frozen packaged products of a large national fish processor. No firm specialized in a single species of fish. Shrimp and crabs were most frequently mentioned as major products, followed by halibut, bottomfish. scallops. lobster tails, salmon, and swordfish.

While the brokers studied drew on worldwide sources for their products. most sales were made in the Southwest United States. Canada and Mexico were important U. S. suppliers. Other foreign suppliers were Iceland, Japan. Central and South America, India, and Australia. Within the United States, Alaska, Oregon, and Washington were important sources of supply of West Coast species while the major U. S. fish markets at New York. Boston, and Chicago were major sources of both East Coast species and imported products.

The main market areas served were Southern California (nine firms), Northern California (eight firms), Nevada (five firms). Arizona, Oregon. and Washington (four firms each), and Idaho and Montana (two firms each). Two brokers also had important export markets. All but one broker listed wholesalers (including both fish and food wholesalers) as the main customers, while one-half named grocery chains as important customers. Export sales were made through foreign importers, agents and wholesalers, or through U. S. exporters, including brokers and jobbers specializing in military supplies.

Conduct. Like the primary producerwholesalers, brokers appeared to be reasonably competitive within certain gentlemanly limits. One broker stated that Southern and Northern California firms had a tacit agreement not to bid aggressively for business in the other's territory. These territories were defined to include southem Nevada, Arizona, and west Texas in the southern area and the remaining Pacific and mountain states in the northern area. Brokers also tried to avoid competing with their own wholesaler customers. For example, in deciding 
whether or not to fulfill requests from large food chains for supplies, brokers, as a general rule, would only meet such a request if no wholesaler customer was already serving the chain retailer's territory. No doubt the potential volume of business with the food chain and the strength of possible adverse reaction from other customers were important offsetting factors in such decisions.

Advertising and promotion were not major factors in competition. The species handled and its source, e.g., Alaska King crab, Mexican shrimp, West Australian lobster, were the main guarantees of a product's desirability, although some of the larger brokers, and those affiliated with larger corporations, placed greater emphasis on their own brand.

The price setting operations of the broker, which will be examined more thoroughly in a subsequent section, appear to be critical in transmitting the proper price signals to producers. distributors, and consumers. Because ex-vessel prices in many cases have a fixed minimum, primary producer-wholesalers have a relatively constant markup to cover preparation costs, and because retail prices tend to be maintained at the same base level for long periods, the broker bears much of the brunt of adjusting price to the current level of supply and demand. If supplies are plentiful, the broker may take a smaller gross margin, if supplies are drying up, he may raise his margin. ${ }^{s}$ Changes in margin tend to be made gradually. For example, if the broker believes price ought to rise, he can reduce quantity discounts, switch the range of quotes, e.g., $60-70$ cents per pound to 65-70 cents per pound or 6575 cents per pound, and in other ways test out the firmness of demand. Similarly, he will reduce price only gradually, for example, by giving an especially farorable quantity discount on current price to a large-volume buyer.
One last aspect of conduct of relevance to pricing is the extent of the speculative activities of broker firms. The uncertainty of the fish trade and the seasonal nature of harvesting of important species, such as salmon, halibut, and crab, lead to considerable price fluctuations over a period of a few months. Speculators willing to buy at a time of plenty for future resale at a time of shortage help to reduce price fluctuations and stand to make considerable profit once price has risen sufficiently to offset storage costs. While it is clear that brokers participate in this kind of speculation, it is not so clear what the economic impact of such speculation is on other sections of the California fresh and frozen fish trade.

Economic overview. The brokers examined in our study were primarily involved in scouring the world for supplies of many species of fish to satisfy the large Pacific and mountain market. Their operations were complementary to the primary producer-wholesalers studied, in that they sought products not available from the California fisheries. In addition, because many of their overseas suppliers were small with limited capital, they usually financed those firms.

Because of the two main prerequisites for a brokerage business-capital and availability of a telephone-the size of existing firms did not seem to be a serious barrier to entry of new firms. However, qualifying experience and a lack of established sales contacts could have been insurmountable obstacles. One large canner had entered and subsequently withdrawn from the brokerage business hecause the required flexibility and speed of decisions with respect to large sums of money demanded a kind of expertise that could not be obtained within the normal decision-making process in its other corporate activities. Brokers are more vulnerable to gradual whittling away of parts of their product line. Many claimed

\footnotetext{
${ }^{8}$ More detailed cost studies would be required to determine how low gross margin may go before break-even point is reached.
} 
that their operations could only be kept profitable by handling an ever wider variety of products, due to the inroads being made on their markets by integrated, multiproduct, producing, and marketing firms.

The seasonal nature of many of the products handled by brokers had encouraged many of them to accumulate inventory for speculative purposes. Their central position in the distribution chain also had given them a major role in price setting. Both these aspects and their relationships will be examined in later sections.

\section{Fabricators}

Both fresh and frozen fish arrive in the larger consumption areas from local or remote supply areas still in the form of a raw commodity. At the same time. many fish products are unacceptable to restaurants, retailers, or consumers in this commodity form. The conversion into convenient prepared ready-to-cook or precooked consumer cuts and packs has grown up as a separate business activity usually at major distribution centers. In California. processing for sale to final consumers tends to take place in Los Angeles. Seven of the largest fabricators in Los Angeles were interviewed about their activities. Because of the importance of imported items in their product mix, much of their supplies were bought through the brokers.

Structure. Six of the seven fabricators interviewed were small, financially independent firms; the seventh was a subsidiary of an international conglomerate with large interests in fish and food. Firms at this level tended more often to specialize in specific products or product groups. Three specialized in shrimp processing; a fourth specialized in fresh products bought through brokers from outside California. The remaining three firms handled a wide variety of products. Among all firms scallops, oysters, and cod were next to shrimp in importance.
The primary operations performed were breading (principally of shrimp), filleting, and steaking. The chief customers of the fabricators were food chains, caterers to the restaurant and institutional trade, and general-line wholesalers.

Ability to carry inventory of frozen fish is an important determinant of survival in the business because many of the products handled are produced on a seasonal basis. Five of the firms held an average of three months' inventories of raw materials in their own freezer storage, and a sixth used commercial freezer storage. Of the five who also kept some inventory of finished products, four kept these in commercial storage, only one in its own facilities. It was not possible to obtain details of other important structural characteristics such as size of firm, extent of concentration, etc.

Conduct. Even though they sell a more finished product than previous types of firms discussed. fabricators do not seem to wield other than a minor influence on price at any level. They are price-takers both as buyers and sellers. They must buy at or near the world or I.S. market price and sell to firms with large bargaining power, such as general wholesalers and retail food chains that often have alternative supply sources in other states or countries. Some have made efforts at product differentiation by advertising and promoting their branded products in consumer size packages, but only one or two have brands recognized outside the Los Angeles area. The owner of one firm which had voluntarily adopted the U. S. Department of Interior's quality inspection program believed that a reputation for high quality was the best competitive weapon.

Industry comments. Of the seven fabricators, four cited shortages of supply of the species they handled as their major operating problem, another cited lack of capital and rising labor costs, and a sixth named deficiencies in the quality of products handled. However, improved de- 
mand for processed fish products in recent years, and their belief that this would continue, seemed to four firms to be the mast encouraging aspect of the industry. Two foresaw fewer but larger firms which would be capable of securing a steady share of the available supplies. Two had plans to diversify into nonprocessing activities associated with fish, while one planned to move his shrimp operation to Mexico because of the higher wage levels in Los Angeles.

Economic overview. The fabricating sector of the trade is now in its present location as a result of the environment that existed in California one or two decades ago. If the sector were to be reorganized, it is doubtful if the same location and size of firms would be judged optimal. The independent firms, squeezed between the world market price on the supply side and large buyers on the demand side, have sought the remedy of broadening their business functions and the range of products carried. Their main competitors were and are the national packers of branded frozen fish products. Some have been forced to become distributors for national packers of frozen food. Their processing operation was the type which could benefit from the capital, technical expertise, and organizational capacities of larger corporations, so that their future as independent California operators may be limited.

\section{Retailers}

Thirty years ago fresh and frozen fish was retailed primarily by small, independent seafood retailers and by independent retailers of meat. Today, fresh and frozen fish is sold mainly by supermarket grocery firms stocking an average of more than 7,000 other items. In 1968, the approximately 227,000 grocery stores in the United States totaled sales of $\$ 78$ billion. The 35,900 supermarkets accounted for 16 per cent of all stores but 74 per cent of total sales. Firms with 11 or more stores accounted for 18,900 supermarkets, or 41.3 per cent of all sales. The five largest retail food chains together sold over 20 per cent (Parsons, 1969). Since such a small number of firms have extensive control over the primary point of contact of producers with consumers, the attitudes of store managers toward selling fresh and frozen fish is especially significant to all sectors of the fishery trade.

It would have been desirable to study in depth the structure and conduct of food retailers as they affect sales of fish products. However, because of the limitations of time and money, it was possible to examine only a few firms. Hence, it was decided to interview three grocery chains which had made efforts to improve on the unsatisfactory results experienced by chains in general in handling fish. One of these firms was a national chain, another was a large Los Angeles-based chain, and the third was a small Los Angeles-based chain. Contrary to the Progressive Grocer findings (1969, supra, p. 20), all three chains were convinced that fish, properly handled, could be a highly profitable item with considerable customer drawingpower. The chains disagreed, however, on the most effective path to profitahility in handling fish.

The largest chain handled little fresh fish, but it was attempting to build up its fish sales with frozen and precooked items. The meat marketing manager tried to maintain quality in frozen fish by insisting that products still unsold after three days on display in a refrigerated cabinet be disposed of. He admitted difficulty in enforcing this order. The firm charged a price at or below that of most competitors for both frozen and precooked fish.

The large Los Angeles-based chain had built up its seafood products section to the point where it accounted for $6 \frac{1}{2}$ to 7 per cent of total dollar sales (more than four times the national average) by emphasizing quality, stocking fresh fish 
wherever possible (fresh sales accounted for one-third of its seafood sales), and charging a price considerably above its competitors to reinforce the claims of superior quality and freshness. The small Los Angeles chain emphasized quality, freshness, and the competitive prices of its seafood items.

The latter two chains were committed to what they termed "service" selling of seafood. This policy was particularly applicable to fresh fish and shellfish, but it also helped sales of frozen seafood. By service selling these chains meant having a trained fish butcher available in any retail outlet where volume warranted it to prepare fish cuts to housewives' specifications and to give advice on purchasing and cooking of fish. Both claimed to have the training programs and the supervisory capacity necessary to insure high quality service from their fish butchers. Providing a competent fish butcher in every major supermarket of every major retail food chain would be a formidable task, and is still a long way in the future. Most food chains are more likely to follow the pattern of the largest chain interviewed, which was giving increasing emhpasis to prepacked, precooked seafood items. It is possible that both methods of promoting seafood could prosper side by side. A Florida study covering the years 1965-1967 reported. "None of the respondent stores relied solely on frozen fish, but an impressive number expected the frozen pack to increase in use. It is significant, also, that they expected fresh fish to make a comeback." (Hearn and Menke, 1968, p. 57)

The two larger food chains, whenever possible, bought directly from producerwholesalers or fabricators of fresh, frozen, and prepacked items. The second of these, which had large fresh sales, relied heavily on local producer-wholesalers for these supplies. The small Los Angeles food chain used local producer-wholesalers and brokers for most of its supplies of fresh, frozen, and prepackaged fish. The larger chains carried up to six months inventory of high-priced frozen fish and reflected a seasonal supply pattern in their own or commercial cold storage facilities. The smaller chain carried only 7-10 days inventory of frozen fish. Fresh supplies were purchased twice a week and inventory averaged two days supply. All three chains had noted a lessening of the prominence of Friday as a sales day for fish with a resultant easing of the weekly inventory problem. Waste and spoilage losses were put by one chain at "probably under 5 per cent," much of it due to cutting up fish in the store.

All three chains considered their fish husiness relatively successful with good growth prospects. The largest chain saw greatest potential in prepackaged, precooked items. The other national chain had found that in opinion surveys, consumers associated its name with its quality fresh fish department. Paradoxically, while its "service" seafood trade was huoyant, it had not had the same success as competitors with precooked items. While the firm desired to maintain its existing trade, it was concerned about being left behind in the convenience end of the market. The small Los Angeles chain, believing that its survival in competition with larger rivals depended on the special appeals it could offer customers, was planning to increase its efforts to supply fresh fish where possible, and to provide a qualified fish butcher to serve customers in each of its stores. 


\section{IMPACT OF STRUCTURAL CHANGES ON PERFORMANCE}

Sales volume of California's producer-wholesalers, after 1954, concentrated in fewer firms because, between 1954 and 1963, 37 per cent of the smaller firms dropped out (compared to an 11 per cent national average) and a few firms adopted more aggressive production and selling practices. The 1963 average annual sales for the California firms of $\$ 563,900$ was 30 per cent above the national average. Data for the entire country indicates that operating expenses as a percentage of sales were considerably lower for larger- than smaller-volume firms, which implies that economies were obtained through increased sales volume, resulting from a better use of plant, labor, and equipment and delivery facilities.

The number of brokerage firms in California remained stable while elsewhere in the nation it declined by 18 per cent. California brokers averaged annual sales of $\$ 1.57$ million, or about 20 per cent more than the national average. Sales volume of fish brokers was problably maintained by diversification into new products and into fish jobbing-wholesaleing functions.

The number of California fabricators rose from 13 to 29 , but the value of production per establishment averaged much lower than similar firms elsewhere in the country. The lower volume reflects the localized trade territory of the California firms and the unavailability of the species most commonly used by the fabricators.

In general, the fisheries industry showed little evidence of the dynamic growth that is needed to meet the requirements of an expanding population. One reason may be a shortage of fish because of depletion. Another, the availability of more suitable outlets for labor and capital.

In this section we shall (a) examine the statistical changes that have occurred at each level of the California fresh and frozen fish trade since 1954. (b) compare these with the changes that have taken place in other states, and (c) draw some inferences from the analysis regarding the relative impact of structure on the economic performance of each level of the California trade. Basic data were drawn from the Census of Manufactures for 1954, 1958, 1963, and 1967 (preliminary) and the Census of Business for 1954, 1958, and 1963, on the three classifications relevant to our analysis:

(a) Fish, seafood, merchant wholesalers (SIC5046),

(b) Fish, seafood, merchandise agents. brokers (SIC5046), and

(c) Fresh or frozen prepackaged fish (SIC2036).

Each classification is discussed separately beginning with general results and trends for the United States and the Pacific region, and comparing and contrasting these with specific results for California.

\section{Merchant-wholesalers}

This Census of Business category includes the special group of primary producerwholesalers discussed previously, including both those wholesalers whose prime characteristic was their close ties with supplying fishermen and those who acted primarily as distributors of fishery products purchased for resale.

General results for the United States. While the number of fish merchant-wholesalers in the United States declined by more than 10 per cent from 1954 through 1963, total dollar sales and dollar sales per establishment (one indicator of size of firm) apparently rose (table 11). However, if one deflates these dollar values by either the consumer price index or the index of wholesale 
FISH, SEAFOODS, MERCHANT-WHOLESALERS, U. S. ESTABLISHMENTS AND SALES BY REGIONS, SELECTED, STATES AND SELECTED SMSA's1954, 1958, AND 1963

\begin{tabular}{|c|c|c|c|c|c|c|c|c|c|}
\hline \multirow{2}{*}{ Location } & \multicolumn{3}{|c|}{ Establishments } & \multicolumn{3}{|c|}{ Sales } & \multicolumn{3}{|c|}{ Sales per establishment } \\
\hline & 1954 & 1958 & 1963 & 1954 & 1958 & 1963 & 1954 & 1958 & 1963 \\
\hline & \multicolumn{3}{|c|}{ number } & \multicolumn{3}{|c|}{ million dollars } & \multicolumn{3}{|c|}{ thousand dollars } \\
\hline United States. & 1,808 & 1,591 & 1,602 & 653.6 & 621.6 & 692.8 & 361.6 & 390.7 & 432.5 \\
\hline \multicolumn{10}{|l|}{ Regions } \\
\hline North East. & 650 & 597 & 601 & 276.1 & 260.5 & 298.9 & 424.8 & 436.3 & 497.4 \\
\hline North Central. & 227 & 169 & 166 & 122.7 & 107.4 & 92.9 & 540.6 & 635.2 & 559.6 \\
\hline South......... & 711 & 653 & 665 & 167.6 & 176.7 & N. A. & 235.8 & 270.7 & N. A. \\
\hline West... & 220 & 172 & 170 & 87.2 & 77.1 & N. A. & 396.5 & 448.1 & N. A. \\
\hline \multicolumn{10}{|l|}{ States } \\
\hline Maine. & 117 & 109 & 111 & 22.6 & N. A. & 28.2 & 192.9 & N. A. & 254,0 \\
\hline Massachusetts. & 150 & 128 & 128 & 76.1 & 73.2 & 90.4 & 507.6 & 572.1 & 706.6 \\
\hline New York. & 226 & 214 & 204 & 119.1 & 117.8 & 122.3 & 5270 & 550.5 & 599.7 \\
\hline Florida.. & 158 & 154 & 168 & 42.8 & 44.5 & 56.9 & 270.7 & 288.9 & 338.9 \\
\hline Washington. & 51 & 41 & 44 & 14.9 & 19.5 & 27.4 & 291.8 & 476.6 & 622.3 \\
\hline Oregon....... & 22 & 15 & 11 & 4.4 & N. A. & 4.1 & 200.6 & N. A. & 373.5 \\
\hline California. & 127 & 99 & 87 & 58.0 & 47.2 & 49.1 & 456.5 & 476.5 & 563.9 \\
\hline \multicolumn{10}{|l|}{ SMSA's } \\
\hline Los Angeles-Long Beaclı. & 43 & 32 & 30 & 23.3 & 16.3 & 16.0 & 542.2 & 507.8 & 534.8 \\
\hline San Francisco-Oakland. & 40 & 30 & 29 & 18.5 & N. A. & 19.0 & 463.6 & N. A. & 656.1 \\
\hline
\end{tabular}

N. A. = Data not available.

Source: U. S. Bureau of the Census, 1954, 1958, and 1963.

prices of fish, it is clear that in real terms total wholesale sales decreased and sales per establishment increased little during the three census periods. The decline in number of establishments and relative stagnation in sales volume was experienced in every region.

The census data reveal some of the ways in which the trade adjusted to this situation. In 1954, merchant-wholesalers in Standard Metropolitan Statistical Areas with more than one-half million inhabitants accounted for 28 per cent of all establishments and almost 50 per cent of total sales. By 1963 their share had risen to 41 per cent of all establishments and almost 60 per cent of total sales. The number of establishments in the remainder of the United States (i.e., nonSMSA's) fell dramatically from 1,034 in 1954 to 671 in 1963. The survivors had average sales 30 per cent larger than a decade previously, although still below the overall U.S. average.

An important factor in the survival of the smaller firms in the industry seems to have been their success in reducing the percentage of operating expenses to sales between 1954 and 1963, either through greater utilization of capacity or through general improvements in operating efficiency (table 12). In contrast, firms with sales of over $\$ 1$ million experienced increases in their operating expense ratio in the same decade. The larger firms were hit more by increasing payroll expenses, either because of their greater proportion of hired nonfamily labor or their urban location where collective bargaining is a more important factor. At the same time they failed to increase their share of total seafood sales. Despite heavy attrition, establishments with annual sales of less than $\$ 200,000$ 
TABLE 12

MERCHANT-IVHOLESALERS, U. S. NUMBER OF ESTABLISHMENTS BY DOLLAR SALES VOLUME AND OPERATING EXPENSES AS A

PERCENTAGE OF DOLLAR SALES, 1954, 1958, AND 1963

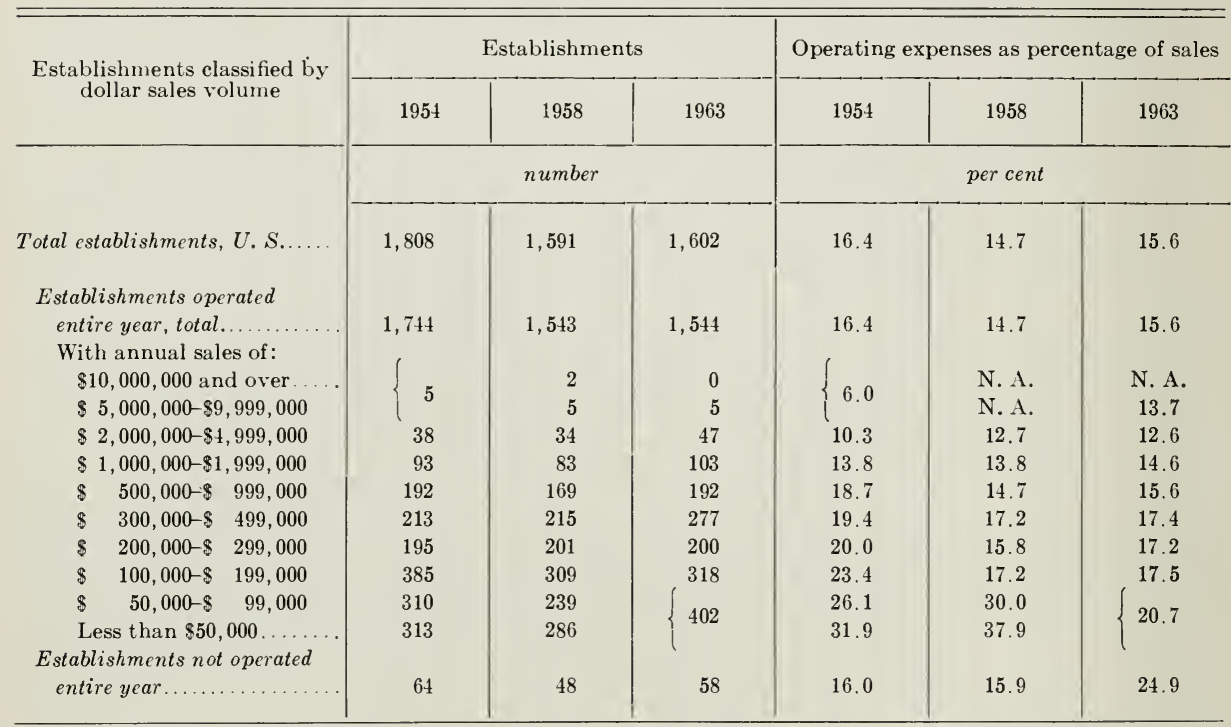

N. A. = Data not available.

Source: U. S. Bureau of the Census, Census of Business, Wholesale Trade, 1954, 1958, and 1963.

in 1963 accounted for 45.6 per cent of establishments and almost 10 per cent of total sales.

The Pacific region. In contrast to the entire United States, the Pacific region, including Washington, Oregon, and California, experienced a significant growth in the share of regional sales accounted for by larger establishments. Those with sales of more than $\$ 500,000$ increased their share from 60.8 per cent in 1954 to 67.6 per cent in 1958. In the 1963 data. with Alaska and Hawaii also included, such firms accounted for 70.3 per cent of Pacific area sales. This growth has not heralded an expansion of total Pacific area sales over the period, but rather rapid attrition among smaller establishments in the area.

California. Inevitably. merchant-wholesalers in California have been affected by national and regional trends. The number of establishments fell from 127 in 1951 to 99 in 1958 and 87 in 1963. California's share of total U. S. sales fell from 8.9 per cent in 1954 to 7.1 per cent in 1963. Although sales per establishment consistently remained above the national average, they were lower at each successive census. In contrast to the national scene, the two major SMSA's in California, Los Angeles-Long Beach and San Francisco-Oakland saw their share of total U. S. sales decline from 6.4 per cent in 1954 to 5.0 per cent in 1963.

This series of unfavorable statistics does not mean that the surviving firms in the California wholesale fish trade may not have been able to improve their profits even though Stigler (1958, pp. 51-71) would argue that falling share of industry output by a particular class of firm is an indication of inefficiency. Undoubtedly. California firms have suffered such a drop, and subsequent heavy attrition in firm numbers. However, the decline in local supplies of fish has been a major contributing factor. Firms have tried to offset rising unit costs by handling a wider range of new products and 
FISH SEAFOODS, MERCHANDISE AGENTS, BROKERS, U. S. ESTABLISHMENTS AND SALES BY REGIONS, SELECTED STATES, AND SELECTED SMSA's

\begin{tabular}{|c|c|c|c|c|c|c|}
\hline \multirow{2}{*}{ Location } & \multicolumn{2}{|c|}{ Establishments } & \multicolumn{2}{|c|}{ Sales } & \multicolumn{2}{|c|}{ Sales per establishment } \\
\hline & 1958 & 1963 & 1958 & 1963 & 1958 & 1963 \\
\hline & \multicolumn{2}{|c|}{ number } & \multicolumn{2}{|c|}{ million dollars } & \multicolumn{2}{|c|}{ thousand dollars } \\
\hline United States. & 86 & 71 & 125.5 & 92.6 & $1,459.8$ & $1,304.4$ \\
\hline \multicolumn{7}{|l|}{ Regions } \\
\hline North East. & 26 & 19 & 39.2 & 24.7 & $1,506.8$ & $1,298.3$ \\
\hline North Central. & 16 & 13 & 5* & 27.9 & 1408 * & $2,148.2$ \\
\hline South......... & 17 & 17 & $46.5^{*}$ & N. A. & $1,408.2^{*}$ & N. A. \\
\hline West. & 27 & 22 & 39.9 & N. A. & $1,477.6$ & N. A. \\
\hline \multicolumn{7}{|l|}{ States } \\
\hline Maine. & 1 & N. A. & N. A. & N. A. & N. A. & N. A. \\
\hline Massachusetts & 9 & 6 & 14.9 & 3.8 & $1,650.2$ & 638.2 \\
\hline New York.... & 13 & 10 & 19.5 & 18.5 & $1,503.3$ & $1,851.5$ \\
\hline Florida. & 6 & 6 & 4.2 & 5.1 & 701.5 & 852.5 \\
\hline Washington. & 13 & 4 & 23.0 & 1.9 & $1,768.4$ & 468.5 \\
\hline California.. & 13 & 13 & 15.5 & 20.4 & $1,193.0$ & $1,567.2$ \\
\hline \multicolumn{7}{|l|}{ SMSA's } \\
\hline $\begin{array}{l}\text { Los Angeles-Long } \\
\text { Beach }\end{array}$ & 9 & 7 & 116 & 136 & 1.285 .2 & 1.9363 \\
\hline San Francisco-Oak- & 3 & 3 & $\mathrm{~N}$ & 30 & $N$ & 12117 \\
\hline
\end{tabular}

* Estimated for combined North Central and South.

N. A. = Data not available.

Source: U.S. Bureau of the Census, Census of Business, Wholesale Trade, 1958 and 1963.

increasing throughout of existing products. Clearly, their efforts have met only limited success.

\section{Merchandise agents, brokers}

General results for the United States. Less complete data are available here than on the merchant-wholesalers. The census category, "merchandise agents, brokers" is indistinguishable from the broker group described on page 29. The number of establishments, total dollars sales, and average sales per establishment all declined from 1958 through 1963 (table 13). Only the South and the state of Florida recorded no decline.

The share of total U.S. sales accounted for by the five leading states, Massachusetts, New York, Florida, Washington, and California, dropped from 61.4 per cent to 63.6 per cent between 1958 and 1963.
On average, sales per brokerage establishment in 1963 at $\$ 1.3$ million were three times as large as sales per merchant-wholesaler establishment. About 80.3 per cent of establishments and 91.3 per cent of sales were in SMSA's with more than one-half million inhabitants. More than 70 per cent of brokerage establishments had less than seven employees. Approximately the same proportion of wholesaler and broker firms were partnerships. Among brokers, average sales per partnership establishment were more than twice the national average and almost twice that of the more numerous corporate establishments. In contrast, sales of partnership establishments among merchant-wholesalers averaged only half those of corporate establishments and were almost 20 per cent below the national average for all merchantwholesalers. 
California. For the purposes of our study, a most pertinent contrast is that the number of California brokers remained unchanged from 1958 through 1963, but their total sales increased 31.4 per cent. California brokers also were larger, sales per establishment being 20 per cent above the national average in 1963. California's share of national sales rose from 12.4 to 22.0 per cent in the five-year period. Clearly, much of this increase in sales arose in the Los AngelesLong Beach and San Francisco-Oakland SMSA's. These two areas increased their share of national brokerage sales from less than 12 per cent to 18.8 per cent. The large decline in brokerage sales in the state of Washington may indicate at whose expense, at least on the West Coast, California brokers have increased their sales.

From the limited data available, one can assume that, as of 1963, California brokers were successfully combating the general decline in the seafood brokerage business, possibly by adding new product lines and by increasing their merchandis- ing activities. From our discussions with brokers in 1969, we learned their importance in the trade channel has been undermined somewhat by processorwholesalers and fabricators selling direct to retail chains.

\section{Fresh or Frozen Fish Prepackagers or Fabricators}

General results for the United States. Establishments in the fresh or frozen prepackaged fish category of the Census of Manufacturers would include those firms, described as fabricators. Output of these establishments in dollar terms has increased each year since 1954 (table 14). Total value added also has increased each year except for a minor check in 1962. However, the number of establishments and the total number of employees has shown only halting growth over the years 1954 to 1967 . While output per establishment has risen in each successive census period, output per production worker has shown a faltering, upward progress. This latter condition may reflect not solely the relative effi-

\section{TABLE 14}

FRESH OR FROZEN PREPACKAGED FISH C. S. KEY INDUSTRY

INDICATORS, 1954-1967

\begin{tabular}{|c|c|c|c|c|c|c|c|c|}
\hline \multirow[b]{2}{*}{ Year* } & \multirow[b]{2}{*}{$\begin{array}{l}\text { Establish- } \\
\text { ments }\end{array}$} & \multirow{2}{*}{$\begin{array}{l}\text { Produc- } \\
\text { tion work- } \\
\text { ers }\end{array}$} & \multirow{2}{*}{$\begin{array}{l}\text { Value of } \\
\text { produc- } \\
\text { tion }\end{array}$} & \multirow{2}{*}{$\begin{array}{l}\text { Value } \\
\text { added by } \\
\text { manu- } \\
\text { facturer }\end{array}$} & \multicolumn{2}{|c|}{ Value of production } & \multirow{2}{*}{$\begin{array}{l}\text { Value add- } \\
\text { ed/ralue of } \\
\text { production }\end{array}$} & \multirow{2}{*}{$\begin{array}{l}\text { Capital ex- } \\
\text { penditure, } \\
\text { new/value of } \\
\text { production }\end{array}$} \\
\hline & & & & & $\begin{array}{l}\text { Per estab- } \\
\text { lish- } \\
\text { ment }\end{array}$ & $\begin{array}{c}\text { Per produc- } \\
\text { tion } \\
\text { worker }\end{array}$ & & \\
\hline & number & $\begin{array}{l}\text { thousand } \\
\text { dollars }\end{array}$ & \multicolumn{2}{|c|}{ million dollars } & $\begin{array}{c}\text { thousand } \\
\text { dollars }\end{array}$ & dollars & \multicolumn{2}{|c|}{ per cent } \\
\hline 1967. & 499 & 21.5 & 558.2 & 165.3 & $1,118.6$ & 28,773 & 29.61 & 1.56 \\
\hline 1966. & N. A. & 19.2 & 492.7 & 151.7 & N. A. & 39,154 & 30.79 & 1.91 \\
\hline 1965. & N. A. & 18.7 & 464.2 & 138.3 & N. A. & 27,467 & 29.79 & 1.34 \\
\hline 1964. & N. A. & 20.6 & 428.2 & 128.1 & N. A. & 23,022 & 29.92 & 1.26 \\
\hline 1963. & 547 & 20.1 & 391.2 & 118.5 & 715.2 & 21,855 & 30.29 & 1.56 \\
\hline 1962. & N. $\Lambda$. & 16.0 & 344.5 & 101.3 & N. A. & 22,226 & 29.40 & 2.90 \\
\hline 1961. & N. A. & 17.2 & 332.3 & 101.5 & N. $A$. & 21,719 & 30.54 & 1.02 \\
\hline 1960. & N. $\Lambda$. & 18.8 & 328.3 & 100.3 & N. $A$. & 19,426 & 30.55 & 1.22 \\
\hline 1959. & N. A. & 18.0 & 317.0 & 89.7 & N. $\Lambda$. & 19,937 & 28.30 & 2.18 \\
\hline 1958. & 446 & 17.6 & 310.1 & 83.5 & 695.3 & 19,878 & 26.93 & 1.19 \\
\hline 1954. & 295 & 11,232 & 176.8 & 48.7 & 599.2 & 15,738 & 27.57 & 1.59 \\
\hline
\end{tabular}

* 1967-census preliminary report; 1959-1962, 1964-1966-annual survey of manufacturer's data; 1954, 1958, and 1963-census report.

N. A. = Data not available.
Source: U. S. Bureau of the Census, Census of Manufacturers, 1967, Fresh and Frozen Prepackaged Fish (preliminary report, Washington, D. C., 5 pp.) 
ciency of labor but, in addition, certain factors exogenous to the firm such as availability of total supply, mix of products available (whether expensive or inexpensive species), and the demand for that product mix.

Value added by manufacture, as a proportion of the industry's total value of production, was stable at around 30 per cent from 1960 through 1967. Value added is derived by subtracting the cost of materials, supplies, containers, fuel, purchased electricity, and contract work from the value of production plus miscellaneous receipts. It represents all business inputs, including all fixed and variable costs, plus net profit. In the absence of actual profit data, value added represents the best available economic measure of the relative importance of different industries and of different segments within an industry. Where value added represents a stable percentage of value of production, and value of production is increasing as in this case, it can be taken as a long-run sign of a reasonably healthy industry.

The industry's total new capital expenditure in 1967 amounted to less than $\$ 20,000$ per establishment or 1.56 per cent of the value of production, the same percentage as in 1963. The 1963 Census reveals that the entire industry spent less than $\$ 2$ million on new structures and additions to plant, and only $\$ 4.1$ million on new machinery and equipment. The capital expenditure percentage compares unfavorably with that in other similar food processing industries. ${ }^{9}$ The limited information available by firm size suggests that, contrary to expectation, the larger firms did not report ploughing back a greater proportion of earnings in new capital expenditure. This may be a reflection of the failure of larger firms to increase their share of total output from 1954 through 1963. Data on the per cent of value of production accounted for
TABLE 15

FRESH OR FROZEN PACKAGED FISH, U. S. PER CENT OF VALUE OF

PRODUCTION ACCOUNTED FOR BY THE LARGEST COMPANIES, 1954 AND 1963

\begin{tabular}{|c|c|c|c|c|}
\hline \multirow[b]{2}{*}{ Year } & \multicolumn{4}{|c|}{ Percentage accounted for by } \\
\hline & $\begin{array}{c}\text { Four } \\
\text { largest } \\
\text { companies }\end{array}$ & $\begin{array}{c}\text { Eight } \\
\text { largest } \\
\text { companies }\end{array}$ & $\begin{array}{l}\text { Twenty } \\
\text { largest } \\
\text { companies }\end{array}$ & $\begin{array}{c}\text { Fifty } \\
\text { largest } \\
\text { companies }\end{array}$ \\
\hline & \multicolumn{4}{|c|}{ per ccnt } \\
\hline 1963 & 25 & 38 & 53 & 68 \\
\hline 1958 & 18 & 30 & 47 & 68 \\
\hline 1954 & 24 & 37 & 56 & N. A. \\
\hline
\end{tabular}

N. A. = Data not available.

Sorrce: U. S. Bureau of the Census, Ccrsus of Manufacturers, 1963, Vol. I, Summary and Subjct Statistics, Washington, D. C., 1966.

by the largest companies shows little evidence of increased concentration (table 15). Indeed, evidence on firm size in terms of number of employees shows that in 1963 establishments with fewer than 50 employees increased their share of total establishments to 80.6 per cent over the decade and their share of total output to 30.5 per cent.

California. Based on the criteria discussed above, the California trade emerges favorably in comparison with other states and with results for the entire United States. In the years from 1954 through 1967 the number of California fabricating establishments more than doubled and value of production increased twelve-fold (table 16). California's share of total U.S. output rose from 1.35 per cent in 1954 to 4.91 per cent in 1967. Even though dollar value of output per establishment in California has been below the national average, output per production worker has been consistently above the national average. California's percentage of value added to value of production has remained slightly above the national average at each census. Since payroll expenses as a propor-

\footnotetext{
${ }^{9}$ For example, new capital expenditure was 3.66 per cent of value of production in 1967 for frozen fruits and vegetables, 1.99 per cent for poultry dressing plants.
} 
TABLE 16

FRESH OR FROZEN PREPACKAGED FISH, KEY INDUSTRY INDICATORS, COMPARATIVE DATA FOR THE U. S. AND CALIFORNIA,

1954, 1958, 1963, AND 1967

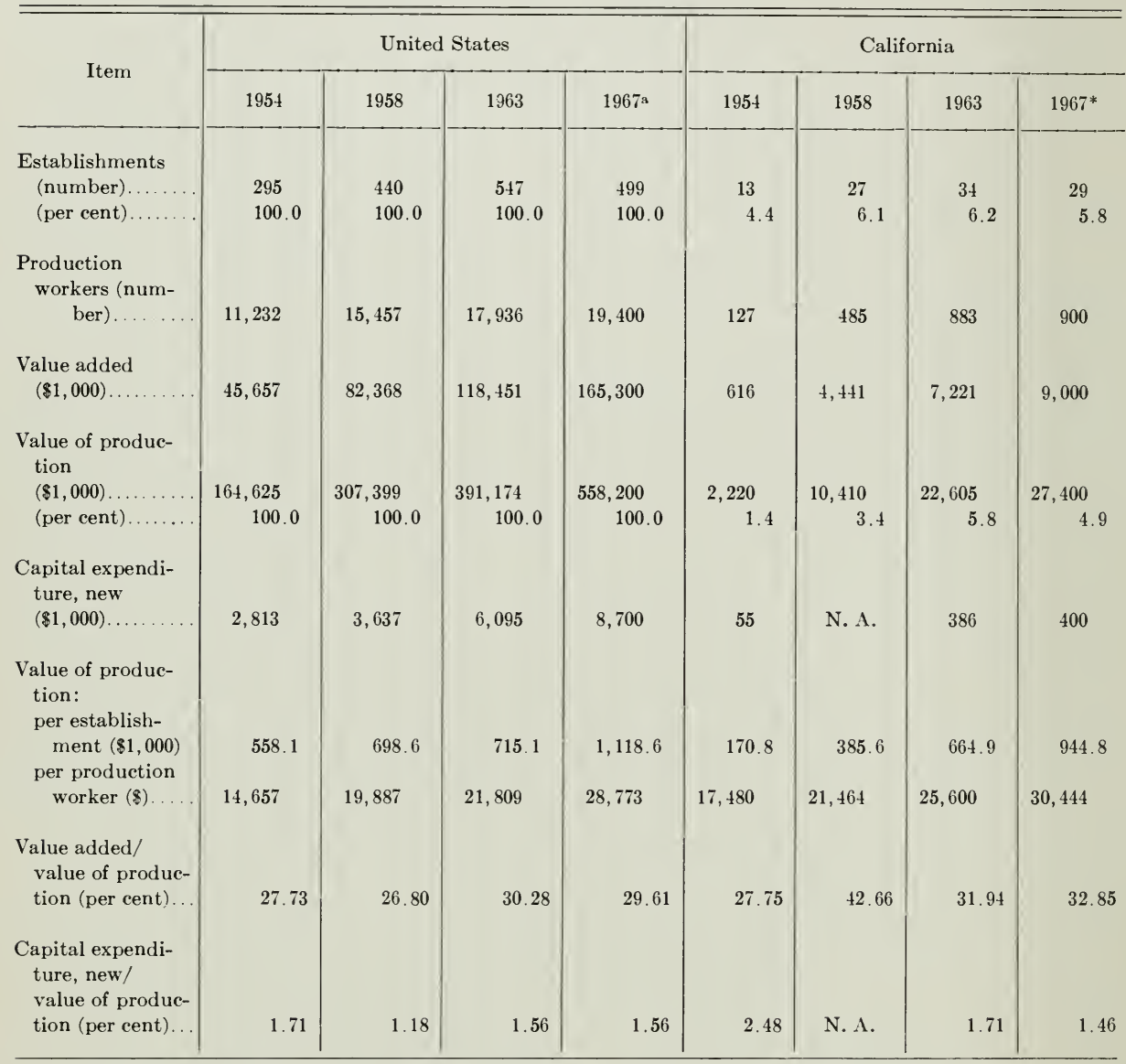

* Preliminary.

N. A. = Data not available.

Source: U. S. Bureau of the Census, Census of Manufacturers, 1954, 1958, 1963, and 1967.

tion of value of production are below the national average, one would expect the California industry to be more profitable than that in many other states. The percentage of new capital expenditure to total value of production was above the national average in both 1954 and 1963 , during the period of continued growth in establishments and sales. Significantly enough, however, the new capital expenditure percentage was below the national average in 1967, the first census for more than a decade in which the number of California establishments showed a decline. Clearly, firms in California are suffering some attrition, perhaps because of supply or cost constraints. 


\section{A PROCEDURE FOR MEASURING PERFORMANCE}

Our analysis indicated that at least eight of the 26 producer-wholesalers had insufficient management inputs, and that the industry in general could have used its capital, labor, and management inputs more effectively. Three tables of optimal combinations of inputs derived from our analysis are presented for use by firm managers and policy-makers as tentative indicators of relative firm efficiency.

While our surveys provided some evidence of inefficiencies in the California fresh and frozen fish trade at every level, these data were not such as to allow us to develop objective measures of performance of the industry. For example, it would have been desirable to measure profit levels in the industry relative to an objective norm such as the average profit level in comparable industries. However. no usable data on profit levels were available. Even if the data had been available, the use of profit measures as a performance norm would have been vitiated by the fact that some firms appeared to seek the maximum profits that could be obtained only after they had fulfilled such objectives as (1) providing employment for family members, (2) avoiding those forms of competition which would arouse retaliatory action, and (3) minimizing price fluctuations as a means of increasing industry stability.

Despite data limitations for the most meaningful type of analyses, we chose to seek some measures of performance by using our 26-firm survey data to derive a production function from which we could get some indication of the level of efficiency of firms in the California primary producer-wholesaler sector.

\section{Outline of Procedure}

Regression analysis was used to derive an aggregate production function for the primary producer-wholesaler sector relating dollar value of sales to the capital, lalor. and management factors of production. The working hypothesis was then made that competition in the sector was perfect. and the estimated function used to determine the Pareto-optimum level of output in terms of the optimal mix of factor inputs for given prices of the factors. The efficiency of each firm's production was then measured in terms of deviations from the optimal input mix. Because firms may not be flexible in their ability to alter the level of use of each input, tables were derived setting out the optimal level of each input for given levels of the other two inputs. The production function analysis was extended to examine the influence of certain structural characteristics on sales. Finally, in light of the results obtained, the aggregate production function approach to measurement of performance was reevaluated. and the validity of the working hypothesis of perfect competition reexamined in terms of the sensitivity of results to relaxation of some of the tenets of perfect competition.

It was believed that an attempt to measure technological relationships between inputs and outputs would have benefits over and above any tentative results we obtained (1) in detecting any gross inefficiencies or misallocation of resources within the sector, and (2) in focusing attention on those features of the sector on which future data collection and economic analysis might most profitably he centered.

The assumption of perfect competition could be justified on the grounds that in general firms in the sector were small, they had to compete with many other types of firms at the local level for supplies of labor, capital, and management, and to sell their products in state and national markets open to products from many sources. 


\section{Estimating A Production Function for the Primary Producer-Wholesaler Sector}

Although the production function is intended to represent the technological relationship between inputs and output of a single firm (Henderson and Quandt, 1958, pp. 42-84), its use has been extended to the measurement of interfirm, interindustry, and international relationships (see also Walters, 1963). An empirical estimate of an aggregate production function using firm observations as data points can be thought of as representing an envelope curve to existing production possibilities or a long-run technological relationship assuming firms are at tangency points to the envelope. Its obvious applications are to throw light on broad policy issues. Either linear programming or calculus can be used to seek that combination of inputs which will maximize output and achieve other pertinent profit, cost, or technical requirements.

Given the form of the data available, it seemed reasonable to proceed on an assumption that a continuous, singlevalued function could be estimated using regression analysis. The linear programming approach was abandoned because it was found impossible to define "typical" or "representative" processes relating fixed combinations of inputs to outputs.

\section{Problems encountered in the esti-} mation process. The problem involved in assuming a uniform technology among firms in the industry was paralleled when we tried to define industry inputs and output. In empirical estimation, firms were assumed to have three inputslabor, capital, and management-and one output, sales revenue in dollars. Labor per firm was reckoned in terms of full-time equivalent employees, four seasonal employees being assumed to be the equivalent of one full-time employee. Differences in age, skill, and specialization were not taken into account.

Capital could not be quantified so readily. Capital includes all those production and financial services which combine with labor to generate output. However, no census of plant, machinery, equipment, or financial resources was available. From our interviews a figure was obtained for total assets employed in the business, both at book value and at estimated replacement value. While book value generally is arrived at by standard accounting procedures and replacement value is based on subjective judgment, the estimates of replacement value should more accurately represent the relative amounts of capital employed in each firm. However, what contributes to output is not capital per se (which is a stock concept) but the flow of capital services during a year. This flow was assumed to be equal to depreciation plus market rate of interest on average capital invested. For an investment of $\$ 1,000$ in year one, assuming straight-line depreciation of 10 per cent per annum and given a market rate of interest of 10 per cent, the flow of capital services would be $\$ 155$ or approximately 15 per cent of the total investment. ${ }^{10}$ Other combinations of methods of depreciation and levels of depreciation and market rate of interest could be used. Given the broad policy aims and the assumptions of the analysis,

\footnotetext{
${ }^{10}$ Capital in year $t(t=1,2 \ldots 10)$ will equal $\$ 1,000-(t-1)(\$ 1,000 d)$, where $d$ is rate of depreciation.
}

Averaqe capital $=\sum_{t=1}^{10}[\$ 1,000-(t-1)(\$ 1,000 d)] / 10$.

Flow of capital services $=\left[\$ 1,000 \mathrm{~d}+r \underset{t=1}{\sum}[\$ 1,000-(t-1)(\$ 1,000 d] / 10\right.$.

For $d=.10, r=.10$, flow of capital services $=\$ 155$. 
the production function was estimated arbitrarily using only one level of flow of capital services, i.e., 15 per cent of the replacement value of each firm's total assets. In addition, since we were using cross-section data for assets at replacement value at one point in time, we could more readily accept the assumption that all firms faced the same rate of depreciation and the same market rate of interest.

The third factor of production included in our analysis was management. Other attempts have been made to incorporate a management variable in production functions by use of analysis of covariance (Hoch. 1962, pp. 34-53), test devices (Johnson, 1961), etc. It seemed to us that in the fresh and frozen fish trade the caliber of management available to a firm would be reflected in the actual steps taken to adjust to changing market and technological conditions. Each firm had provided answers to questions about (1) adoption of new technology, (2) new products, (3) new production and handling techniques, (4) changes in business functions, in the decade 1959-1969, and (5) ahout current attitudes to advertising. On each of the first four criteria, firms were allotted points from 0 to 10 - the greater the number and size of adaptations made, the higher the score. For example, firms which had adopted no new technology scored 0 on the first criterion, the one firm which had adopted new packaging, quick freezing, shrimp peeling, and refrigeration methods scored 10 points. On the fifth criterion, firms were assigned one point for each favorable answer to the questions on use of and attitudes to advertising and promotion. An index of management for each firm was obtained by summing its scores on each criterion. Out of a maximum of 43 points, the highest score obtained was 27 , the lowest 1. Despite the inevitable intrusion of subjective judgment, the scores do appear to represent relative strength of management. ${ }^{11}$ It was recognized that one could not be certain a priori that the management factor so derived was independent of labor and capital.

Finally, mention must be made of the problems associated with the measure of output used. Some of the 26 firms studied were primarily processors with a ratio of value added to raw material costs of about one to one (based on Nash and Miller, 1969, p. 10). Others were primarily wholesalers whose services were represented by the wholesale markup, so that the ratio of raw material costs to value added averaged four to one (estimated survey data). Nor did firms handle a uniform product. Most handled a wide variety of products ranging from high-priced items such as shrimp to low-priced items such as catfish. Even on the same item, firms claimed that markup tended to vary with the strength of competition, local trade practices, and level of buyer sophistication. Accordingly. there were a number of imponderables in each firm's production function which might render invalid attempts to relate the capital, labor, and management of firms to their sales. It was necessary to make the assumption that the effect of such imponderables would be random and contained in the error term of our estimated function and that the error term would be small, or that its mean would be zero.

It would also have been preferable to have measured output of these firms in "units" of service provided rather than in dollar terms, and furthermore, if dollar terms had to be used, dollars of value added rather than dollars of total sales would have been preferable. However, the only data that were available were dollar value of total sales.

Of the 26 primary producer-wholesalers studied, usable data on dollar sales,

${ }^{11}$ Analysis of covariance tests showed that a management index greater than 10 was significantly related to increased sales revenue. 
capital, labor, and management were obtained from 22 firms. Various possible forms of production function were tested. In general, linear equations had a large standard error, and squared or crossproduct variables had insignificant coefficients. A Cobb-Douglas form gave best overall results. It was estimated by ordinary least squares using a log transformation. The usual assumptions were made that the functional relationship was correctly specified, that there were no errors in the variables and that the disturbance terms were not correlated. ${ }^{12}$ The estimates obtained suggest that one can approximately delineate broad structural relationships within this sector of the California fish trade and can make deductions about its economic efficiency.

Results. The basic equation attempted to derive the relationship between the capital, labor, and management variables discussed above and 1968 firm sales. The following notation was used:

$Y=1968$ sales (thousand dollars) ;

$K=$ Capital employed (thousand dollars) ;

$L=$ Labor employment (numbers) ;

$M=$ Management (progressiveness index).

The resulting estimate was as follows:

$$
\begin{aligned}
\log Y & =1.887+.130 \log K \\
& +.639) \\
& (2.580 \log L \\
& +.305 \log M \\
& (1.763)
\end{aligned}
$$$$
R^{2}=.709 d=2.848 S_{y}=.268
$$

The multiple correlation coefficient is sig- nificant at the 1-per cent level. The coefficients are all less than 1 and positive. With 18 degrees of freedom, the t-value (below the coefficients in parentheses) of labor is significant at the 5-per cent level, of management at the 10-per cent level. The capital coefficient is nonsignificant, probably because of high correlation (.83) of capital with labor. The Durbin-Watson statistic is in the inconclusive range. However, the standard error of the estimate of the dependent variable is slightly less than 5 per cent of its actual mean value, a reasonably encouraging result.

The numerical results are also in the anticipated range. Because the coefficient of each variable input is less than 1 , the requirement of diminishing marginal productivity holds. The sum of the coefficients gives an estimate of returns to scale of .925. However, the hypothesis that the true value equaled 1 was rejected. ${ }^{13}$ At this stage, it is reasonable to hypothesize that firms in the industry are operating at about the level of constant returns to scale. As might be expected in an industry with rather simple technology the labor input contributes most to output, and capital least. However, the contribution of management is higher than expected.

One objection to derivation of a production function from cross-section data is the "regression fallacy" pointed out by Stigler (1952. p. 143). ${ }^{14}$ Because two years of sales data were available, but only one year's data on inputs, the average firm sales over the two years were

${ }^{12}$ Presence of errors in the variables would lead to parameter estimates that are biased and inconsistent. Presence of serial correlation may imply misspecification of the functional relationship and while yielding unbiased parameter estimates, will render invalid the usual tests of significance.

${ }^{13}$ We tested the hypothesis that the production function is linear, homogeneous, i.e., the coeffcients sum to 1 , by means of an $F$-test, $F=\left[\left(Q_{2}-Q_{1}\right)(N-P)\right] / Q_{1}$ distributed with 1 and $N-P$ degrees of freedom, where $Q_{1}=$ sum of squares of deviations of the original regression, $Q_{2}=$ sum of squares of deviations of the same regression with the coefficients restrained to sum to $1, N=$ number of ohservations, and $P=$ number of independent variables. The $F$-value of 268 was not significant at the 5-per cent level (Tintner, 1965, p. 122).

${ }^{14}$ Observations at a point in time may contain purely random elements. Empirical relationships derived from such observations cannot be taken to represent the true underlying relationships. Before estimation, these random elements must be removed. 
regressed against the input data. In a separate formulation, the two annual observations for each firm were regressed against the input data. The results were little different from those derived from the basic model, suggesting that the regression fallacy is not a major problem in our results.

\section{Efficiency measures based on the assumption of perfect competition}

If we assume that all firms are profit maximizers and that perfect competition exists in both product and factor markets, it is possible to reach preliminary conclusions about the industry's effciency. The industry will maximize output within any specified cost constraint, where the rate of technical substitution between two factors is equal to the ratio of their prices. Rates of tech-
TABLE 17

CONDITIONS FOR MAXIMUM

OUTPUT DERIVED FROM THE

ESTIMATED PRODUCTION

FUNCTION

\begin{tabular}{c|c|c}
\hline Input pairs & $\begin{array}{c}\text { Rate of techni- } \\
\text { cal substitution* }\end{array}$ & $\begin{array}{c}\text { Ratio of } \\
\text { prices }\end{array}$ \\
\hline Capital-labor...... & $3.77 \frac{K}{L}$ & 30.00 \\
$\begin{array}{c}\text { Capital-manage- } \\
\text { ment........... }\end{array}$ & $2.35 \frac{K}{M}$ & 10.00 \\
$\begin{array}{c}\text { Labor- } \\
\text { management..... }\end{array}$ & $.62 \frac{L}{M}$ & 0.33 \\
\hline
\end{tabular}

* For example, the rate of technical substitution between capital and labor is defined as $\partial K / \partial L$ and is equal to $\partial Y / \partial L / \partial Y / \partial K$, the ratio of the marginal value productivities. The rate of technical substitution between capital and labor is the rate at which capital must be substituted for one unit of labor so as to keep output constant. For a firm with 100 units of labor and $\$ 50,000$ worth of capital it would require $\$ 1.885$ of capital to substitute for one unit of labor (i. e., $(3.77 \times 50) / 100=1.885)$. SOURCE: Survey data.

nical substitution between factors, derived from our estimated equation, are

TABLE 18

CALIFORNIA PRIMARY PRODUCER-WHOLESALERS, OPTIMAL RATIO OF FACTOR INPUTS AND ACTUAL FOR 22 FIRMS

\begin{tabular}{|c|c|c|c|}
\hline & Capital/labor & Capital/Management & Labor/management \\
\hline $\begin{array}{r}1 \\
1 \\
1 \\
1 \\
1 \\
1 \\
1 \\
1 \\
1 \\
1 \\
2 \\
2 \\
2 \\
\text { Mean }\end{array}$ & $\begin{aligned} \text { (0) } 7.96(33.00) \\
5.26 \\
2.12 \\
3.00 \\
3.45 \\
2.63 \\
9.11 \\
6.04 \\
2.81 \\
12.00 \\
1.50 \\
2.78 \\
4.80 \\
1.73 \\
7.53 \\
4.82 \\
2.15 \\
7.93 \\
10.00 \\
3.38 \\
2.50 \\
2.86 \\
2.63 \\
4.59\end{aligned}$ & (0) $\begin{array}{r}4.25 \\
11.53 \\
6.36 \\
4.20 \\
2.65 \\
1.31 \\
4.55 \\
36.25 \\
25.00 \\
4.29 \\
1.13 \\
5.77 \\
3.43 \\
45.00 \\
45.15 \\
8.43 \\
1.00 \\
11.10 \\
9.38 \\
3.18 \\
.83 \\
3.72 \\
1.17 \\
9.58\end{array}$ & 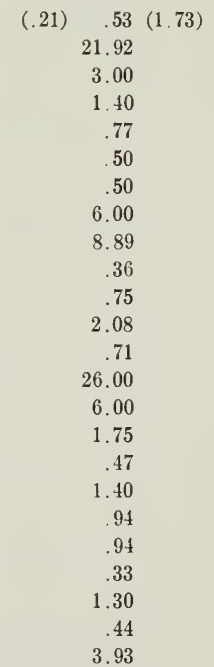 \\
\hline
\end{tabular}

* The figures in parentheses give lower and upper bounds for the optimal values (without parentheses) derived from the production function on the assumption that the true values may lie within one standard error of the computed coefficients.

SOURCE: Survey data. 
shown alongside estimates of the ratios of their prices (table 17). The prices chosen, $\$ 6,000$ for one unit of labor, $\$ 200$ for a $\$ 1,000$ unit of capital, and $\$ 2,000$ per unit of management, are intuitive estimates. Average wages per fulltime employee in the industry are probably close to the figure cited. The price of capital includes charges to cover interest, risk factors, etc. The return of $\$ 2,000$ per unit of management is based on the reasoning that a manager with a progressiveness index of 20 should be able to earn $\$ 40,000$ in the best alternative employment.

From table 17 we can derive the optimal ratio of factor inputs. These, together with lower and upper bounds on the optimal ratio and the current actual ratios for the 22 firms studied, are presented in table 18. It seems clear that the optimal capital/labor and capital/ management ratios are very sensitive to errors in the estimated coefficients. However, it does seem that at least eight firms have insufficient management relative to the labor employed.

The dependent variable, $\mathrm{Y}$, used in estimation is in dollar value terms. Accordingly, the first derivative of $\mathrm{Y}$ with respect to any factor is the marginal value product of that factor. ${ }^{15}$ The firm will maximize profits where the marginal value product of each factor equals its price. For given levels of any two factors it is possible to determine what level of use of the third factor will maximize profits (table 19a, b, c). For example, a firm with 100 employees and a management index of 15 could maximize profits by having an annual flow of capital services of $\$ 44,130$, equivalent to total assets of over $\$ 220,000$. Managers in the industry can compare these tables of optimum combinations of inputs with their current use of inputs as a broad guide to firm efficiency.

Variations in the basic model were used to explore other aspects of the production function for the primary producer-wholesaler sector. Through use of dummy variables added singly to the basic forms of the production function described above, a test was made of the influence of other firm characteristics on sales revenue. Only two, ownership of a fleet, and location north of Monterey (that is, near the largest supply sources), were significant at less than the 20-per cent level. Form of incorporation (partnership or corporation), family ownership, dependence on internal financing,

TABLE 19(a)

OPTIMAL LEVEL OF ANNUAL CAPITAL FLOW FOR GIVEN LEVELS OF LABOR AND MANAGEMENT*

\begin{tabular}{|c|c|c|c|c|c|c|c|}
\hline & & \multicolumn{6}{|c|}{ Number of employees } \\
\hline & & 25 & 50 & 100 & 200 & 400 & 600 \\
\hline \multirow[b]{2}{*}{$\begin{array}{l}\text { Management } \\
\text { Index }\end{array}$} & & \multicolumn{6}{|c|}{ dollars } \\
\hline & $\begin{array}{r}5 \\
10 \\
15 \\
20 \\
25 \\
30\end{array}$ & $\begin{array}{l}13,740 \\
17,520 \\
20,190 \\
22,340 \\
24,160 \\
25,740\end{array}$ & $\begin{array}{l}20,310 \\
25,880 \\
29,840 \\
33,000 \\
35,690 \\
38,040\end{array}$ & $\begin{array}{l}30,020 \\
38,280 \\
44,130 \\
48,810 \\
52,780 \\
56,260\end{array}$ & $\begin{array}{l}44,310 \\
56,490 \\
65,120 \\
72,020 \\
77,890 \\
83,030\end{array}$ & $\begin{array}{r}65,460 \\
83,470 \\
96,200 \\
106,400 \\
115,100 \\
122,700\end{array}$ & $\begin{array}{r}82,260 \\
104,800 \\
120,900 \\
133,700 \\
144,500 \\
154,100\end{array}$ \\
\hline
\end{tabular}

* For each combination of number of employees (column heads) and management index (row heads) we can read off the optimal level of capital required. For example, for a firm with 200 employees and a management index of 15 , the optimal level of annual capital flow would be $\$ 65,120$, which would be equivalent to total firm assets of $\$ 434,000$. SOURCE: Empirical analysis discussed in the text.

${ }^{15}$ For example in the Cobb-Douglas form used where $Y=A K^{a} L^{b} M^{c}, A, a, b$, and c constants, $\alpha Y / \alpha K=$ the marginal value product of capital and is equal to $a A K^{a-1} L^{b} M^{c}$. 
OPTIMAL LEVEL OF LABOR FOR GIVEN LEVELS OF CAPITAL AND MANAGEMENT*

\begin{tabular}{|c|c|c|c|c|c|c|c|}
\hline & & \multicolumn{6}{|c|}{ Capital (dollars) } \\
\hline & & 25,000 & 50,000 & 100,000 & 200,000 & 400,000 & 600,000 \\
\hline \multirow{7}{*}{ Management Index } & & \multicolumn{6}{|c|}{ employees } \\
\hline & 5 & .15 & .18 & .22 & .26 & .31 & .34 \\
\hline & 10 & .23 & .27 & .33 & .39 & .47 & .52 \\
\hline & 15 & .29 & .35 & .42 & .50 & .59 & .66 \\
\hline & 20 & .35 & .42 & .50 & .59 & .71 & .78 \\
\hline & 25 & .40 & .48 & .57 & .68 & .81 & .90 \\
\hline & 30 & .44 & .53 & .63 & .75 & .90 & .99 \\
\hline
\end{tabular}

* For each combination of capital (column heads) and management index (row heads) we can read off the optimal level of labor required. For example, for a firm with capital of $\$ 50,000$ and a management index of 20 , the optimal leve 1 of labor required would be .42 employees or less than two seasonal employees (given four seasonal employees in equivalent to one full-time employee).

SourCE: Empirical analysis discussed in the text.

\section{TABLE 19(c)}

OPTIMAL LEVEL OF MANAGEMENT FOR GIVEN LEVELS

OF CAPITAL AND LABOR*

\begin{tabular}{|c|c|c|c|c|c|c|c|}
\hline & & \multicolumn{6}{|c|}{ Capital (dollars) } \\
\hline & & 25,000 & 50,000 & 100,000 & 200,000 & 400,000 & 600,000 \\
\hline \multirow{7}{*}{ Number of employees } & & \multicolumn{6}{|c|}{ management index } \\
\hline & 25 & 2.94 & 3.35 & 3.82 & 4.34 & 4.95 & 5.33 \\
\hline & 50 & 4.80 & 5.46 & 6.22 & 7.08 & 8.06 & 8.70 \\
\hline & 100 & 7.82 & 8.90 & 10.14 & 11.54 & 13.14 & 14.18 \\
\hline & 200 & 12.76 & 14.50 & 16.55 & 18.81 & 21.47 & 23.12 \\
\hline & 400 & 20.79 & 23.67 & 26.95 & 30.68 & 34.93 & 37.68 \\
\hline & 600 & 27.67 & 31.51 & 35.87 & 40.83 & 46.49 & 50.16 \\
\hline
\end{tabular}

* For each combination of capital (column heads) and labor (row heads) we can read off the optimal level of management required. For example, for a firm with capital of $\$ 100,000$ and 100 employees the optimal level of management would have an index of 10.14 .

SOURCE: Empirical analysis discussed in the text.

unionization of workers, urban location, distance to main markets, age of firm, and favorable and unfavorable attitude to advertising all had insignificant coefficients. Data were not available to allow further tests of the relationship between structure and conduct and market performance.

\section{Evaluation of the Aggregate Production Function Approach to Measurement of Firm Performance}

Despite the stated data limitations the empirically derived production function gave results consistent with theoretical expectations, and with known information about the level of technology available in the industry. While better data may aid in refining the estimates presented here, it is believed that they fulfill the broad aims outlined at the beginning of this chapter, namely, (1) showing the approximate relationships between inputs and output in the industry, in particular the prominent role of labor and management, (2) detecting gross inefficiencies, especially in the use of labor relative to insufficient managerial talent, and (3) by focusing attention on these apparent problem areas, demon- 
strating to future researchers where economic analysis might most profitably be applied.

\section{Validity of the Working Hypothesis of Perfect Competition}

The results of our analysis, using the assumptions of perfect competition, suggested that in only one respect, namely the managerial talent available relative to total labor employed, did firms in the industry significantly deviate from the optimal position of perfect competition. One might conclude that competition was thereby rendered imperfect and that nothing could be said about the relative efficiency of firms. However, we would argue that the weaknesses in the industry's performance highlighted by the analysis under the assumption of perfect competition do accurately reflect the inefficiencies actually present in the industry and do indicate the direction of the changes which must be made if the industry is to improve its performance. Accordingly, the tables of optimal input mix derived under the assumption of perfect competition can be used by firm managers and policy-makers as tentative indicators of relative firm efficiency.

Our results, however, have been shown to be sensitive to error because of data and statistical problems encountered during the estimation process. Much still remains to be known about the influence of capital and management on the relative performance of firms in the industry.

\section{EX-VESSEL PRICES}

An effort was made to quantify the main factors influencing the average annual exvessel prices of the twelve leading California species of fish and shellfish sold in the fresh and frozen fish trade. Price variations could be explained mostly by the volume of landings of the species, the price of its leading substitute product, and the prevailing level of per-capita income in California. In the case of all species, a 1-per cent increase in landings caused a less than 1 per cent decrease in price and thereby increased the gross returns to fishermen. An increase of 1-per cent in the level of income led to an increase in landings, varying by species between 0.26 and 8.4 per cent. The elasticity coefficients are generally favorable for fishermen who can increase their landings of fish. However, the factors favorable to increasing landings are offset by negative forces, particularly by the mounting evidence that the known supplies of the most desirable and some of the less desirable species harvested in California waters are already fully utilized.

This section shows the results of our statistical analyses of the chief influences on ex-vessel prices of the 12 leading species of finfish and shellfish handled by the California trade. We applied a simple standard analysis to each species, namely that price was functionally dependent on three independent variables-quantity offered, price of the leading substitute commodity, and consumers' income.

In Waugh's words: "Such routine mass production methods have both advantages and disadvantages. They enable us to get enormous amounts of statistical results which are comparable between commodities. On the other hand, any analysis which uses the same equations for all commodities is likely to overlook essential features in the markets for the individual foods." (Waugh, 1964, p. 27) The analyses also allowed us to look at performance in one further aspect-the economic efficiency of the industry in harvesting the California fishery resources. To offset the disadvantages cited by Waugh we determined the structural, 
institutional, or biological factors influencing the price of each species, and, where possible, analyzed the factors influencing the price of the species studied in the broader Pacific Coast supply and marketing area, including Alaska, Washington, Oregon, and California.

\section{Ex-vessel demand for California species}

No previous statistical estimates of demand for California species have been published. Some guidance was available from the growing number of empirical demand studies of East Coast U.S. species which have been completed during the 1960's (Nash and Bell, 1969). However, the background information on many of the California species is not complete enough to consider these estimates as definitive. Apparent deficiencies in our results are pointed out, to guide other researchers.

\section{The basic model}

The basic model hypothesized for all 12 species was:

$$
P_{i}=f\left(Q_{i}, P_{j}, I\right),
$$

wherc

$$
\begin{aligned}
P_{i}= & \text { annual average California ex-ves- } \\
& \text { sel price of the } i^{\text {th }} \text { species, } \\
& (i=1 \ldots 12), \\
Q_{i}= & \text { annual average California per- } \\
& \text { capita catch of the } i^{\text {th }} \text { species, } \\
& (i=1 \ldots 12), \\
P_{j}= & \text { annual average California ex- } \\
& \text { vessel price of the } j^{\text {th }} \text { species, } \\
& (j=1 \ldots 12 \text { and } j \neq i), \\
I= & \text { annual average California per- } \\
& \text { capita personal income. }
\end{aligned}
$$

All prices and income were deflated by the consumer price index. In a number of cases it was difficult to specify an appropriate substitute price, $P_{j}$, either because it was unclear which species were close substitutes, or because data were not arailable on substitute species. In some cases, a "reference product" price was used in place of a substitute price, a reference product being one whose price appears to act as a reference or guide to the price of another product. For example, the price of Dover sole appears to influence the price of less abundant sole varieties. Such reference prices are an important guide to the pricing decisions of fishermen, entrepreneurs and policy-makers.

The major variations in the basic model employed were (1) the addition of dummy variables to examine the presence of a time trend or cyclical factors in price or to isolate abrupt shifts in price because of institutional changes, and (2) deletion of the substitute price variable where it was a major source of collinearity.

\section{Method of estimation and func-} tional forms used. All equations were estimated by single-equation least squares. Conceptually, a recursive model (e.g., a Cobweb model) or a system of simultaneous relationships would seem more appropriate, but a lack of data on the factors other than price-biological, oceanographic, climatic, etc.-which affect the supply of each species, make these methods of estimation inapplicable.

The specification of price as the dependent variable appears logical for fish species, because of the erratic harvest from the ocean, daily, seasonally, and over time, and the resultant variation in both prices and gross returns. Usually, the volume of catch is price determining rather than price determined.

Data on volume and value of catch of approximately 60 species or subspecies of fish landed in California are reported in the annual catch bulletins of the California State Department of Fish and Game. We selected for analysis the 12 species consistently most important in dollar terms to the fresh and frozen fish trade, and used graphic analysis to determine the most appropriate functional form for each regression. As a result, linear, logarithmic, semilogarithmic, and 
inverse forms were used in analyzing the supply-price responses for different species.

Results of basic equations. The best equation for each species is shown in table 20. In general, the statistical properties of the estimated equations were good. Except for the quantity coefficient for sablefish, all the coefficients had signs which conformed to theoretical expectations. Alternative specifications of the problem failed to produce a satisfactory sablefish equation. ${ }^{16}$

The salmon, rockfish, shrimp, and oyster equations showed evidence of posi. tive serial correlation. This may be related to the other major problem encountered in analyzing the influences on prices of these species, i.e., the difficulty of finding a substitute product yielding statistically significant results. More detailed study is needed in this area. With the exception of abalone, cyclical or trend variables were not significant in explaining price variations.

The impact of changes in the independent variables on the dependent variables can best be seen when expressed in relative terms. The price flexibilities can be read directly from table 20 for those equations in $\log$ form. For example, the sole equation tells us that a 1-per cent increase in the quantity of sole landed would lead to a decrease in ex-vessel price of .386875 of 1 per cent, a 1-per cent increase in the beef price index would lead to an increase in the sole price of .532769 of 1 per cent, and a l-per cent increase in income to an increase of .301233 per cent.

For comparative purposes it is more convenient to present the results in terms of price elasticities with respect to quantity and income (table 21). The outstanding feature of the quantity elasticities is that they are greater than unity in absolute terms for all species, implying that fishermen by catching more of any species or by reducing the price could increase their total returns. Conversely, efforts to curtail catch or to raise price would reduce their total returns. For all species the income elasticity was positive, although for three species the elasticity coefficient was less than unity.

\section{Why Do Fishermen Not Increase Landings?}

The results suggest that total revenue for each species can be increased by increasing the quantity available. In the unlikely event that quantity of all species were increased simultaneously, this would not automatically still hold, because buyer's preferences for the species may vary. However, the fishermen's total revenue for individual species could be raised by increasing quantity available. A number of different hypotheses as to why the fishermen themselves do not take steps to increase landings were suggested in discussions with industry leaders:

- Long-run elasticities derived from annual data are less relevant to the decision-making processes of fishermen and primary producer-wholesalers than the occasional bad days when an exceptional run of fish, especially those marketed fresh, have led to plummeting prices and total revenue. (See, for example, Thomas, 1968, pp. 15-17.)

- Total gross revenue is not usually considered to be as relevant to the fishermen as total net revenue. Fishermen may be unwilling to increase landings because net revenue would decline.

- Because of the limited size of many fish populations, quantity landed cannot be increased.

- Various legal and institutional restraints, or lack of capital, prevent the fisherman from harvesting the available resources to the fullest.

It is possible to examine some of these hypotheses critically in light of available evidence for each species discussed. In

${ }^{10} \mathrm{Graphic}$ analysis revealed no clear pattern of relationship between landings and price of sablefish. The problem may be due to inaccurate reporting of prices or landings by fishermen. 


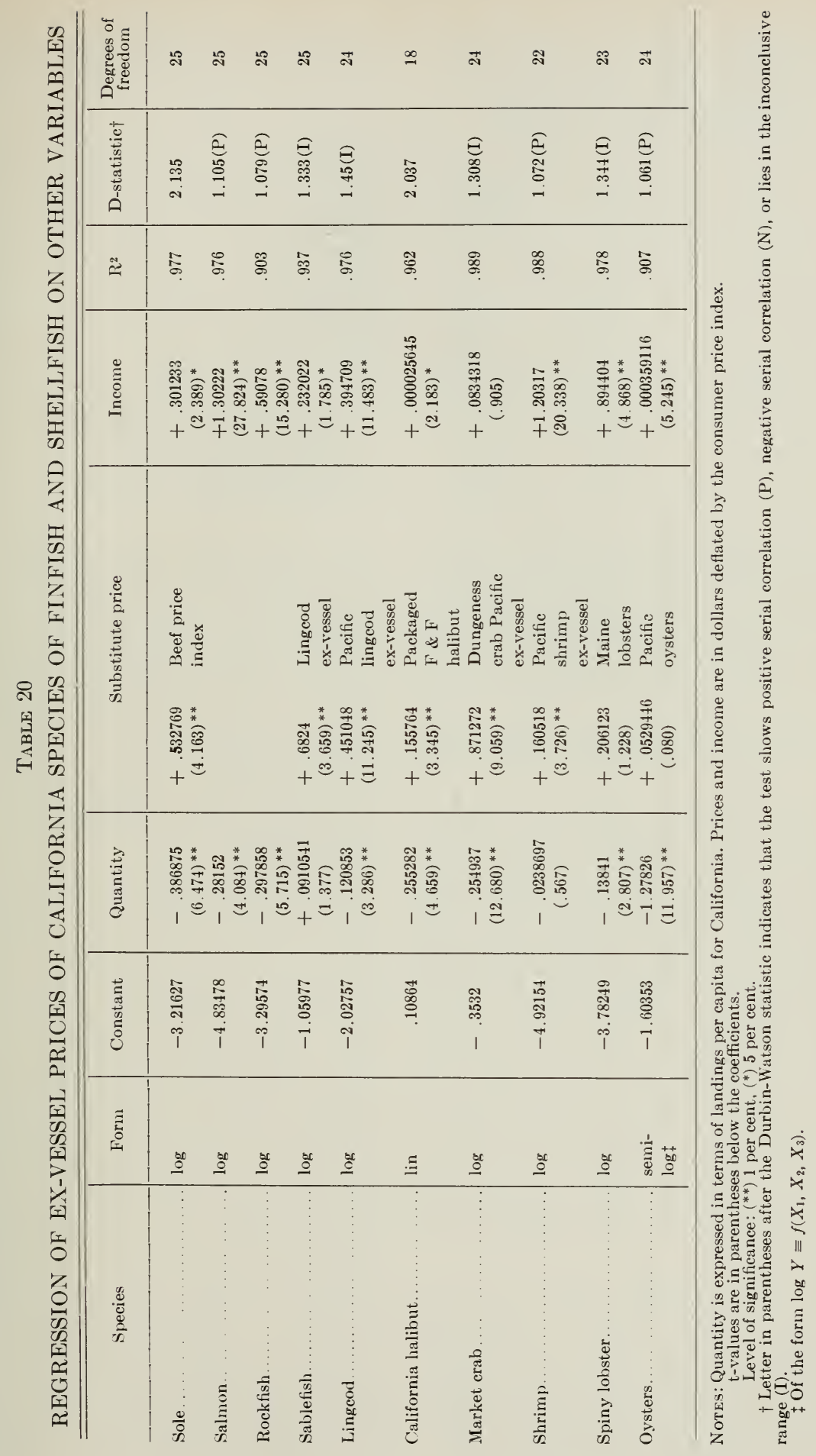


TABLE 21

EX-VESSEL PRICE AND INCOME ELASTICITIES FOR SELECTED CALIFORNIA SPECIES OF FINFISH AND SHELLFISH

\begin{tabular}{|c|c|c|}
\hline Species & $\begin{array}{c}\text { Quantity } \\
\text { elasticity } \\
\text { with respect } \\
\text { to price }\end{array}$ & $\begin{array}{l}\text { Quantity } \\
\text { elasticity } \\
\text { with respect } \\
\text { to price }\end{array}$ \\
\hline Sole. . & $-2.585^{*}$ & $+779^{*}$ \\
\hline Salmon. & $-3.552^{*}$ & $+4.626^{*}$ \\
\hline Rockfish. & $-3.357^{*}$ & $+1.983^{*}$ \\
\hline Lingcod. . & $-8.275^{*}$ & $+3.266^{*}$ \\
\hline California halibut & $-10.441^{*}$ & +.262 \\
\hline Sea bass, white. . & $-4.128^{*}$ & $+2.005^{*}$ \\
\hline Market crab.... & $-3.923^{*}$ & +.327 \\
\hline Shrimp..... & -4.189 & +5.041 \\
\hline Spiny lobster. & $-7.225^{*}$ & $+6.462^{*}$ \\
\hline Abalone...... & -6.435 & +8.445 \\
\hline Oysters... & $-3.471^{*}$ & $+2.166^{*}$ \\
\hline
\end{tabular}

Notes: For the form $\log P_{i}=$ Constant $-a \log Q_{i}+$ $b \log P_{j}+c \log I$ the quantity elasticity is $-1 / a$, the income elasticity is $+c / a$. While this method does not give the true elasticity (of demand theory) it is sufficiently accurate for our purposes and is "less objectionable" than alternative methods (Sosnick, 1962, p. 731). For the form $P_{i}=$ Constant $-a Q_{i}+b P_{j}+c I$, the quantity elasticity is $\bar{P} / \bar{Q} / \partial P / \partial Q$ and the income elasticity $(\bar{I} / \bar{Q})$ $(\partial P / \partial I) /(\partial P / \partial Q)$. For the form $\log P_{i}=$ Constant $a Q_{i}+b P_{j}+c I$, the quantity elasticity is $1 / a \bar{Q}$, the income elasticity is $a \bar{I} / c \bar{Q}$.

Estimates of elasticity based on coefficients significant at the 5 per cent level are marked with a single asterisk $\left({ }^{*}\right)$.

the case of salmon, landings have been on a downward trend since 1946. Competition from sport-fishermen is likely to remain keen. At the same time that spawning grounds for salmon are being reduced by logging and other lumbering operations, dams, and various forms of pollution, the number of licensed trollers operating in California has increased, apparently attracted by high and rising prices relative to other fish. Without further protection or large-scale development of spawning grounds, salmon is likely to remain in short supply, from both California and other Pacific Coast waters.

The liest available data for other species of fish and shellfish are found in the 1965 California Fish and Wildlife Plan which classifies fish by level of utilization and quality of scientific information available (table 22). Good or moderate information was available on all items
TABLE 22

RESOURCE INVENTORY INDEX

\begin{tabular}{|c|c|}
\hline Spccics & Status \\
\hline 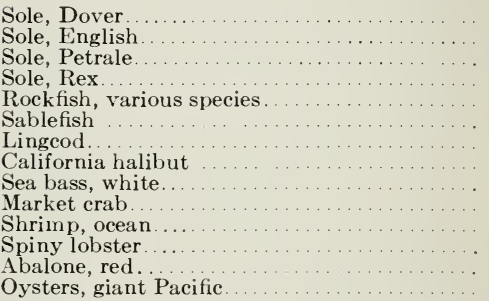 & $\begin{array}{l}3 \mathrm{~A} \\
2 \mathrm{~A} \\
2 \mathrm{~A} \\
3 \mathrm{~B} \\
3 \mathrm{~A}-3 \mathrm{C} \\
3 \mathrm{~B} \\
3 \mathrm{~B} \\
2 \mathrm{~A} \\
3 \mathrm{~A} \\
2 \mathrm{~A} \\
2 \mathrm{~A} \\
2 \mathrm{~B} \\
3 \mathrm{~A} \\
2 \mathrm{~A}\end{array}$ \\
\hline $\begin{array}{l}\text { Kcy } \\
\text { 1. Overfished or needs to be protected. } \\
\text { 2. Substantially fully utilized. } \\
\text { 3. Moderate potential of expanded use. } \\
\text { 4. Large potential for expanded use. } \\
\text { A. Good information. } \\
\text { B. Moderate amount of information. } \\
\text { C. Largely speculative. }\end{array}$ & \\
\hline
\end{tabular}

listed. Seven species were thought to be "substantially fully utilized," seven-including Dover sole and rockfish-were thought to have moderate potential for expansion. With existing technology, California is near the maximum possible yield, as is evidenced by the fact that increases in boats, fishermen, and operating gear in use in trolling, salmon, and crab fishing, has not brought increased total landings.

Evidence also shows that fishermen are more concerned about the short-term impact on their income of increased landings rather than the long-term market development possibilities which could bring a permanently higher level of income. This applies particularly to the many part-time and small boat fishermen (Thomas, 1968). However, negotiated agreements, notably between trawlermen and primary producer-wholesalers are more concerned with longer-run effects. Through sliding price scales, based on volume delivered and size of fish, these agreements attempt to smooth the natural fluctuations of landings and prices. For example, a number of major primary producer-wholesalers specify before each trip the quantity of bottomfish which they require from their affiliated fishing vessels, and, in case of changed market 


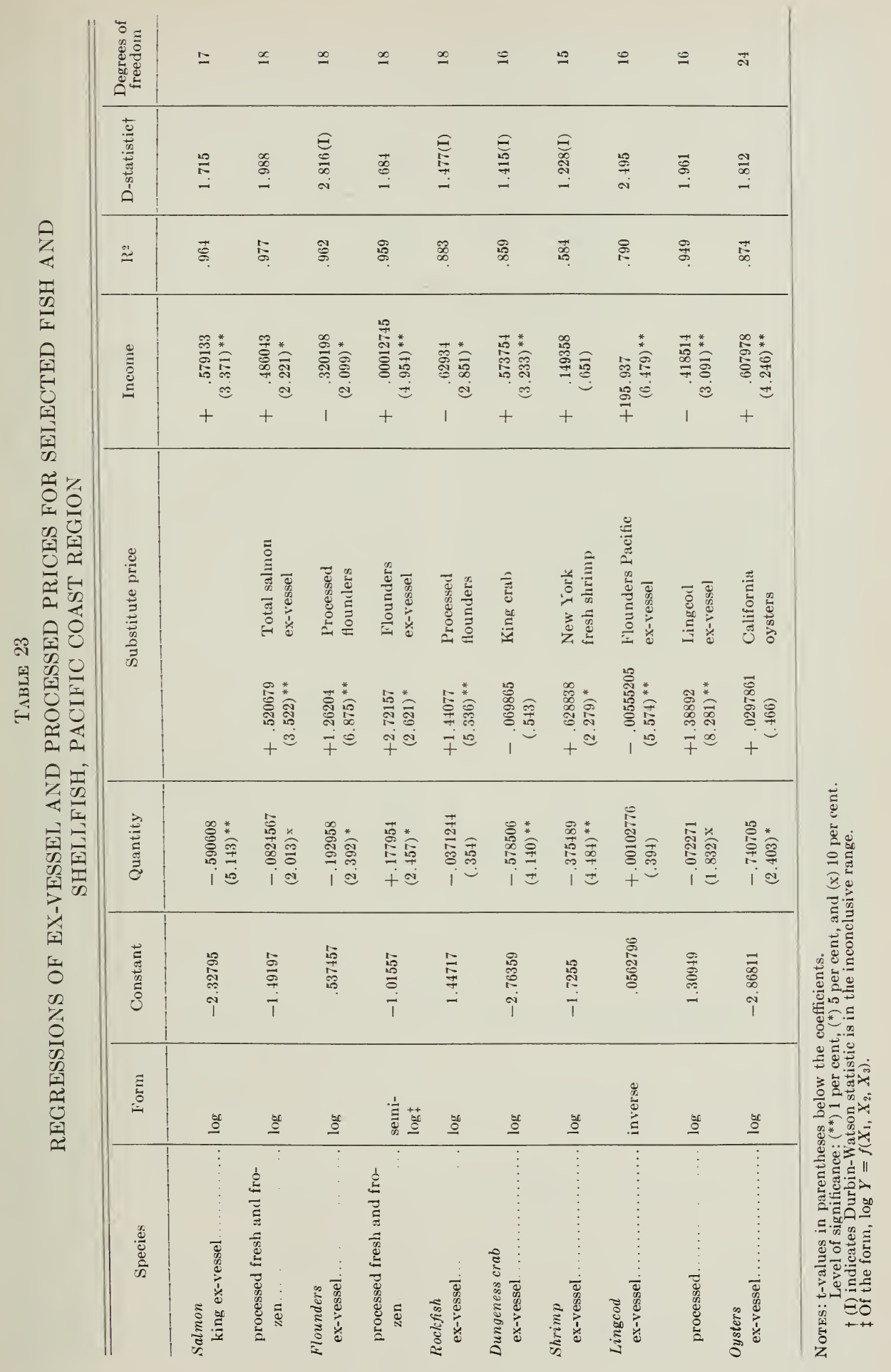


conditions, amend their instructions by radio contact with vessels still at sea. These arrangements have greatly reduced the violent fluctuations in prices and income once so typical of the fish trade. Where these protective arrangements exist it should be more feasible for fishermen and primary producer-wholesalers to plan for long-term expansion of landings.

A more serious obstacle to long-range planning seems to be lack of capital. Increases in operating units have been greatest in those sections of the industry -for example, salmon trolling or crab fishing-where costs of entry are low. New entries to the trawler fleet are limited by the high cost of a fully-equipped vessel. Most trawlers are owned or financed by primary producer-wholesaler firms or their affiliates. In turn, the willingness of these firms to add to the trawler fleet must depend on the relative weights they attach to increased catch in good years compared to increased fixed charges in poor years.

\section{Fish Prices in the Pacific Coast Region $^{1 \tau}$}

It would have been desirable to analyze prices of the species already studied at the wholesaler, broker, fabricator, and retailer levels in California. Because data were not available, we attempted to gain insights from analyzing the prices of those species within the broader Pacific Coast market. In a number of cases we could estimate price equations for the whole fish ex-vessel and the fresh or frozen processed product (table 23). Equations tend to include lower $\mathrm{R}^{2}$ and a greater number of insignificant coeffcients than their California counterparts. All $d$-statistics are adequate, but the problem of correct specification of substitute products remains intractable. For processed flounder, the quantity coeffcient had a positive sign, probably the result of faulty data. For flatfish and rockfish, ex-vessel and processed lingcod, the income coefficient was negative and significant, yielding negative income elasticities. This is not consistent with the results for California and requires further study. The price and income elasticities derived from these equations are shown in tables 24(a) and 24(b). One would anticipate that elasticity of quantity with respect to price would be smaller for the larger market area or the processed version of a product, and that elasticity of quantity with respect to income would be larger. Where the coefficients are significant and one can have confidence in the elasticity estimates, this does tend to hold true.

\section{TABLE 24(a)}

ELASTICITY OF QUANTITY WITH RESPECT TO PRICE FOR SELECTED SPECIES OF FISH AND SHELLFISH

\begin{tabular}{|c|c|c|c|}
\hline \multirow{2}{*}{ Species } & \multirow{2}{*}{ California ex-vessel } & \multicolumn{2}{|c|}{ Pacific Coast } \\
\hline & & Ex-ressel & Processed \\
\hline 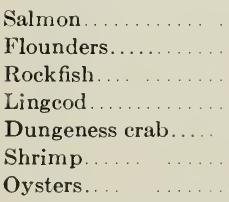 & $\begin{array}{l}-3.552^{*} \\
-2.585^{*} \text { (sole) } \\
-3.357^{*} \\
-8.275^{*} \\
-3.923^{*} \text { (market) } \\
-4.189 \\
-3.471^{*}\end{array}$ & $\begin{array}{l}-1.693^{*} \text { (king) } \\
-5.182^{*} \\
-26.936 \\
-\ldots \ldots \\
-1.729^{*} \\
-2.663^{*} \\
-1.350^{*}\end{array}$ & $\begin{array}{l}-12.128 \\
\ldots \ldots \\
-13.837 \\
\ldots \ldots \\
\ldots \ldots\end{array}$ \\
\hline
\end{tabular}

Note: Estimates of elasticity based on coefficients significant at the 5 per cent level are marked with a single asterisk $\left(^{*}\right)$.

${ }^{17}$ Includes Alaska, Washington, Oregon, and California. 


\begin{tabular}{|c|c|c|c|}
\hline \multirow{2}{*}{ Species } & \multirow{2}{*}{ California ex-vessel } & \multicolumn{2}{|c|}{ Pacific Coast } \\
\hline & & Ex-vessel & Processed \\
\hline $\begin{array}{l}\text { Salmon.......... } \\
\text { Flounders........ } \\
\text { Rockfish ......... } \\
\text { Lingcod ......... } \\
\text { Dungeness crab } \\
\text { Shrimp........... } \\
\text { Oysters........... }\end{array}$ & $\begin{array}{l}+4.626^{*} \\
+.779^{*} \text { (sole) } \\
+1.983^{*} \\
+3.266^{*} \\
+.327 \text { (market) } \\
+5.041 \\
+2.166^{*}\end{array}$ & $\begin{array}{l}+.981 \text { (king) } \\
-1.659 \\
-16.952 \\
+31.216^{*} \\
+\quad .992^{*} \\
+. .394 \\
+.821^{*}\end{array}$ & $\begin{array}{l}+5.895 \\
+2.865^{*} \\
\ldots \ldots \ldots \\
-5.791 \\
\ldots \ldots \\
\ldots \ldots\end{array}$ \\
\hline
\end{tabular}

Note: Estimates of elasticity based on coefficients significant at the 5 per cent level are marked with a single asterisk $\left({ }^{*}\right)$.

Our analysis suggests that California fishermen could increase their total re. turns by increasing landings of any individual species. However, an attempt to increase landings of all species at the same time could so overburden existing markets and market facilities that prices and total returns would decline. Clearly, long-term efforts to increase fishermen's income must depend on selective increases of landings complemented by the adaptations in marketing facilities among primary producer-wholesalers, brokers, and retailers needed to insure that the increase can be absorbed without undue short-term market distortion.

\section{PRICING PRACTICES}

Administered pricing was commonplace at most levels of production and marketing of fresh and frozen fish and shellfish landed in California. This form of pricing helped stabilize the market, particularly for products in relatively short supply. The effectiveness of such a system rested on the ability of primary producer-wholesalers to estimate their market needs under given price conditions and to inform their fishermen-suppliers. Contracts between the Eureka fishermen's association and the primary producer-wholesalers kept prices paid to fishermen from fluctuating within a season, and also discouraged over-harvesting by providing a downward sliding scale of prices when the volume delivered exceeded a prescribed level.

Follow-the-leader pricing was necessary for the survival of smaller producer-wholesalers. Monopoly pricing was customary for both fishermen and handlers of such less plentiful species as abalone and salmon.

The price stability at the retail level reflected the administered pricing of each retail firm. Minor upward or downward variations in wholesale prices were not carried through to retail prices.

Market conditions during 1968-1969 favored sellers at all levels. Hence, both prices and margins on most species rose appreciably above those of previous years.

As could be expected from the diversity of the California fresh and frozen fish trade, and the problems associated with low income to fishermen and uncertain supply of fish, the trade has devel- oped different pricing practices. To carry out our analysis of pricing practices, weekly data on prices and quantities were needed. It was possible to acquire such data only for some species at some levels 
of the marketing system, for the years 1967, 1968, and 1969. ${ }^{18}$ Even though price and quantity data were lacking for a completely self-contained model of the entire price system for the California fresh and frozen fish trade, it was possible to do partial analyses of the main relationships within the price system.

In the first part of our analysis we examine the week-to-week influences on the price paid to California fishermen for Dover sole, rockfish, king salmon, silver salmon, and crab. Of particular importance in our analysis is the extent of the influence exerted by the special marketing arrangements in the Eureka statistical area on the California prices. A second section looks at the pricing practices of one Los Angeles broker who is a major handler of fresh fish from Eureka, California, and of frozen fish from the Atlantic seaboard. A third section focuses on the pricing practices of a major national food chain with supply sources and retail outlets both inside and outside California. A fourth section analyzes the available data on the prices and quantities of species imported into California and their relationship to cold storage holdings and to the pricing decisions of fishermen, wholesalers, brokers, and retailers. The business policy implications of the findings from these separate sections on the firm, industry, and public are drawn together in the last section of this chapter.

\section{Prices Received by California Fishermen}

Dover sole. Landings of Dover sole have a pronounced seasonal cycle (figure 7). On the average, about 80 per cent of the California catch is landed between May and October. In 1967 and 1968, a reduced California price in the summer months reflected these increased land- ings. However, in 1969, despite the usual peak summer landings, price did not decrease, as usually. An examination of Eureka prices helps to explain this. Eureka accounts for 90 per cent of the California landings of Dover sole. The Fishermen's Marketing Association, bargaining agent for the Eureka trawlermen. secured an agreement from the Eureka primary producer-wholesalers setting the minimum price for Dover sole at 7.257.50 per pound for the six months begin. ning May 1, 1969. The higher price, 7.50 cents, was to be paid for the first 12,000 pounds on each boat trip, and 7.25 cents for any catch above 12,000 pounds. ${ }^{19}$ This compared with the minimum price of a flat 7.50 cents for the previous six months. In addition, two large producer-wholesalers stated that they specified in advance the quantity of bottomfish, such as Dover sole, they required on each trip. In a sense, therefore, institutional controls were used to reduce the uncertainties associated with the catch levels of Dover sole and to hold price paid to fishermen within fairly narrowly prescribed limits on that species.

Our statistical analysis of Dover sole at Eureka showed that last week's price, seasonal pricing arrangements, and miscellaneous cyclical factors significantly influenced current price (table 25). The quantity landed in any one week did not significantly affect price in that week, evidencing the tight institutional control over price. The general level of Dover sole prices tended to fall about one-half cent during the summer months.

Rockfish. Based on the figures for 1967-1969, the California rockfish catch averaged approximately the same volume, price, and total value to fishermen as that of Dover sole. However, unlike Dover sole, total landings were more evenly distributed throughout the year,

\footnotetext{
${ }^{18}$ Special analysis conducted by the Marine Fisheries Statistics section of the California Department of Fish and Game, Terminal Island, California.

${ }^{19}$ These agreements are negotiated for a season or a year and set minimum prices for all leading species landed in Eureka.
} 
Price

(cents per pounds)

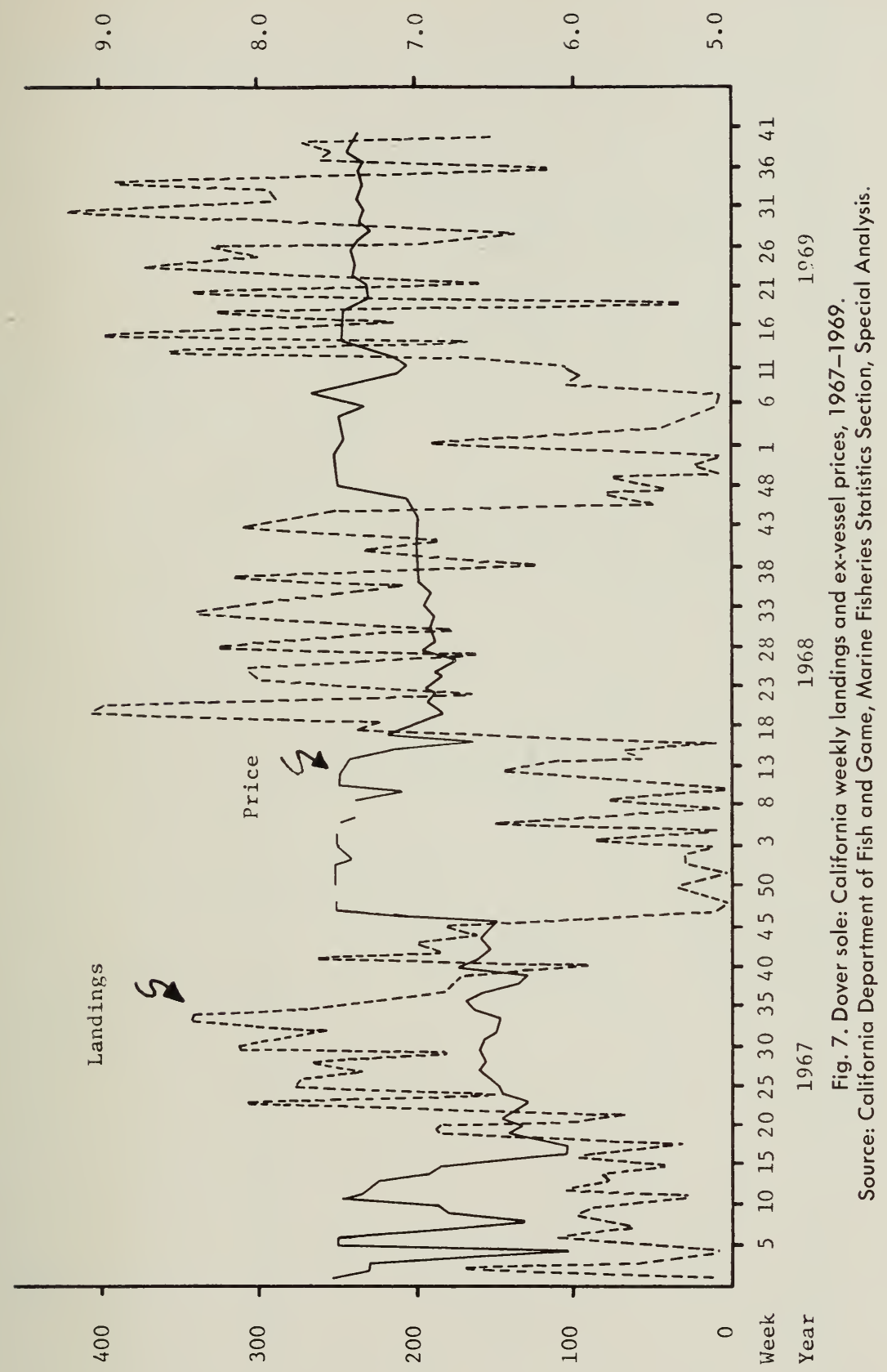

(spunod $000^{\circ}$ กCI)

şuṭpuet 


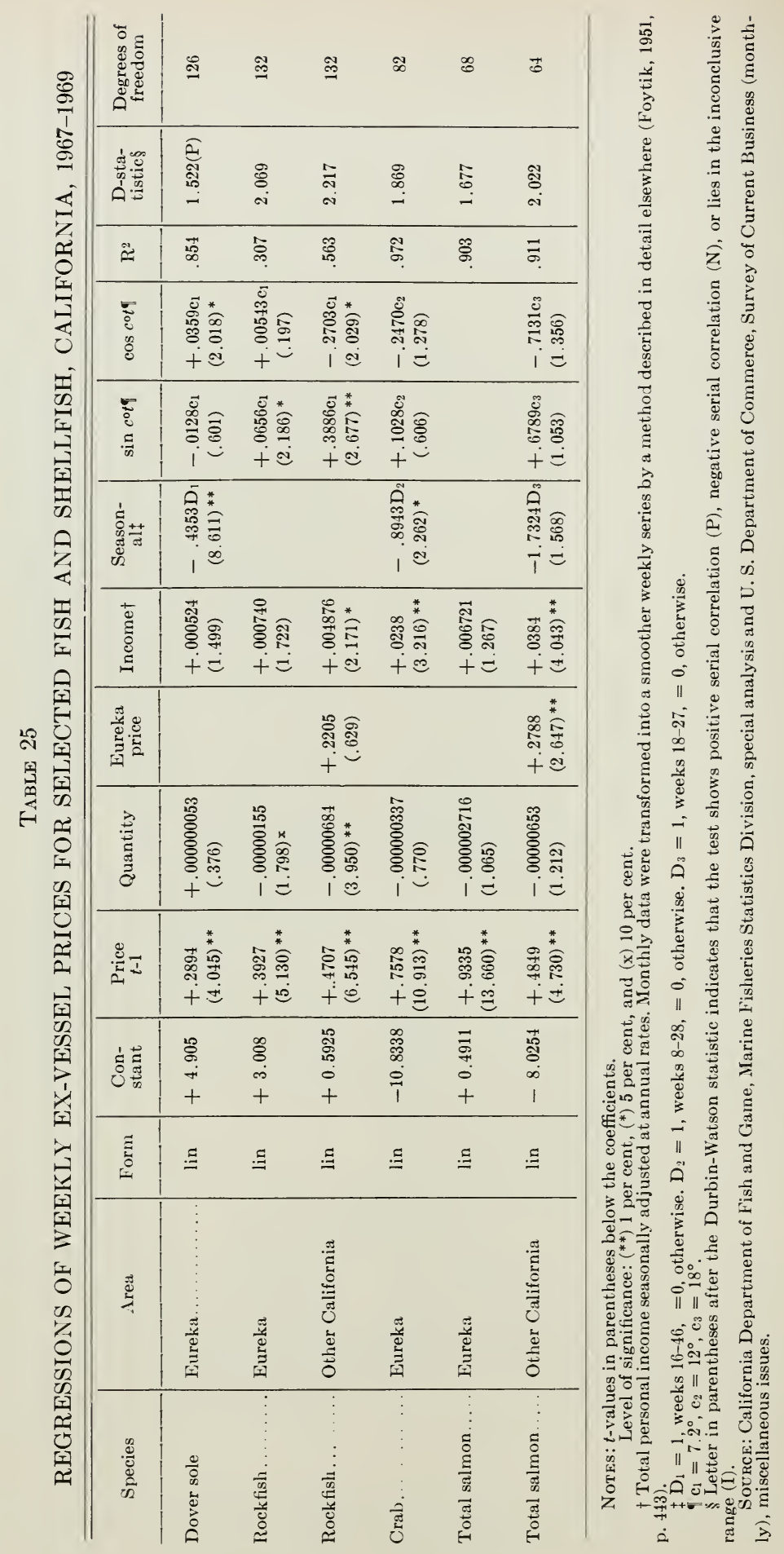


Price

(cents per pound)

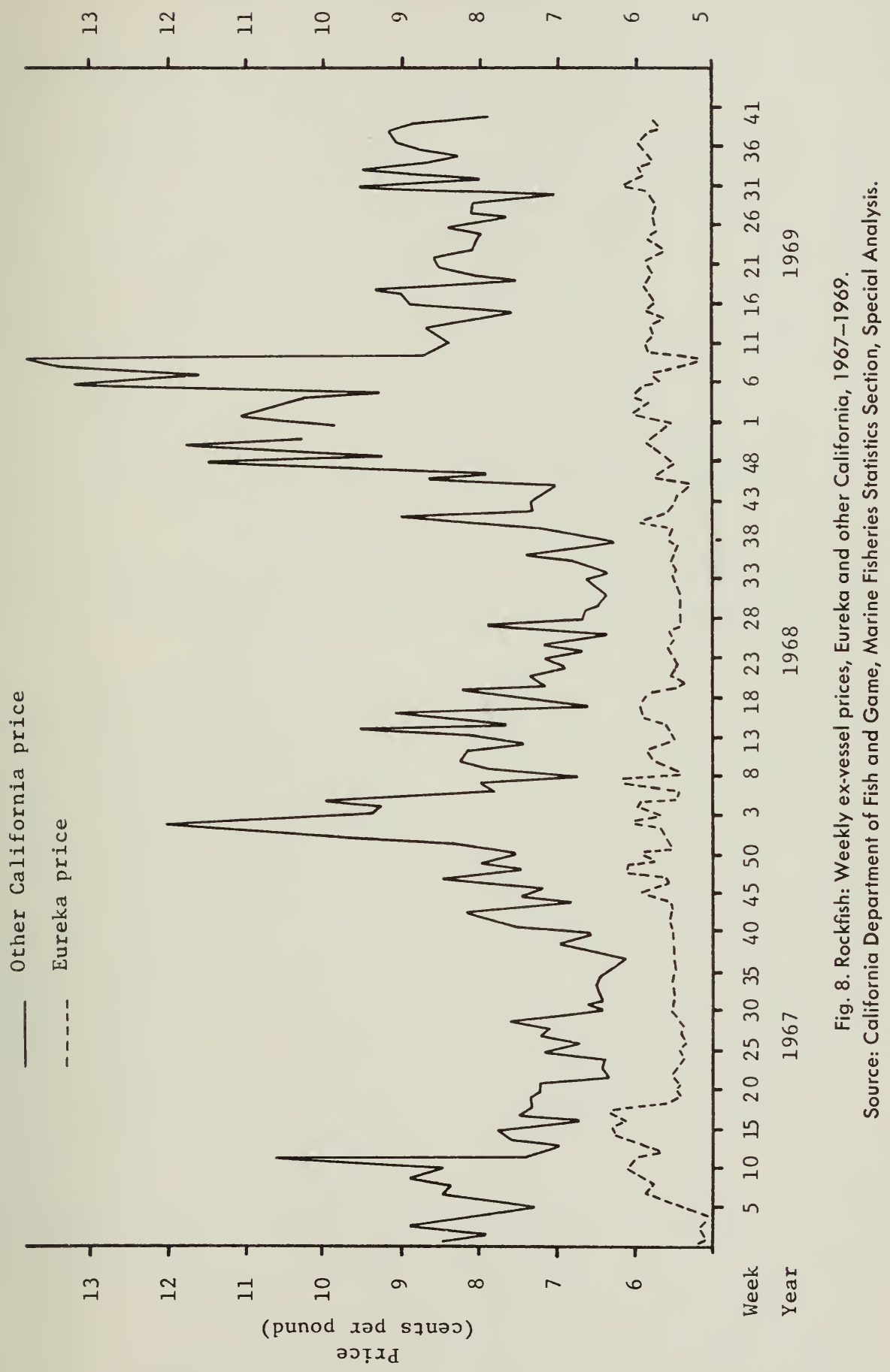


less than one-third were made in the Eureka area, and the average Eureka price was below, not above, the average California price. The Eureka trawl fish price also showed remarkable stability over the three-year period when compared with the average price for all other California (fig. 8). This reflects (a) the Eureka arrangement for negotiating minimum prices and (b) the fact that most Eureka rockfish were purchased for further processing, i.e., filleting and freezing. In contrast, most rockfish were caught with hook and line and in areas other than Eureka and and were sold fresh in Southern California markets. Buyers claimed the method of capture and handling affected fish quality. In 1969, while Eureka landings were above average, and "other California" ${ }^{\text {o }}$ landings below average, the Eureka trawl fish price held firm while other California price moved sharply higher.

Quantity of landings in Eureka did not significantly affect Eureka prices, but this was not so in the other California area (table 25). Moreover, Eureka rockfish prices did not significantly affect prices in the other California area, thus casting doubt on the hypothesis that the Eureka pricing arrangements for rockfish put a floor under California rockfish prices. Solving the cyclical variables to find the peak of the cycle, it appears that miscellaneous demand factors lead to peak prices in the other California area in the first week of January and in Eureka in late March (Waugh and Miller, 1969, p. 19). In contrast, the average price of rockfish in the remainder of California was significantly affected by both the volume of landings and the price at Eureka.

King salmon. Many fishermen did not indicate on the sales receipt submitted to the California Department of Fish and
Game the species of salmon landed; therefore, there is some doubt that the volume of king or silver salmon reported in each week was a fair and consistent representation of total quantity of each species landed. The reported week-toweek prices is more likely to be representative because the workings of the marketplace tends to equalize these among fishermen. The overall trend in king salmon prices is clearly upward. This is also true for the fishing season, April through September (figure 9). Once again, Eureka prices seem least affected by peak volume. However, one further caution in interpreting these prices must be mentioned. The Eureka fishermen-wholesaler minimum pricing agreements stipulate a different price for large, medium, and small king salmon, and large, medium, and small silver salmon. ${ }^{21}$ Accordingly, seasonal changes in the size composition of the catch (on which no data are available) could distort prices considerably.

Silver salmon. Available evidence suggests that landings of silver salmon have a more extreme seasonal peak than king salmon, the peak month being either June or July. While the upward trend of prices within season and between years is evident, prices do tend to dip in midsummer (figure 9). This may partly reflect the overlap of the landing season in Seattle, the main competing supply area. The price effect of peak landings is less pronounced in Eureka than in the other California area. A decline in total landings has stimulated the upward movement of prices between years. Data did not permit separate statistical analysis of silver and king salmon. However, analysis of average weekly prices for all salmon showed Eureka price heavily dependent on last week's price only, while other California price was influenced by the

${ }^{20}$ That is, California, excluding the Eureka statistical area.

${ }^{21}$ Size specification of salmon, all dressed, heads on:

King large, 12 pounds up; medium, 8 to 12 pounds; small, under 8 pounds.

Silver large, 10 pounds up; medium, $4 \frac{1}{2}$ to 10 pounds; small, under $4 \frac{1}{2}$ pounds. 


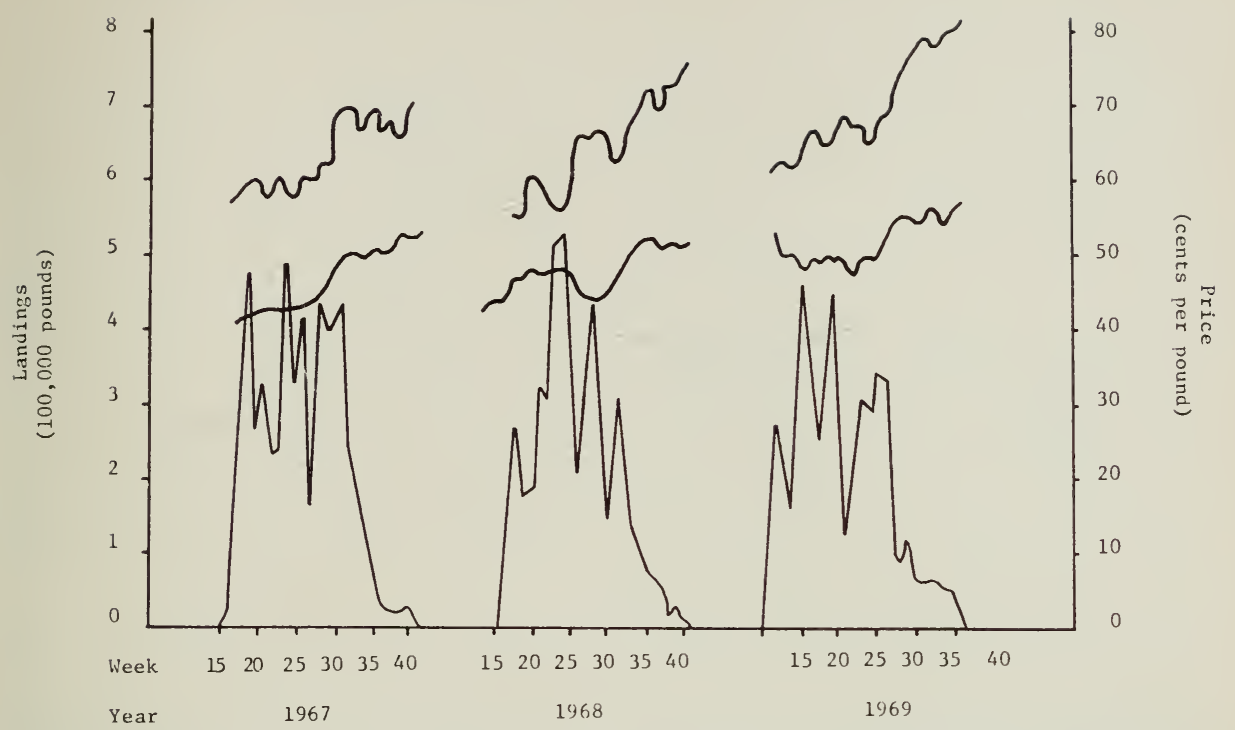

Fig. 9. California, total salmon landings and ex-vessel prices of king and silver salmon, weekly, 1967-1969.

Source: California Department of Fish and Game, Marine Fisheries Statistics Section, Special Analysis.

level of both Eureka price and income. Crab. Crab landings are characterized by an extreme seasonal peak in December or January. The two main species, market crab (Dungeness crab) and rock crab are not distinguished in our data. However, market crab account for 97 per cent of California crab landings and almost 100 per cent of Eureka landings. Eureka supplied about 90 per cent of all California crab, mostly during the four months December through March. Accordingly, the Eureka price can le taken as a reasonably accurate measure of market crab price. As in the case of Dover sole, despite increased landings, fishermen were able, through collective hargaining, to raise seasonal prices from 15 cents in 1967 to 25 cents in 1969 (figure $10)$. This reflects the fact that nationwide demand for crab continues to exceed supply available from all sources.

As in the case of Eureka Dover sole and rockfish, statistical analysis suggests that volume of landings did not significantly influence the price of market crab at Eureka. Last week's price, upward adjustment of minimum prices during the period. and current income were significantly related to current weekly price. The annual midseason upward shift in prices raised prices, on average, almost nine cents per pound. It appears that miscellaneous cyclical demand factors had little influence on crab price. However, a long time-series would be needed to confirm these findings.

\section{Case Study: A Los Angeles Broker}

The broker studied, while occasionally buying on his own account in the manner already described, handled a large proportion of species from Eureka and from the Atlantic seaboard marketed in the Los Angeles area for the normal brokerage fee. Through almost daily telephone contact with suppliers on the Atlantic and 


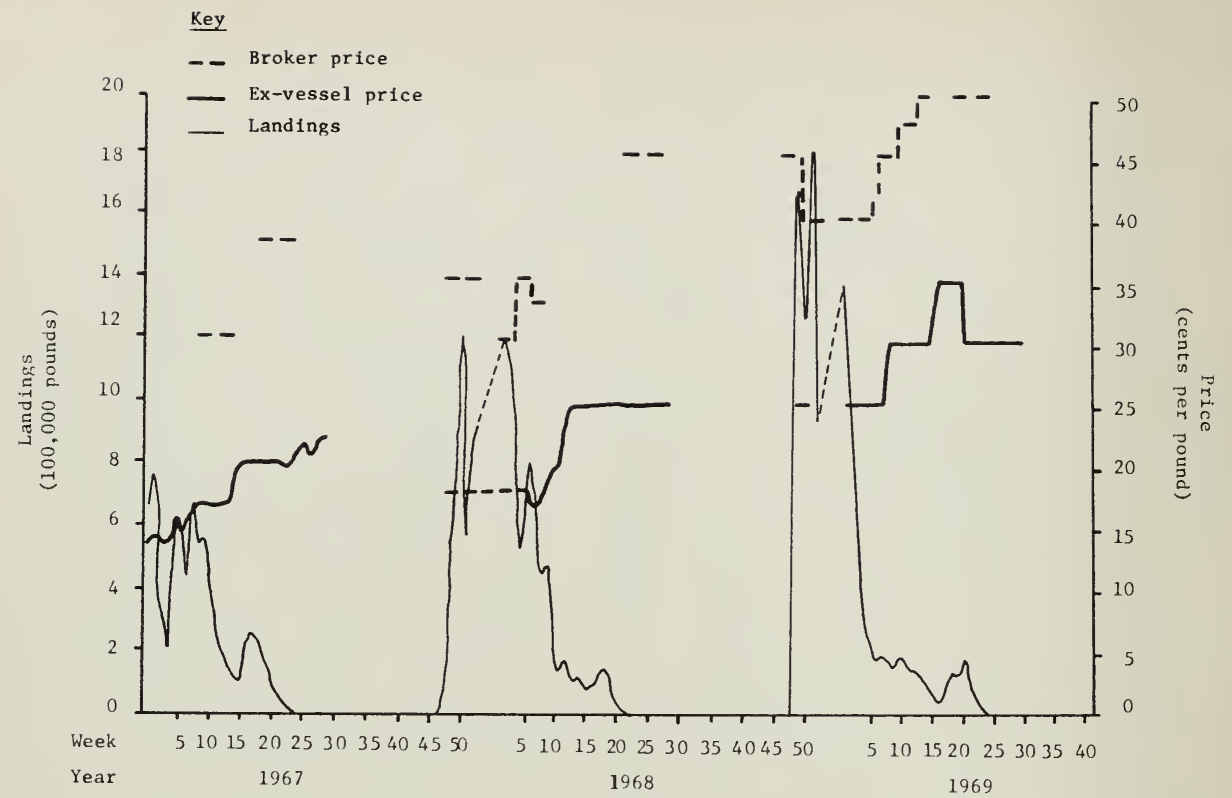

Fig. 10. Market crab: Landings and ex-vessel prices (live weight) and broker prices (fresh cooked, weekly, 1967-1969.

Source: California Department of Fish and Game, Marine Fisheries Statistics Section, Special Analysis and Los Angeles broker records.

Pacific coasts and its many wholesaler customers in California, Nevada, and Arizona, the brokerage firm kept well informed on both the current supply-demand situation and on emerging factors likely to affect that situation in the future.

Pricing methods. For many Atlantic species, the broker, whether acting on his own account or on a commission, based his price on the East Coast market price, plus a fixed charge to cover transportation cost and, where applicable, a brokerage fee. For example, the broker's price for scallops was based on the price paid to fishermen at New Bedford, Massachusetts, as reported in the U. S. Bureau of Commercial Fisheries' daily Fishery Products Report from New York. This pricing method reflected the relative unimportance of one broker's requirements in the large eastern markets.

However, in the case of Eureka sole, rockfish, salmon, and crab, the same broker, through the volume of his purchases and his frequent contact with principals in Eureka, had a powerful influence on the price negotiated by fishermen and primary producer-wholesalers. The broker was, in effect, the marketing arm of the Eureka producers. Accordingly, pricing patterns tend to be similar at the ex-vessel and broker levels, e.g., broker prices duplicate the winter-summer price differences, the relative stability within season, and the upward drift of prices since 1967 (figure 10).

\section{Fisherman - to - broker marketing} margins. While prices at all levels had been moving upwards, the marketing margin betwen fisherman and broker price was widening. The fisherman-tobroker marketing margin for the main Eureka species includes the broker's fee (normally 5 per cent of the selling price, 4 percent on crab and shrimp), and the costs of processing, storing, and transporting, normally borne by the primary 
producer-wholesalers. For Dover sole, assuming live weight at 3.45 times (Nash and Miller, 1969, p. 9) fillet weight, the primary producer-wholesaler's part of the broker price was, in dollar terms, subject to the widest fluctuations (table 26). Also, the primary producer-wholesaler improved his position most, relative to that in 1967, because of the more favorable demand for all fish. However, the minimum price for Dover sole, effective November 15, 1969, would push the fishermen's return per pound of fillet up by 2.6 cents and help improve their relative position. Statistics such as those in table 26 would be needed over a much longer period to determine the likely economic outcome of bargaining.

Price stability. The broker tended to quote the same price over long periods for the main Eureka species. For salmon, this usually included a range of prices for large, medium, and small sizes. However, the normally stable price pattern for rockfish was briefly altered upward or downward during weeks of exceptionally small or large landings, probably as a result of the greater price flexibility of competing supplies from sources other than Eureka. The broker pattern of prices for Eureka market crab may be considered stable in the sense that it moved up or down fairly much in line with the ex-vessel prices (figure 10). Broker price rose from 30 cents per pound in March 1967 to 50 cents in March 1969. During the first 16 weeks of 1969 the broker price moved upwards in four successive increases of $4,6,6$, and 4 cents, the ex-ressel price in two large steps of 10 cents each.

Traditionalism in pricing. Much of the stability in the California pricing system at each level resulted from an industry effort to insure operation above the break-even point. However, a number of differential pricing practices were based on assumed quality differences rather than on actual measurement of the forces of demand. For example, in August 1969, when the price of Dover sole at Eureka averaged 7 cents per pound and petrale sole over 12 cents per pound, the respective prices for Dover and petrale sole at broker level for fresh fillets were 50 cents and 65 cents, and for frozen fillets, 55 cents and 65 cents. Similar anomalies existed in the economics of pricing the different sizes and varieties of salmon. An extensive analysis of demand and cost factors would be required to resolve or justify existing differences. They seem.

TABLE 26

APPROXIMATE SHARE OF BROKER PRICE FOR ONE POLND OF DOVER SOIE FILLET RECEIVED BY EACH MARKETING AGENCY, MID-SEASON, 1967-1969

\begin{tabular}{|c|c|c|c|c|c|c|c|c|}
\hline & \multirow{3}{*}{ Season } & \multirow{3}{*}{$\begin{array}{c}\begin{array}{c}\text { Broker } \\
\text { price }\end{array} \\
\text { cents }\end{array}$} & \multicolumn{6}{|c|}{ Share going to each marketing agency } \\
\hline & & & \multicolumn{2}{|c|}{ Fisherman* } & \multicolumn{2}{|c|}{ Wholesaler } & \multicolumn{2}{|c|}{ Broker } \\
\hline & & & $\begin{array}{l}\text { cents per } \\
\text { pound }\end{array}$ & per cent & $\begin{array}{l}\text { cents per } \\
\text { pound }\end{array}$ & per cent & $\begin{array}{l}\text { cents per } \\
\text { pound }\end{array}$ & per cent \\
\hline Winter & $1966-1967$. & 57 & 25.9 & 45.4 & 28.2 & 49.6 & 2.9 & 5.0 \\
\hline Summer & 1967. & 42 & 23.3 & 55.5 & 16.6 & 39.5 & 2.1 & 5.0 \\
\hline Winter & $1967-1968$ & 55 & 25.9 & 47.0 & 26.3 & 48.0 & 2.8 & 5.0 \\
\hline Summer & 1968. & 50 & 24.2 & 48.3 & 23.4 & 46.7 & 2.5 & 5.0 \\
\hline Winter & 1968-1969. & 60 & 25.9 & 43.1 & 31.1 & 51.9 & 3.0 & 5.0 \\
\hline Summer & 1969. & 57 & 25.5 & 44.8 & 28.6 & 50.2 & 2.9 & 5.0 \\
\hline
\end{tabular}

* One pound fillet equals 3.45 pounds live weight fish.

Source: California Department of Fish and Game, Marine Fisheries Statisties Section, Special Inalysis, and Los Angeles broker records. 
however, to have become institutionalized at every level, with questionable benefit to the industry.

\section{Case Study: A Major National Retail Chain}

Pricing information was obtained for a major national retail chain with operations in many parts of the United States and a leading position in California. Retail prices of fresh and frozen fish, discussed here, are not exactly comparable to the broker prices because the retail chain frequently bought directly from producers all over the United States, at eastern fish auctions, and, when necessary, through brokers. This chain also bought in carlot quantities while an individual sale of our Los Angeles broker would usually be measured in cases. However, it is reasonable to assume that the broker's selling prices approximated the retailer's cost prices. Hence, price trends for the same product at broker and retail level are compared, to help pinpoint the consequences of retailer inflexibility.

Stability. The retail price of the main domestic species of fish showed remarkable seasonal stability over the three years, 1967-1969. In the company's San Francisco region, no change was recorded for haddock and halibut fillets in 1967, nor for haddock, cod, and perch fillets in 1968, nor for haddock fillets in 1969. Relative prices also tended to be kept in line. For example, in July 1967, the price of both frozen, prepackaged cod and perch fillets were raised from 59 rents to 63 cents. at which level they remained until raised to 65 cents in October 1969. Frozen, prepackaged sole fillets maintained a list price identical with that of haddock fillets, but the retailer cut prices occasionally for advertised specials for a limited period. usually during Lent or the period of peak California landings, July-August. In mid1968, the chain introduced a new line of precooked and prepackaged frozen fish, including haddock, sole, cod, and perch, which were featured in advertising, at price reductions ranging up to 24 per cent, almost every other week up to the end of 1969. This price policy coincided with a generally more aggressive company policy towards the promotion of fish. On these new products, the company goal was a gross margin of 35 to 39 per cent of sales but the actual gross margin was probably nearer 30 per cent.

The prices of some species of domestic shellfish and of imported shrimp, lobster tails, halibut, and swordfish, sharply increased during the three years, 19671969. The number, kinds, and varieties of species regularly listed for the company's different sales regions varied widely. Among standard products carried, Denver prices were generally higher. Washington, D.C. prices generally lower. than those in San Francisco. Washington had by far the largest range of prices regularly quoted. In its broad policy towards stocking of fish in each region, the chain retailer did appear to give consideration to rarying consumer demand. However, it appears doubtful if its pricing policy gave much attention to demand for individual species.

\section{Scallops : comparison of broker and} retailer selling price. The case of eastern scallops illustrates the effects of the retailer's stable price policy (figure 11). The retail price is the quoted price for the San Francisco district, the broker price is that quoted by our Los Angeles hroker. The broker price includes transportation cost from New Bedford, thus can be taken as the price the retailer would have to pay if he bought his needs in California on a weekly basis. Under such circumstances, the retailer would have been selling almost at cost price in December 1967. However, through volume discounts, contracting ahead for requircments, and holding some supplies in cold storage, the retailer's average pur- 


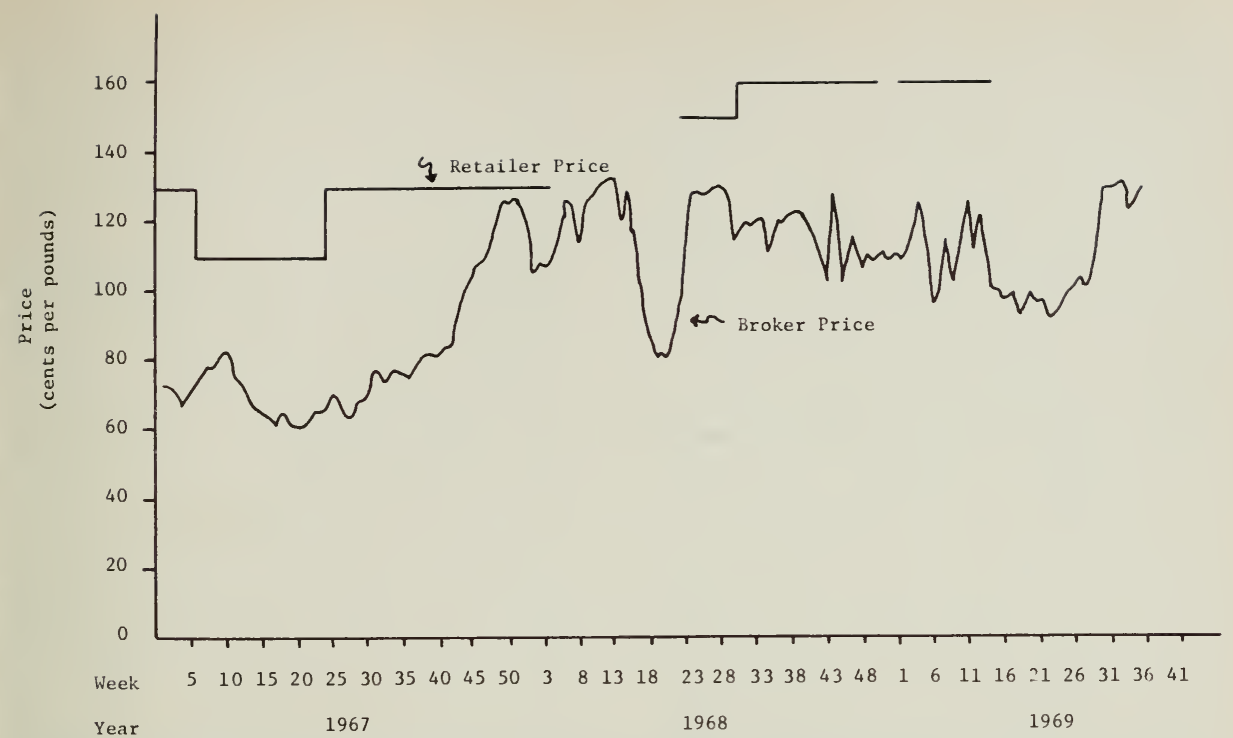

Fig. 11. Eastern scallops (raw, frozen): Broker and retailer price per pound, weekly, 1967-1969. Source: Los Angeles broker records and major national retail chain records.

chase price would have a more stable pattern than suggested by the broker price. Clearly the administered retail price, whether yielding an adequate profit to the retailer or not, has a long lag in signaling increased demand or reduced supply when compared with the competitively determined broker price. Also, as the gaps in the retailer price sug. gest, the retailer's central buying office did not handle any eastern scallops, in one case for a period of 18 weeks.

\section{Imported products and cold storage}

holdings are linked because both can be used (a) to add to supplies of fish available to the California market or (b) to withhold supplies through delaying imports or adding to cold storage, thus affecting both current and future market prices. The only price data available on many imported products are the weekly quotations from Los Angeles brokers (Terminal Island, Fishery Market News Report). Once again, these reports show stability for many weeks at a time with price being adjusted to a new level rather than constantly responding to changes in supply. This reflects, in part, the arrange- ment by which brokers finance small foreign producers and buy their output at a prearranged price. In the period studied, brokers did not seem to have been prevented by competitive forces from maintaining a fairly stable price on products such as crab and shrimp that were in short supply. It remains to be seen whether this would hold true in a period of demand less buoyant than that experienced from 1967 through 1969. This stability of price at the broker level does make it easier for wholesaler, retailer, and restaurant users of imported products to maintain their selling prices at a relatively stable level while insuring a satisfactory gross margin on most species.

Cold storage holdings serve four main functions: (1) reduce price fluctuations, (2) provide the needed raw materials for further processing, (3) provide the finished goods inventory required to meet normal trading needs in the marketing of frozen fish, and (4) serve speculative purposes. Holdings of any species will tend to vary seasonally within a year depending on peak supplies and periods closed to fishing. However, average levels 
of holdings of raw materials and finished goods for inventory purposes should vary from year to year only by the change in level of demand. The remaining change in inventory must reflect supplies withheld from market for speculative purposes, either to prevent current prices being depressed, or to increase prices in the future. In 1969, average cold storage holdings of blocks and slabs, fillets and steaks (notably cod, haddock, and salmon), spiny lobster tails and shrimp, and all other (breaded or precooked) rose by between 60 and 300 per cent above average levels in 1967 or 1968 (table 27). Because prices of all of these species were running at record high levels in the first half of 1969, the increase in holdings was probably largely speculative. If so, the apparent weakening of prices on several species in late 1969 may mean that such large holdings acted to curtail further rises in prices.

TABLE 27

SOUTHERN CALIFORNIA: AVERAGE MONTHLY COLD STORAGE HOLDINGS OF SELECTED ITEMS, 1967, 1968, AND 1969*

\begin{tabular}{|c|c|c|c|}
\hline Item & 1967 & 1968 & 1969 \\
\hline & \multicolumn{3}{|c|}{ thousand $l b$} \\
\hline Blocks and slabs. & 246 & 131 & 495 \\
\hline \multicolumn{4}{|l|}{ Fillets and steaks: } \\
\hline Cod...... & 181 & 125 & 400 \\
\hline Haddock. & 25 & 36 & 130 \\
\hline Halibut.... & 432 & 486 & 509 \\
\hline Ocean perch. & 33 & 23 & 40 \\
\hline Salmon.. & 144 & 198 & 589 \\
\hline Swordfish. & 231 & 55 & 205 \\
\hline TOTAL. & 1,047 & 923 & 1,873 \\
\hline Halibut...... & 444 & 485 & 297 \\
\hline Salmon...... & 366 & 604 & 197 \\
\hline Trout, all species. & 296 & 355 & 271 \\
\hline Lobsters, whole.... & 887 & 365 & 244 \\
\hline Lobster tails, spiny. & 724 & 894 & 1,346 \\
\hline Scallops....... & 137 & 121 & 115 \\
\hline Shrimp, raw headless. & 2,822 & 4,008 & 3,805 \\
\hline Shrimp, all other.... & 354 & 408 & 656 \\
\hline TOTAL All Itemst. & 8,325 & 8,294 & 9,299 \\
\hline
\end{tabular}

* $\Lambda$ s reported for the last day of each inonth by $9-10$ cold storage warehouses in the Los Angeles-Long Beach area and in San Diego.

t Rounding error present.

SourCE: U. S. Bureau of Commercial Fisheries, Market News Service, Terminal Island, Fishery Product Report, (tri-weekly) miscellaneous issues.

\section{Efficiency of pricing practices}

Because prices cannot be explained solely in terms of supply-demand, we shall now examine the practices in terms of the institutional environment in which the system operates.

The principal short-run function of the fish price is to clear the market of the supplies of fresh and frozen fish offered to buyers. The principal long-run function is to guide managers in their allocation of a firm's resources among its existing operating functions or to new business ventures. The general environment of pricing during the three years analyzed in this section was not typical of the past. A deficiency in the supply of desirable species of fish from California and other sources coincided with a period of rising prices of major competing foods such as beef and chicken. Accordingly, any conclusions reached at this stage must be tentative, awaiting statistical confirmation over a longer period.

\section{General characteristics of the pricing system}

The effectiveness of pricing in the California fresh and frozen fish trade was difficult to determine because prices were often set by personalized decisions rather than a free interplay of market forces. Neither was the conventional model of firm pricing easy to apply (1) when a firm must make many pricing decisions on many heterogeneous products, (2) when a firm is restrained in the quantity of inputs (in the form of raw products) it can purchase by the vagaries of nature, and, frequently, (3) when it is impossible to disentangle joint variable costs in a multiproduct operation. Only in an aggregate sense could a firm attempt to equate marginal revenue with marginal cost so as to maximize profits. To our knowledge, none of the firms surveyed made such an attempt.

Three main procedures for price setting. Our analysis of pricing policy 
at different levels of the California trade and of pricing practices indicates the prices were determined by at least three main procedures. First, collaboration in product pricing. This is done, at each level, by a few large firms which are aware of their overcapacity and the uncertainty created by a highly volatile sup. ply, and are motivated by mutual protection and benefit. Second, negotiation of prices for specialties by a few small firms, through control of limited supplies of a specialty item-for example, abalone. Third, price leadership. This procedure was that forced upon many small, independent firms at each market level by their lack of control over either supplies or markets. Such firms either had to follow the price lead of the larger firms or try to compete by cutting prices. The latter practice is hazardous for small businesses that wished to survive.

Informal trade practices agreements among the larger firms appeared to have a stabilizing effect on those parts of the fishing, processing, and marketing sectors of the industry conforming to the agreements, particularly in pricing fish at each level of trading. However, such arrangements were tenuous indeed. Prearranged maximum prices paid to fishermen were abandoned when it was necessary to purchase available fish. When supplies were overly plentiful, wholesalers would drop their contract minimums by discounting their prices "because of lower quality." However, in the main, the pricing practices of larger operators were designed to yield a return on investment that would be considered adequate by all participating parties in both insuring survival and preventing undue variation in level of return. The policy was based on a "live and let live" principle.

Individual firms not only tried to achieve greater stability through cooperation among competitors, but also sought to stabilize their supplies and markets by ownership or contractual agreements, i.e., by vertical and horizontal integration and by the "de facto" or contractual integration of the business activities of independent firms. Eureka fishermen, in particular, supplied fish under seasonal price contracts. Foreknowledge of prices should enable the fisherman to estimate fairly accurately the value of the catch he had aboard at each stage of a fishing trip and to weigh the costs of further fishing against the possible additional returns. Lower prices for larger quantities, e.g., more than 12,000 pounds of Dover sole, were designed to insure a primary producerwholesaler of adequate but not excessive supplies. In addition, he was able to make reasonable advance estimates of cost of raw materials and of possible selling prices for each species. and thus to facilitate planning for production and sales. Los Angeles and San Francisco brokers benefited from access to regular supplies at a stable price, because they in turn could offer their customers relatively stable prices for a continuous supply of fish that was purchased for resale to consumers, restaurants, and institutional users. Much of the above type of cooperation was made necessary by the absence of any established means for providing the trade with the market information needed to make accurate business decisions independently.

It is difficult to say where cooperation ends and integration or "de facto" integration begins. For example, some vessels in the Eureka otter trawl fleet were owned or financed by Eureka primary producer-wholesalers. This provided a further partial method of controlling the volume of supplies. The larger producerwholesalers. in addition to using branch establishments, used horizontal integration to gain access to supplies at a number of ports outside their main area of operation. An example of "de facto" integration of major significance in imported products was the link between brokers and small foreign producers, 
where brokers provided the financing and marketing functions without which production would not take place.

Despite the "live and let live" pricing practices described above, price setting power was limited by a number of external restraints. First of these was the need to meet competition from both substitute products and firms in and outside the industry that were only too willing to seize any opportunity for competitive advantage. Second, the informal arrangements were not exclusive. Eureka firms sold to midwestern, eastern, and California markets other than Los Angeles. Los Angeles selling brokers represented frozen fish producers worldwide and fresh fish producers from Washington, Oregon, and Mexico. They were the principal link between producer-wholesalers and wholesale and retail fish dealers in the Los Angeles area. Third, price had to be set at a level where the volume of products handled could at least he main- tained, or the fishermen became dissatisfied.

The efforts to stabilize and build a more viable industry have been only partially successful. Guaranteed minimum prices have drawn increased numbers of small operators into the Eureka crab and salmon fleet, thereby depressing gross returns to each participant. Even in the Eureka otter trawl fleet, where the high cost of new vessels and the limited number of producer-wholesaler buyers are a barrier to entry for new fishermen, returns per vessel in the 1960 's remained at the 1950 's average level of $\$ 30,000$ per annum (Lyles, 1968).

Coefficient of variation data pinpoint the gains and limitations of efforts to stabilize prices and supplies (table 28). The variation in ex-vessel prices has been kept remarkably low in all cases except squid. The variation in prices for products in their more processed form has

TABLE 28

COEFFICIENTS OF VARIATION FOR QUANTITY, VALUE, AND

PRICE OF SELECTED CALIFORNIA SPECIES AT

DIFFERENT STAGES OF PROCESSING

\begin{tabular}{|c|c|c|c|c|}
\hline \multirow{2}{*}{ Species } & \multirow{2}{*}{ Years covered } & \multicolumn{3}{|c|}{ Coefficients of variation } \\
\hline & & Quantity & Value & Price \\
\hline & & \multicolumn{3}{|c|}{ per cent } \\
\hline \multicolumn{5}{|l|}{ Flounders: } \\
\hline Sole, ex-vessel. ......... & $1939-1967$ & 14 & 13 & 11 \\
\hline Processed fresh and frozen. & $1950-1966$ & 35 & 39 & 7 \\
\hline \multicolumn{5}{|l|}{ Salmon: } \\
\hline Total, ex-vessel. & $1939-1967$ & 16 & 15 & 10 \\
\hline Processed, fresh and frozen. & $1951-1966$ & 54 & 56 & 5 \\
\hline \multicolumn{5}{|l|}{ Market crab: } \\
\hline Ex-vessel & $1939-1967$ & 19 & 17 & 9 \\
\hline Cooked & $1951-1966$ & 76 & 81 & 34 \\
\hline \multicolumn{5}{|l|}{ Squid: } \\
\hline Ex-ressel & $1939-1967$ & 68 & 82 & 27 \\
\hline Canned. & $1943-1966$ & 65 & 78 & 15 \\
\hline $\begin{array}{l}\text { All California processed fishery } \\
\text { products....................... }\end{array}$ & $1947-1966$ & 46 & 67 & 9 \\
\hline
\end{tabular}


been kept even lower than in ex-ressel prices for the same product with the single exception of cooked crab. However, hecause it was impossible to keep variation in quantity from year to year at a low level, total value of catch of the main species shows much greater instability than does price. Also, since variations in quantity at the landing stage are clearly magnified at stages of higher processing, as evidenced by the much higher coefficients of variation, the value of products in their processed state showed even greater instability than at the landing stage (table 28).

The second main approach to pricing was that characteristic of a few small firms which through ownership of their own fleet or special ties with fishermen were able to dominate supplies of a specialty fish. In the case of abalone where price has shown an upward trend since World War II, this control of supply was aided by the State fixing the minimum size of abalone that could be captured, therely affecting the total supply. Some specialization also was possible at the processor or broker level through close ties with the primary producer-wholesalers. The primary producer-wholesaler could influence price up to a point by selling catch immediately, holding it in cold storage, or freezing it. The limitations on this monopoly power arose from the fairly narrow market for these specialty products. It was easy to miscalculate potential sales at any price. Also, the higher the price rose, the more tempting it became for husiness customers to bring in alternative supplies from distant world markets. Finally, it is probable that the specialists approach to pricing was influenced by awareness of how similar specialty businesses in the California fish trade have frequently been submerged by the dis- appearance of their specialty from local waters. This has happened to the Morro Bay abalone trade in the last three years. Hence, the specialty firms frequently price according to "what the market will bear."

The last main procedure for determining prices uncovered in our study concerned the many small firms at every level of the California fish trade. Of necessity, these firms were price takers or followers, the price being set either by the cooperative actions of larger firms as, for example, in the case of Dover sole, or hy the operations of the free market, as in the case of rockfish. Our analrsis suggest: that non-Eureka firms were not sheltered by the special Eureka area pricing arrangements. Because each of these firms was small and financially weak, it could not adjust quantity to reduce the uncertainty caused by lack of control over price. In conditions of temporary oversupply. firms either had to take a sharply reduced price or find friendly firms in other areas willing to absorb some of the surplus. In recent years, however. a greater problem has been shortage of supply. While this has led to a rise in the general level of fish prices. many of the smaller firms have not been able to maintain sufficient volume to offset rising cost. A chronic overcapacity exists in almost every sector of the trade. Net margins have been depressed to a level which permits many firms to survive but few to prosper. None of the small firms surveyed had sufficient confidence in its own solvency to adopt a really agressive sales policy for fear that it would be the one to perish in any subsequent price war. Several of the small firms surveyed were surviving only by using their invested capital as a substitute for business income. 


\section{UNCERTAINTY OF FUTURE SUPPLY}

Uncertainty of the future supply of fish and shellfish from California's coastal waters is a major stumbling block to long-term planning for the State's fresh and frozen fish trade. Known existing stocks are small and threatened by overfishing, by domestic and foreign commercial fishermen, and by pollution. The known remedies for supply shortages-hatcheries, harvesting of species not now generally utilized for human consumption, and fish farming-have contributed little to a lasting solution of the supply problem. Because many activities of a modern industrialized society have become incompatible with a large, healthy coastal fishery, society may have to decide whether it is willing to forego or limit certain other uses of its natural resources in order to conserve its fisheries. In turn, the fishery industry must decide whether to exploit the domestic stocks while they last or try to build up those stocks as a basis for future growth. Another alternative for the industry is to abandon its dependence on local supplies and, if possible, become distributors and fabricators of imported fish and shellfish.

The marketing order sought by the California fresh and frozen fish trade in 1966 saw the industry's main task to increase per-capita and total consumption. However, as our study has shown, total fish consumption has increased, but the supply situation has deteriorated to such an extent that it caused anxiety among our interviewees.

The uncertainty about the volume of California landings of most species for any day, week, or month makes shortterm planning of fishing effort, level of employment, production, and sales extremely difficult. The greater uncertainty as to whether the commercial fish trade can continue to harvest annually the same or increased quantities of the various species also increases both the risk and uncertainty of long-term decisions about continuance in business, renewal of assets, extent and location of new investments, and adoption of more efficient technologies that require additional capital. Many firms have deferred these decisions for years by using up their assets, but such deferment is not possible indefinitely.

We shall now examine (1) the major causes of current supply problems, (2) attempted remedial measures to maintain or increase this California resource, and (3) the choices facing the fish trade and society.

\section{Major Causes of Current Supply Problems}

The decline of the commercial catch and fishing activity in many California localities can be attributed to four types of causes discussed here.

Biological or ecological. Almost all the fresh and frozen species landed in California are caught in the narrow band of sea running parallel to the California coast above the continental shelf. Since the shelf is narrow, it can only support a finite population of the desirable species. A large proportion of the fish populations live in a few large rivers, estuaries, and shallow bays. The size of the population of any species, if left undisturbed by man, mainly depends on the population on which it feeds, and on the population which feeds on it. Cycles of nature can lead to changes in the size of population at any level in the food chain.

Fish populations are a renewable resource in the sense that if man harvests only some of the population each year, and sufficient spawners are left to produce replacements for those captured or lost from other causes, the population size will remain stable. Biologists speak of "maximum sustainable yield" to define the maximum catch that can be taken from a fish population without 
causing it to decline. However, under conditions of free entry into most fisheries and in the absence of controls on volume, operators tend to fish up to that level where average revenue equals average cost, which often occurs at levels of catch beyond "maximum sustainable yield." This could result in overfishing and a decline in the absolute size of the fish population. Apparently, this has been one factor in the decline of the San Francisco area catch and it is now a threat to the Eureka fisheries, especially crab and salmon.

A second major threat to fish populations is pollution. It is blamed for the destruction of valuable salmon runs, oyster beds, and other fishing grounds. In the "hydrologic cycle" the waters of the ocean turn into vapor, are carried to land by winds, fall as rain or snow, and gradually return by overland flow or subsurface percolation to the ocean (Parson, 1964, p. 23). Water at each stage of the cycle is a valuable ingredient for human activities, either as an aid in production, for power and energy, for recreation, or for disposal and dilution of society's wastes. However, as population has grown and the uses of water have multiplied, the finiteness of the supply has become apparent. Alternative uses have increasingly come into contention. Pollutants of every kindsewage, soil, silt, toxic wastes, thermal pollutants. radioactive wastes, and other contaminants - have reached levels in many rivers where all fish life is threatened (Webb, 1966, pp. 26-28). A further danger from pollutants arises from the tendency of biological systems to concentrate pollutants at increasingly higher levels as one moves up the food web: "Measurements taken after an 0.2 part per million application of toxaphene in Big Bear Lake, California, show how concentrations grow through each successive link in the food chain. As a result of this treatment plankton had concentrated it to 73 parts per million; fish that ate the plankton, to 200 parts per million; and pelicans that ate the fish contained 1,700 parts per million. Hatchery trout fed the contaminated plankton were poisoned." (Hull, 1964, p. 139).

Pollution adds to the uncertainty surrounding the future supply of California species of fish because one cannot foretell when a single major source of pollution, for example. a wrecked oil tanker, may destroy a major fishing ground. Nor can anyone foretell the long-term ecological consequences of the gradual buildup in quantities of pollutants entering the ocean (Ehrlich and Ehrlich. 1970, pp. 53-64; Hull, 1964, pp. 13538). With California's 20 million people and technologically advanced agriculture, industry, military, and power activities, use of water (and risk of abuse) certainly will continue to grow, leading to increasing strains on fish populations. Competition for existing supplies of fish. Competition for California commercial fishermen in harvesting of supplies of fish comes from two main sources -California sportfishermen and foreign fleets. The number of angling licenses issued in California has more than doubled from less than one million in 1950 to more than two million in 1969 (California Statistical Abstract, 1959. p. 125). Already sportfishermen take a high proportion of the annual catch of rockfish, salmon, and other important commercial species. To meet expected rapid growth in sportfishing, the California Fish and Wildlife Plan calls for more access routes, marinas, and piers which will bring the sportfisherman and the commercial fisherman into more direct confrontation (California Department of Fish and Game, 1966a, p. 33).

Little is known about the volume of catch or the species taken by foreign fleets in international waters off the California, Oregon, and Washington coast. However, for years the Pacific Marine Fisheries Commission (1970) has been calling on the federal government to find 
some way to prevent Russian and Japanese vessels fishing off the California coast from taking any species already being harvested at maximum sustainable yield, to regulate the take of species not fully utilized, and thereby prevent depletion, and to protect U. S. fishermen from damage to their boats or gear by foreign vessels. The industry is particularly aggrieved that foreign vessels may fish off the U. S. coast using gear or methods forbidden to $\mathrm{U}$. S. fishermen and then sell their catch in competition with domestic fishermen. However, there is no such competition in the California fresh-fish market.

Should the U. S. government find a way to curtail the fishing operations of foreign vessels off the California coast, the same restrictions are likely to be applied to U. S. fishermen by Mexico and Peru. Hence, there is no easy solution.

Competing uses of the sea. Competing uses of the sea may reduce supplies of fish available to the commercial fish trade either by cutting off access to certain areas, by making it more difficult and costly to fish certain areas, or by directly affecting fish populations. The sea remains a major thoroughfare for goods to flow into and out of California from the United States and the world. Density of shipping is particularly damaging to fishing grounds near major ports or estuaries. Pleasure hoats, now mainly motorized, proliferate. Offshore oil rigs and similar underwater obstructions endanger vessels and fishing gear. In addition, the growing need for metals has turned attention to the possibility of deep-sea mining (U. S. Commission on Marine Science. Engineering. and Resources. 1969).

Institutional restrictions. A maze of legal restrictions on the commercial fish trade has developed over the years in response to special interest groups among commercial fishermen, sportfishermen. conservationists. and others. The catch which can be taken from a fishery is regulated by such means as closed seasons, limits on gear used, restrictions on size or sex of fish which may be harvested, with little regard for the economic consequences of such regulations. Some species or locations in California rivers or coastal areas are already completely closed to commercial fishermen.

In a national context, the California fresh and frozen fish trade is profoundly influenced by the protection accorded to $\mathrm{L}$. S. boatbuilders, and the lack of protection for the fish trade in comparison with fishermen in other countries. New ressel costs are often twice as high in the United States than in other countries. Yet our law forbids the use of a foreign-built vessel in the U. S. commercial fisheries (Dykstra and Holman, 1968, p. 106). At the same time, labor and operating costs in the United States are far above levels in other countries. Continuing high levels of imports are virtually assured by plans to eliminate tariffs (already at a low level) on most fish and shellfish by January 1, 1972 (U. S. Tariff Commission, 1968 and 1969). In the case of groundfish fillets. repeated studies have found imports contributing to the economic deterioration of that sector of the industry $\left(\mathrm{L}^{-}\right.$. S. Department of the Interior. 1969. pp. 3-4). Imports depress U. S. prices, and while the $\mathrm{U}$. S. fish trade is left to adjust as best it can, foreign countries compensate their fishing industry by subsidies both direct and indirect. An expected imposition of new sanitary regulations on fishing ressels. processing. and distribution plants will likely take its toll of the less efficient firms.

\section{Attempted remedial measures}

California has been among the leading states in attempting to remedy deficiencies in its fish supply. The first salmon hatchery in California opened on the McCloud River before 1880, and fish culture has continued (despite frequent 
shortage of funds) since then (Cobb, 1930, pp. 643-52). A small but valuable oyster fishery was kept going for many years although seed oysters had to be imported (Barrett, 1963). Successful efforts have been made to revive the northern California shrimp fishery (Dahlstrom and Gotshall, 1969, pp. 2025). Even pollutants have been turned to advantage. Auto wrecks dropped in the sea off California reportedly provide a refuge for fish and also the necessary base on which kelp beds can get started, which, in turn, attract fish (Hull, 1964, p. 290). However, all these efforts have made only a miniscule contribution to supplies of California fish.

Even though California Fish and Game authorities are testing the feasibility of harvesting greater supplies of presently underutilized species such as hake, saury, anchovy, and jack mackerel. the California fresh and frozen fish trade is unlikely to derive much benefit. These species are more suitable for animal feed. fertilizer, or canning (Ahlstrom, 1968. pp. 65-80). In addition, they are important sources of food for species, such as salmon, which are harvested for the fresh and frozen trade. The net effect of greater harvesting of underutilized species, therefore, might be a decrease in overall supplies available to the fresh and frozen fish trade.

Fish farming may offer a means of increasing the commercial supply of fish. provided prices continue at present levels. Fresh-water fish culture of eel. carp, and trout is a major industry in Japan (Brown, 1969). Catfish farming has become important in Texas, Arkansas, and other southern states, and has gained a foothold in California. One economic study of costs in Georgia catfish farming suggests that cheap and plentiful land and water are vital ingredients for a successful operation (Brown, et al., 1969). Because of the alternative uses for California's land and water, it is unlikely that either ingredi- ent can be used effectively for fish farming. Moreover, heavy market development costs may be needed to provide the sales volume essential to successful operations.

\section{The choices posed to the fish trade and society by inadequate supply}

The fish trade, as well as society, faces a number of critical choices because of the pervasive character of the supply problems of the California fresh and frozen fish trade, inadequate remedial measures, and a likelihood that many fish species native to California waters may he irrevocably lost unless further drastic measures are taken quickly.

Choices facing the fish trade. One alternative for the California fresh and frozen fisheries industry would be to pursue a positive program for development lased on maintaining and restoring the fishery resources of the State. Such an effort to revitalize the industry would require (1) a large transfusion of new capital, management, and technology into the industry, (2) a drastic rationalization of the number, size, gear, and fishing methods of the fishing fleet, and of the number, size, location. and operating techniques of processing and distribution plants, (3) extensive cooperation of members of the industry in self-policing and self-regulation, and (4) persuasion of other parts of society to take the complementary measures needed to make the industry's efforts effective.

A second alternative is a similar revitalization program based on fabricating of both imported and local fish. Because the industry would have no exclusive control over imported supplies, its distribution, marketing, and promotional techniques would need to be competitive with those of large multiproduct corporations.

A further alternative is to exploit what remains of the commercial fishery resources for maximum short-term profit, 
on the assumption that industry efforts will in the long run be futile against adverse forces. If this policy is adopted, society may express its displeasure by directly intervening in fishing, processing, and marketing operations.

Choices facing society. Because the commercial fresh and frozen fish trade is relatively small by any economic criterion, society has not fully explored the choices it faces in that area. Clearly, the level and type of many alternative uses of the State's water resources are not compatible with restoration of the California fisheries. Here are some questions society must ask itself :

(1) Would it derive greater benefits from the improvement of the California fisheries than from existing or other uses of its resources? Such improvement would require large expenditures for restoration and maintenance-in addition to heavy sacrifices of gains currently derived from activities incompatible with such restoration and maintenance. How much is society willing to pay for a viable California fishery?

(2) Would society be willing to sacrifice the benefits derived from a viable California fishery for the increased utility to be gained by devoting its water resources to other ends? Preservation of its fisheries may not be the choice by society. Given the risk of accidental disaster and the probably low returns to investment in a fishery resource, society may opt to exhaust the resource as a commercial venture now, rather than carry the burden of preserving it for future generations (Carlson, 1969. pp. 5-7).

(3) Finally, society in the future might come to consider social welfare from an international rather than a national view. point. In such a case, international welfare might be more nearly maximized by drawing a greater share of the U. S. supplies of food fish from other countries and concentrating more of the U. S. resources now devoted to the commercial fisheries in other activities.

\section{Conclusions and Implications}

One overriding conclusion emerged from our study: The industry's foundation and growth since the mid-nineteenth century rested on the natural abundance of many desirable species of fish and shellfish within easy reach of California ports. For a century fishermen and firms in the industry have exploited those resources, but were ill-equipped to meet either unusual demand conditions or threats to the supply of the species handled. Now natural abundance is under pressure from many activities of civilized man, from the resultant pollutants, and from the claims of recreationists for increasing rights to the ocean and its resources. Hence, the question arises whether desirable fish and shellfish exist in sufficient quantity to fulfill any substantive increase in consumption.
The commercial fresh and frozen fish trade employs only about 4,000 full-time or part-time fishermen or workers or onetwentieth of 1 per cent of the California working force. Even ancillary activities such as boat building, manufacture of gear, demand for special transportation, and packaging. probably contributes less than 1 per cent of California income. Hence, the industry must be well organized and "speak with one voice" if it is to have any substantive influence on state and federal policy formulation. Because the industry has not been able to present a united front to policy-makers, it also has failed to convince the influential groups in society that it deserves any special consideration. This is a severe omission, because the crux of the problem of economic survival of the commercial fresh and frozen fishery rests 
mainly on some major changes in public policy relating to resource use.

The California fresh and frozen fish trade heavily depends on the utilization of local fish supplies. Many of the circumstances which depress returns from such utilization are beyond the trade's control; for example, competition for available supplies from foreign ressels harvesting fish off the California coast, protection to $\mathrm{U}$. S. boat builders which increases fishing costs, gradual reduction of tariff barriers on low-cost imported products, and others. Undoubtedly, also, the fishing industry has received less farorable treatment from policymakers than have many other sectors of society in overcoming their problems. Unlike agriculture, it receives no major subsidies, little protection. and has no extension service. In many cases, the depletion of the commercial fisheries is a direct result of concessions granted to public utilities, land developers, lumber companies, or sportfishermen for which the traditional users, the commercial fisheries, receive no compensation.

Recent favorable trends, however, suggest that it is not yet too late to establish a viable industry, provided adequate supplies are forthcoming. Rising income levels in foreign countries have increased demand, the medical profession is encouraging the use of fish. and grocery chains show evidence of an enlivened interest in fishery products. Should the industry succeed in avoiding sudden disaster from one large-scale pollutant or through the steady attrition resulting from more powerful and hostile bionomic forces, our study suggests several ways in which it might approach its other major problems so as to improve its relative performance.

(1) A large infusion of new capital is required to enable firms to replace obsolete plant and equipment needed to meet sanitary regulations and the technological competition from both domestic and foreign sources. The industry's in- ability to halt the rise in the share of many desirable species being imported is further evidence of its lagging technology.

(2) Choice of new technology must be based on adequate research and development, taking account of the species available, the resources of individual firms in the industry, and the markets to be served. At present, economic research and development is minimal either at the firm or industry. Yet without it, new investment cannot be directed effciently.

(3) Redirection of investment and a rationalization of the production and distribution systems may mean a severe reduction in the present number of firms and plants. But no other alternative appears feasible if the industry is to become a viable force in California's economy.

(4) The structure, conduct, and performance of the industry in the past have heen greatly influenced by the dominance of closely-knit ethnic groups and strong family ties. As in the rest of society, these allegiances have been breaking down. reducing the supply of new talent to the industry. Many principals in the industry are only a few years from retirement and have no family successor. When family members are unwilling or unavailable to enter the industry, little or no effort has been made to hire, train, and pass on control to competent outsiders. Yet such an infusion of new talent is needed to give the industry the will and the energy to make the dramatic changes necessary for its survival.

(5) The primary producer-wholesalers have not accepted the challenge posed to their traditional activities by the growing importance of imports of the most desired species, and by default have allowed this import trade to fali into the hands of fabricators and other types of firms. Even in using California species. they have been lax. Apart from the Eureka area where a high level of rear- 
round supplies has been maintained, the few successful firms were able to overcome their difficulties by departing from their traditional primary producer-wholesaler roles, in particular, by adding restaurant facilities. Firms must acquire flexibility in their business activities. For example, our study indicates that consumer demand is strong for the recently developed prepackaged, pan-ready frozen, fresh, and precooked items that account for about 80 percent of all fish and shellfish sales in California. These frozen fish and shellfish are mainly imported. California-produced fish are now sold largely in fresh form.

(6) Despite industry efforts to reduce the uncertainty of the trade by arrangements which lead to stable prices, variation in quantity by week and by season still causes wide fluctuations in total industry receipts at certain levels. Our analysis has shown that much of the variation can be explained by seasonal and cyclical influences. Advances in biological knowledge of the main California species could make it possible for managers and policymakers better to plan the use of the fisheries' resources.

(7) Price rigidities in the Eureka area seem to arise from collective bargaining with fishermen and the economic power of the producer-wholesalers. Our limited survey of retail prices gives evidence of an administered pricing system. Neither system for stabilizing prices may be conducive to an expansion of consumption.

(8) Finally. the industry needs to make certain that the relevant public authorities are aware of the many legal restraints now hampering the efficient use of the fishery resource. It also should encourage a full official review of the industry's problems and their possible solution.

\section{ACKNOWLEDGMENTS}

Valuable assistance and information was furnished for this study by owners and managers of firms at all levels of the California fisheries' trade. C. M. Ghio and John Gilchrist, President and Manager, respectively, of the California Seafood Institute, were especially helpful in enlisting the cooperation of Institute members in our surveys of producer-wholesale, wholesale, broker, and retail businesses engaged in either buying, processing, or selling fish and shellfish products.

The California Department of Fish annd Game and the U. S. Department of Interior's Terminal Island Office of the Bureau of Commercial Fisheries supplied much of the basic production and price data used in our analysis.

We are thankful to Samuel H. Logan of the Department of Agricultural Economics, University of California, Davis, for his critical reviews of the several drafts of our manuscript.

\section{LITERATURE CITED}

Aнistrou, E. H.

1968. An evaluation of the fishery resources available to California fishermen. The future of the fishing industry of the United States, DeWitt Gilbert, ed., University of Washington Publications in Fisheries-New Series. Vol. IV, pp. 65-80. 
ArNold, John R.

1936. The fishery industry and the fishery codes. Office of United States National Recovery Administration, Work Materials No. 31, Wash. D.C., 117 pp.; Appendix, earnings of fishermen and fishing craft, $170 \mathrm{pp}$.

BaIN, J. S.

1968. Industrial organization. 2nd ed. New York: John Wiley and Sons, Inc., 678 pp.

BARRETT, E. M.

1963. The California oyster industry. California Department of Fish and Game, Fish Bul. 123: $1-32$.

BATOR, F. M.

1957. The simple analytics of welfare maximization. American Economic Review, March, pp. 22-59.

Borgstron, Glorge

1964. Japan's world success in fishing. London: Fishing News (Books), Ltd., 312 pp.

Brandow, George E.

1961. Interrelations among demands for farm productions and implications for control of market supply. Pennsylvania State University, Agric. Exp. Sta. Bul. 680:1-124.

Brown, E. E.

1969. The fresh water cultured fish industry of Japan. University of Georgia, Agric. Exp. Sta. Res. Rept. 41:1-57.

Brown, E. E., M. G. LaPuaste, and L. H. CoveY

1969. A synopsis of catfish farming. University of Georgia, Agric. Exp. Sta. Bul. 69:1-50.

California Departuent of Fixayces

1959. California statistical abstract. Sacramento, Calif.

California Departient of Fish and Gavie

1949. The commercial fish catch of California for the year 1947 with an historical review, 19161947. Sacramento, Calif., 267 pp.

1966a. California fish and wildlife plan, Vol. I, Summary. Sacramento, Calif. 110 pp.

1966b. California fish and wildlife plan, Vol. III, Supporting Data. Part B-Inventory salmon. steelhead and marine resources. Sacramento, Calif. pp.323-679.

Carlsox, E. II.

1969. Bio-economic model of a fishery. U. S. Bureau of Commercial Fisheries, Working Paper 12:1-35.

Carter, H. O., and G. II. Dea.

1960. Income, price, and yield variability for principal California crops and cropping systems. Hilgardia $30(6): 175-218$.

Christy, Fravcis T.. Jr.. and Avthovy Scott

1965. The conmon wealth in ocean fisheries. Resources of the Future, Inc.. Wash., I).C.. 281 pp. Coвr, J. N.

1930. Pacific salmon fisheries. U. S. Department of Commerce, Bureau of Fisheries, Fisheries Document 1092:409-704. 4th ed., Wash.. D.C.

Container Corporation of Auerica

1969. A study of consumer attitudes toward the purchase and consumption of fish and seafood. Oaks, Pennsylvania, $47 \mathrm{pp}$.

Crutchfield, J. A.

1954. The economics of the Pacific Coast fishing industry. Unpubl. Ph.D. dissertation. Berkeley: University of California, $340 \mathrm{pp}$.

Cretchfield, I. A., and A. Zelliser

1963. Economic aspects of the Pacific halibut fishery. U. S. Bureau of Commercial Fisheries, Fishery Industrial Research 1(1):1-173. Wash.. D.C.

Daillstron, II. A.. and D. W. Gotshali.

1969. Will the shrimp boats kecp a comin? Commercial Fisheries Review, 31 (6) :20-25 (U. S. Bureau of Commercial Fisheries, Wash., D.C.).

DeLOaCH, BartoN

1938. Trade in fresh and frozen fishery products and related marketing considerations in the San Francisco Bay Area. U. S. Department of Commerce, Investigational Rept. 39:1-51. Wash., D.C.

Dykstra, J. J., and A. A. Holian

1968. Cost of fishing and foreign competition ... New England. The future of the fishing industry of the United States. DeWitt Gilbert, ed., University of Washington Publications in Fisheries-New Series, Vol. IV:105-07. 
Ehrlich, P. R., and A. H. Ehrlich

1970. The food-from-the-sea myth. Saturday Review, April 4, pp. 53-64.

Farrell, J. F., and H. C. LAMPE

1965. The New England fishing industry: Functional markets for finned food fish I. University of Rhode Island, Agric. Exp. Sta. Bul. 379:1-28.

FinN, D. B.

1960. Fish: The great potential food supply. FAO, Rome, World Food Problems No. 3, 47 pp.

Food and Agricultural Organization

1967. Agricultural commodities-projections for 1975 and 1985. Methodological Notes and Statistical Appendix, Vol. II, 308 pp.

1968. Fisheries in the food economy. Basic Study 19:1-79.

1968a. Yearbook of fishery statistics, 1967. Vol. 24, Catches and landings.

1968b. Yearbook of fishery statistics, 1967. Vol. 25, Fishery commodities.

FoYTIK, J.

1951. Characteristics of demand for California plums. Hilgardia, 20 (20):407-527.

George, P. S.

1969. Measurement of demand for food commodities in the United States. Unpubl. Ph.D. dissertation. Davis: University of California, $256 \mathrm{pp}$.

Goreux, L. M.

1960. Income and food consumption. FAO-UN Monthly Bulletin of Agricultural Economics and Statistics, IX (10) :1-13.

Gruber, R. J.

1968. Problem areas in seafood distribution. The future of the fishing industry of the United States, DeWitt Gilbert, ed., University of Washington Publications in Fisheries-New Series IV:227-32.

Hagerman, F. B.

1952. The biology of the Dover sole. California Department of Fish and Game, Fish Bul. 85:1-48. Heari, Martin E., and C. R. Menke

1968. Seafood marketing and promotional program of the Florida Board of Conservation. Gainesville: University of Florida, Bureau of Economic and Business Research, $132 \mathrm{pp}$.

Heimann, Richard F. G., and H. W. Frey

1969. The California marine fish catch for 1967. California Department of Fish and Game.

Henderson, J. M., and R. E. QuandT

1958. Microeconomic theory. New York: McGraw-Hill Book Company, 291 pp.

Носн, I. I.

1962. Estimation of production function parameters combining time series and cross-section data.

Hull, S.

Econometrica, 30(1):34-53.

1964. The bountiful sea. Englewood Cliffs, N.J.: Prentice-Hall, Inc., 340 pp.

Jensen, Albert C.

1967. A brief history of the New England offshore fisheries. U. S. Department of the Interior, Bureau of Commercial Fisheries, Fishery Leaf. 594:1-13. Wash., D.C.

Johnson, G. L., ed.

1961. A study of managerial processes of midwestern farmers. Ames: Jowa State University Press. Johnston, .I.

1960. Econometric Methods. New York: McGraw-Hill Book Company, 300 pp.

Keilman, L. A., and T. S. Allen

1969. California fisheries, 1967. U. S. Department of the Interior, Fish and Wildlife Service, $20 \mathrm{pp}$. Koopmans, T. C.

1947. Measurement without theory. Review of economics and statistics, 29:161-72.

LEFTWICH, R. H.

1966. The price system and resource allocation. New York: Holt, Reinhart, and Winston, 369 pp. LiPSEY, R. G., and K. LANCASTER

1956. The general theory of second best. Review of Economic Studies, 24(63):11-32.

LYLES, C. H.

1968. Fishery statistics of the United States, 1966: U. S. Bureau of Commercial Fisheries, Wash., D.C., $678 \mathrm{pp}$.

Mundlak, YaIR

1961. Empirical production function free of management bias. Jour. of Farm Economics, 43(1): $44-56$. 
NaSh, Darrel A.

1970. A survey of fish purchases by socioeconomic characteristics. U. S. Bureau of Commercial Fisheries, Annual Report, February 1969 to January 1970, Working Paper 50:1-160.

NASH, D. A., and F. W. Bell

1969. An inventory of demand equations for fishery products. U. S. Bureau of Commercial Fisheries, Div. of Economic Research, Working Paper 10:1-31, July.

Nash, D. A., and M. M. Miller

1969. Industry analysis of West Coast flounder and sole products and an estimation of its economic adaptability to radiation processing. U. S. Bureau of Commercial Fisheries, Div. of Economic Research, Working Paper 11:1-33. October.

National Food Brokers Association

1959. NFBA Covers the Cold Front. NFBA, Waslı., D.C., 16 pp.

Pacific Marine Fisheries Commission

1970. Portland, Oregon, Vol. 1, 1948 to 1970.

Parson, R. L.

1963. Colonial Study. Progressive Grocer, N.Y.

1964. Conserving American Resources. Englewood Cliffs, N.J.: Prentice-Hall, Inc., 520 pp.

1969. April 1969 issue. Progressive Grocer, N.Y.

SCOFIELd, W. L.

1954. California fishing ports. California Department of Fish and Game, Fish Bul. 96, Sacramento, Calif., 159 pp.

SHAPIRo, Sidney

1968. Food from the sea and inland water. USDA Yearbook of Agriculture, pp. 20-33.

Sossnick, S. H.

1962. Orderly marketing for California avocados. Hilgardia 33,(14):707-73. Berkeley: University of California.

State Fish Exchange of California

1918. First annual report. California State Printing Office, Sacramento, Calif., 52 pp.

Stigler, George J.

1952. The Theory of Price. 2nd ed., New York: The Macmillan Comp., 310 pp.

1958. The Economies of Scale. Jour. of Law and Economics, 1:54-71, October.

Suttor, Richard E., and P. Aryan-Nejad

1969. Demand for shellfish in the United States. University of Maryland, Agric. Exp. Sta., Misc. Publ. 695:1-28.

Thomas, J. C.

1968. Management of the white seabass in California waters. State of California, Department of Fish and Game, Fish Bul. 142:1-34, Sacramento, Calif.

Tintner, G.

1940. The variate difference method. Bloomington, Ind.: Principia Press, 175 pp.

1965. Econometrics. Science Edition, New York: John Wiley and Sons, Inc., 370 pp.

U. S. Attorney General's National Comintee to Study the Axtitrust Laws

1955. Report, Wash., D.C., 393 pp.

U. S. Commission on Marine Science, Engineering, and Resolrces

1969. Our nation and the sea. Wash., D.C., January, 305 pp.

U. S. Departient of Agricllture

1966. Food consumption, prices, expenditures. Rept. 138 and Sup. 1968 and 1970. Econ. Res. Ser., Wash., D. C.

1968. Food consumption of households in the United States, Spring 1965. Agric. Res. Serv.. Wash., D.C.

1970. National food situation. Econ. Res. Serv., Wash., D.C., quarterlies, 1968-1970.

U. S. Departuent of Commerce, Bureau of the Census

1956. Census of Business, 1954, Vol. III, Wholesale Trade, Summary Statistics. Wash.. D.C.

1957. Census of Business, 1954, Vol. IV, Wholesale Trade, Area Statistics. Wash., D.C.

1961a. Census of Business. 1958, Vol. III, Wholesale Trade, Summary Statistics. Wash., D.C.

1961b. Census of Business, 1958, Vol. IV, Wholesale Trade, Area Statistics. Wash., D.C.

1966a. 1963 Census of Business, Vol. IV, Wholesale Trade. Summary Statistics, Part I. Wash.. D.C.

1966b. 1963 Census of Business, Vol. V, Wholesale Trade, Area Statistics. Wash., D.C.

1957a. Census of Manufacturers, 1954, Vol. I, Summary Statistics. Wash., D.C.

1957b. Census of Manufacturers, 1954, Vol. III, Area Statistics. Wash., D.C.

1961a. Census of Manufacturers, 1958, Vol. I, Summary Statistics. Wash., D.C. 
1961b. Census of Manufacturers, 1958, Vol. III, Area Statistics. Wash., D.C.

1966a. Census of Manufacturers, 1963, Vol. I, Summary and Subject Statistics. Wash., D.C.

1966b. Census of Manufacturers, 1963, Vol. III, Area Statistics. Wash., D.C.

1967. Census of Manufacturers, 1967, Fresh and Frozen Prepackaged Fish. (Preliminary report), Wash., D.C., 5 pp.

1969. Statistical Abstract of the United States, 1969. Wash., D.C., 1032 pp.

U. S. Department of the Interior

1967. Fishery Market News Report. Bur. of Commercial Fisheries, Terminal Island, Calif., daily issues, 1967 through 1969.

1969a. Food fish situation and outlook, May 1969.

1969b. The effects of imports on the United States groundfish industry. Wash., D.C., 84 pp.

1969c. Fisheries of the United States . . . 1968. U. S. Fish and Wildlife Serv., C.F.S., No. 5000, $83 \mathrm{pp}$.

1970. Food fish situation and outlook, Apr. 1970.

U. S. TARifF Commission

1968. Summaries of trade and tariff information, Sched. 1, 2, Fish: Fresh, Chilled, Frozen, o: Cured. Wash., D.C., 201 pp.

1969. Summaries of trade and tariff information, Sched. 1, 3, Fish Products, Shellfish, and Shellfish Products. Wash., D.C., $171 \mathrm{pp}$.

Walters, A. A.

1963. Production and cost functions: An econometric survey. Econometrica, 31:39-66. JanuaryApril.

WALGH, F. V.

1964. Demand and price analysis. U. S. Department of Agriculture, Econ. Res. Serv., Tech. Bul. 1316:1-94.

WALGH, F. V., and M. M. Miller

1969. Fish cycles: A harmonic analysis. U. S. Bur. of Commercial Fisheries, II orking Paper $30: 1-26$.

Webi, W. E.

1966. Water pollution problems in Idaho in relation to the aquatic resource. Pacific Marin Fisheries Comm. Ann. Rept., 1965, Portland, Oregon, pp. 26-28.

IVhite, Donalid .J.

1954. The New England fishing industry. Cambridge: Harvard University Press, 205 pp. 


\section{CONTENTS}

Introduction

Supply and Demand . . . . . . . . . . . . . . . . . . 6

World . . . . . . . . . . . . . . . . . . . . . . 6

United States . . . . . . . . . . . . . . . . . . . . . . . 9

California . . . . . . . . . . . . . . . . . . . . . . . . . 11

Sportfishing . . . . . . . . . . . . . . . . . . . . . 15

Ethnic Influence . . . . . . . . . . . . . . . . . . . . . 16

Industry Structure . . . . . . . . . . . . . . . . . . . . . 18

Primary Producer- $W$ holesalers . . . . . . . . . . . . . . . . 20

Brokers . . . . . . . . . . . . . . . . . . . . . 26

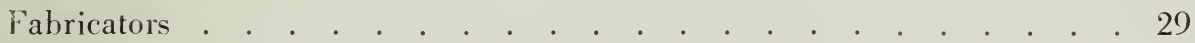

Retailers . . . . . . . . . . . . . . . . . . . . 30

Impact of Structural Changes on Performance . . . . . . . . . . . . . . . . 32

Merchant-Wholesalers . . . . . . . . . . . . . . . 32

Merchandise Agents, Brokers . . . . . . . . . . . . . . . 35

Fresh or Frozen Fish Prepackagers or Fahricators . . . . . . . . . . . . . 36

A Procedure for Measuring Performance . . . . . . . . . . . . . 39

Outline of Procedure . . . . . . . . . . . . . . . . . . . . . . . 39

Estimating A Production Function for the Primary Producer-Wholesale Sector 10

Efficiency Measures Based on the Assumption of Perfect Competition . . . 13

Evaluation of the Aggregate Production Function Approach to Measurement of Firm Performance. . . . . . . . . . . . . . . . . 15

Validity of the Working Hypothesis of Perfect Competition . . . . . . 16

Ex-vessel Prices . . . . . . . . . . . . . . . . . . . . 16

Ex-ressel Demand for California Species . . . . . . . . . . . . . 47

The Basic Model . . . . . . . . . . . . . . . . . . . . 17

Why Do Fishermen Not Increase Landings? . . . . . . . . . . . 18

Fish Prices in the Pacific Coast Region . . . . . . . . . . . . 52

Pricing Practices . . . . . . . . . . . . . . . . . . . . . 53

Prices Received by California Fishermen . . . . . . . . . . . . 54

Case Study: A Los Angeles Broker . . . . . . . . . . . . . . . 59

Case Study: A Major National Retail Chain . . . . . . . . . . . . 62

Efficiency of Pricing Practices . . . . . . . . . . . . . . . . . 64

General Characteristics of the Pricing System . . . . . . . . . . . 64

Uncertainty of Future Supply . . . . . . . . . . . . . . . . . . . . 68

Major Causes of Current Supply Problems . . . . . . . . . . . . . . 68

Attempted Remedial Measures . . . . . . . . . . . . . . . 70

The Choires Posed to the Fish Trade and Society ly Inadequate Supply . . . 71

Conclusions and Implications . . . . . . . . . . . . . . . . . . . . . 72

Acknowledgments . . . . . . . . . . . . . . . . . . . . . . . . . 74

Literature Cited . . . . . . . . . . . . . . . . . . . . . 74 
